NBER WORKING PAPER SERIES

THE EFFECT OF PATIENT COST SHARING ON UTILIZATION, HEALTH, AND
RISK PROTECTION

Hitoshi Shigeoka

Working Paper 19726

http://www.nber.org/papers/w19726

\author{
NATIONAL BUREAU OF ECONOMIC RESEARCH \\ 1050 Massachusetts Avenue \\ Cambridge, MA 02138 \\ December 2013
}

This project is supported by a research grant from the Ministry of Health, Labour and Welfare (H22policy-033, Principle Investigator: Kenji Shibuya and co-investigator: Hideki Hashimoto). The use of data in this paper is approved by Ministry of Health, Labour and Welfare under this grant. I am especially grateful to Douglas Almond for his continuous encouragement through my entire dissertation. I benefited from the suggestions and comments by Janet Currie, Tal Gross, Hideki Hashimoto, Mariesa Herrmann, Takakazu Honryo, Wojciech Kopczuk, Amanda Kowalski, Ilyana Kuziemko, Frank Lichtenberg, Adriana Lleras-Muney, Bentley MacLeod, Robin McKnight, Marcos Yamada Nakaguma, Matt Neidell, Krishna Pendakur, Cristian Pop-Eleches, Bernard Salanie, Louise Sheiner, Yoichi Sugita, Miguel Urquiola, Eric Verhoogen, Till von Wachter, and the seminar participants at Bank of Japan, Columbia University, Hitotsubashi University, Kobe University, McGill University, Ministry of Finance Japan, National University of Singapore, Simon Fraser University, University of Michigan, Uppsala University, NBER Summer Institute, and NBER/CRIW Conference. The views expressed herein are that of the author and do not necessarily reflect the views of Ministry of Health, Labour and Welfare. All errors are my own. The views expressed herein are those of the author and do not necessarily reflect the views of the National Bureau of Economic Research.

NBER working papers are circulated for discussion and comment purposes. They have not been peerreviewed or been subject to the review by the NBER Board of Directors that accompanies official NBER publications.

(C) 2013 by Hitoshi Shigeoka. All rights reserved. Short sections of text, not to exceed two paragraphs, may be quoted without explicit permission provided that full credit, including $(\mathbb{C}$ notice, is given to the source. 
The Effect of Patient Cost Sharing on Utilization, Health, and Risk Protection

Hitoshi Shigeoka

NBER Working Paper No. 19726

December 2013

JEL No. I1,I11,I18

\section{$\underline{\text { ABSTRACT }}$}

This paper exploits a sharp reduction in patient cost sharing at age 70 in Japan, using a regression discontinuity design to examine its effect on utilization, health, and financial risk arising from outof-pocket expenditures. Due to the national policy, cost sharing is 60-80 percent lower at age 70 than at age 69. I find that both outpatient and inpatient care are price sensitive among the elderly. While I find little impact on mortality and other health outcomes, the results show that reduced cost sharing is associated with lower out-of-pocket expenditures, especially at the right tail of the distribution.

Hitoshi Shigeoka

Simon Fraser University

Department of Economics

8888 University Drive WMC 4653, Burnaby

BC, V5A 1S6, Canada

hitoshi_shigeoka@sfu.ca 


\section{Introduction}

Rising medical expenditures due to an aging population and coverage expansion are increasingly posing an acute fiscal challenge to governments. For example, spending growth for Medicare, the public health insurance program for the elderly in the United States, has continued unchecked in spite of a variety of government attempts to control costs. ${ }^{1}$ As more than one-third of current health spending is on the elderly, future cost control efforts can be expected to focus on seniors. ${ }^{2}$

One main strategy for the government to contain health care costs is higher patient cost sharing, that is, requiring patients to pay a larger share of the cost of care. However, cost sharing has clear tradeoffs. While cost sharing may reduce direct costs by decreasing the moral hazard of health care services, it may also reduce access to beneficial and necessary health care that could mitigate future severe and costly health events. Moreover, very high levels of cost sharing may undermine one of the primary reasons of having health insurance, namely financial protection against large out-of-pocket medical expenditure. Thus, to help determine the appropriate level of cost sharing, there is an urgent need for knowledge on how patient cost sharing affects utilization, health, and risk protection, especially among the elderly.

Credible evidence on the price sensitivity of health care consumption and its effect on health among the elderly are scarce. Individuals above the age of 62 years were excluded from the wellknown RAND Health Insurance Experiment (hereafter, RAND HIE). Card, Dobkin, and Maestas (2008, 2009) found that Medicare eligibility at 65 years of age discontinuously increases health care utilization and also has a modest positive effect on the health of elderly patients above 65 years. However, these studies did not conclusively address whether these changes at the age of 65 are the result of health insurance provision per se (extensive margin) or changes in health insurance generosity (intensive margin), given that turning 65 years in the US entails a number of coincident changes. ${ }^{3}$ Chandra, Gruber, and McKnight (2010) examined the effect of an increase in co-payments for physician office visits and prescription drugs in a supplemental Medicare insurance policy for Californian civil servants, but the change in co-payments was very small and limited to office visits and prescription drugs. Only a few studies in the US have examined the effect of health insurance on the distribution of out-of-pocket medical expenditures (Feldstein and Gruber, 1995; Finkelstein and McKnight, 2008; Englehardt and Gruber, 2011; Finkelstein et al., 2011). However, these studies examined the effect of insurance provision rather than that of changes in generosity.

\footnotetext{
${ }^{1}$ Examples of attempts by the US government to control supply side costs include the introduction of prospective payments for hospitals and reductions in provider reimbursement rates (Cutler, 1998).

${ }^{2}$ Patients aged over 65 years consume 36 percent of health care in the US while they account for only 13 percent of the population (Centers for Medicaid and Medicare Services, 2005). Furthermore, Medicare costs are expected to comprise over a quarter of the primary federal budget by 2035, or between 5 and 6 percent of the GDP (Congressional Budget Office, 2011). Likewise, in Japan, the elderly consume five times as many health care services as the nonelderly (Okamura, Kobayashi, and Sakamaki, 2005).

${ }^{3}$ These changes include transitions from private to public health insurance, increases in multiple coverage due to supplementary coverage (e.g., Medigap), and fewer gatekeeper restrictions due to the change from managed care to fee-for-services. Indeed, Card, Dobkin, and Maestas (2009) concluded that it is not clear whether reductions in mortality are due to health insurance provision or generosity.
} 
My research design exploits a sharp reduction in cost sharing for patients aged over 70 in Japan, to examine its effect on utilization, patient health, and financial protection against risk. Due to the prevailing national policy, cost sharing for outpatient visits and inpatient admissions is as much as 60-80 percent lower at age 70 than at age 69 in Japan. ${ }^{4}$ This reduction is substantial, especially for inpatient admissions: out-of-pocket medical expenditures for inpatient admissions can reach as much as 27 percent of the average monthly income of a 69 -year-old patient. ${ }^{5}$ By exploiting this price variation, I compare the outcomes of patients just below 70 versus those just over that age using a regression discontinuity $(\mathrm{RD})$ design.

This setting offers a number of advantages over previous empirical settings. First, there are no confounding factors at age 70, and thus, I can plausibly isolate the effect of patient cost sharing on demand for health care services; under universal health insurance coverage in Japan, the change at age 70 only reflects increases in benefit generosity, rather than the combined effect, of health insurance coverage and generosity. Also, as shown later, turning 70 in Japan does not coincide with changes in any other factors such as employment or receiving pension. Second, I can estimate the elasticities of inpatient admissions of the elderly as well, since cost sharing for inpatient admissions also changes abruptly at age 70. Third, since I have detailed information on outpatient visits, I can investigate the price sensitivity of preventive care in the outpatient setting. In contrast, most existing datasets capture either outpatient visits or inpatient admissions. Fourth, I examine the effect of cost sharing, rather than health insurance per se, on exposure to out-of-pocket medical expenditure risk.

Finally, the unique setting in Japan allows me to separate the demand elasticities of patients from responsive behavior by insurers and medical providers, because they typically play a small (if any) role in patients' demand for health care services; physicians' payments are based on a national fee schedule that does not depend on patients' insurance type, and thus prevents cost shifting, where medical providers charge private insurers higher prices to offset losses from the beneficiaries of government-funded health insurance (Cutler, 1998). Also, there are no restrictions by insurers on patients' choices of medical providers.

I reach three conclusions. First, I find that reduced cost sharing at age 70 discontinuously increases health care utilization. The corresponding elasticity is modest, at around -0.2 for both outpatient visits and inpatient admissions. Examining patterns of utilization in more detail, I also find that lower patient cost sharing is associated with increases in the number of patients presenting both serious and nonserious diagnoses. For example, I find large increases in outpatient visits for diagnoses that are defined as Ambulatory Care Sensitive Conditions (ACSCs), for which proper and early treatment reduces subsequent avoidable admissions.

\footnotetext{
${ }^{4}$ Japan introduced free care for the elderly aged over 70 years in January 1973. However, this policy substantially increased the utilization of health care services and medical expenditure. In fact, medical expenditure rose by 55 percent in just one year. In February 1983, 10 years after the Japanese government had introduced its generous policy, it imposed cost sharing on the elderly aged over 70 years. Despite this, the large discrepancy in cost sharing between those just above and below the age of 70 persists. Due to data availability, this study focuses on the period after the implementation of cost sharing for the elderly.

${ }^{5}$ Note that inpatient admissions are associated with hospitalizations, while outpatient visits refer to visits that do not require an overnight stay in clinics or hospitals.
} 
Second, in terms of benefits, I do not find that lower patient cost sharing improves any of the health measures I examine, such as mortality and self-reported physical and mental health. Since health is a stock, it may take some time for the most observable health effects to be realized. Therefore, it is challenging to address it using the RD approach unless the causes of death are acute. Nonetheless, I do not find any change even in acute cause-specific mortality. The lack of differences in health in spite of utilization changes implies that patient cost sharing can reduce health care utilization without adversely affecting health, at least in the short run.

Finally, I do find that lower cost sharing at 70 yields reductions in out-of-pocket expenditure, especially at the right tail of the distribution, because the reduction in price at age 70 overwhelms offsetting increases in utilization. This finding suggests that patients with high medical spending benefit substantially from financial protection against risk due to lower cost sharing.

The rest of the paper is organized as follows. Section 2 briefly describes the institutional background. Section 3 describes the data and presents the identification strategy. Section 4 shows the main results on utilization. Section 5 refers to the analysis on benefit and examines the health outcomes as well as risk reduction. Section 6 discusses the implications of the findings, and section 7 concludes.

\section{Background}

\subsection{Institutional Setting}

All Japanese citizens are mandatorily covered by health insurance. ${ }^{6}$ Patients have unrestricted choices of medical providers; for example, it is common for the Japanese to visit hospitals rather than clinics for outpatient care (similar to physician office visits in the US). ${ }^{7}$ Patients have direct access to specialist care without going through a gatekeeper or a referral system. There is also no limit on the number of visits. Patients may either go to hospitals or clinics for outpatient visits and to hospitals for admissions, unlike in the US, where those who lack insurance use hospitals for primary care.

A patient pays coinsurance, which is the percentage of medical costs for which the beneficiary is responsible. Since inpatient admissions are more expensive than outpatient visits, the coinsurance rate for inpatient admissions tends to be set lower than that for outpatient visits. The insurer pays the remaining fraction of expenses until the beneficiary meets the stop-loss (also known as the maximum out-of-pocket), and the insurer pays all expenses above the stop-loss. Unlike a normal health insurance plan in the US, there is no deductible in Japan.

The elderly become eligible for lower cost sharing on the first day of the next month after they turn 70. They receive a new insurance card and a notice from the government indicating that they are eligible for Elderly Health Insurance. They can present the card at medical institutions

\footnotetext{
${ }^{6}$ Japan achieved universal health insurance coverage in 1961. See Kondo and Shigeoka (2013) for more details about the effect of the introduction of universal health insurance on utilization and supply side responses.

${ }^{7}$ In Japan, hospitals are defined as medical institutions with 20 or more beds, and clinics are medical institutions with less than 19 beds.
} 
to receive the discount. Elderly Health Insurance is also provided to bedridden people between the ages of 65 and 70, but the proportion of such people is not substantial. According to a report by the Ministry of Health, Labour and Welfare (2009), the fraction of bedridden people between the ages of 65 and 70 was 4.2 percent on average during 1984-2001. Nonetheless, since those covered by Elderly Health Insurance at a younger age should have relatively worse health, the price elasticity and health consequences I estimate may be interpreted as the lower bound.

Table 1 displays the cost sharing formulas for those below and above age 70 for outpatient visits and inpatient admissions for each survey year of the Patient Survey (described in detail in section 3). For those below age 70, the coinsurance rate is determined by the type of health insurance, employment status (retired or not), and whether the person is a (former) employee or a dependent. There are two types of health insurance for those below age 70 . Employmentbased health insurance covers the employees of firms that satisfy certain requirements and the employees' dependents. National Health Insurance (hereafter, NHI) is a resident-based system that provides coverage to everyone else, mainly the employees of small firms, self-employed workers, the unemployed, and the retired. Employment-based health insurance had a lower coinsurance rate than NHI until 2003, after which both were equalized to a common coinsurance rate of 30 percent for outpatient visits as well as inpatient admissions.

At the age of 70, people switch to Elderly Health Insurance and, in principle, face the same cost sharing. ${ }^{8}$ Importantly, on the other hand, all medical providers are reimbursed by the national fee schedule, which is uniformly applied to all patients regardless of their insurance type and age. ${ }^{9}$ Since a patient's insurance type and age do not affect reimbursements, physicians have arguably few incentives to influence patient' demand. For example, from the physician's perspective, in principle, there are few reasons to delay surgeries until age 70, as long as patients can pay, because reimbursements do not differ by the patient's age.

\subsection{Changes in Patient Cost Sharing at Age 70}

Figure 1 illustrates the out-of-pocket expenditures with respect to total monthly medical expenditures for 2008, as an example of the formula in Table 1. Unlike in the US, the stop-loss is set monthly, rather than annually, in Japan. This is for purely administrative reasons. Reimbursements to medical institutions are conventionally paid monthly in Japan. The $x$-axis indicates total monthly medical expenditures, and the $y$-axis, the corresponding monthly out-of-pocket medical expenditures. Since the stop-loss differs for outpatient visits and inpatient admissions for those over 70, I show separate lines for the two services. For those below 70, there was no distinction

\footnotetext{
${ }^{8}$ In fact, high-income earners above 70 have been charged a higher coinsurance rate (20 percent instead of 10 percent) since October 2002. As the bar for "high income" is set quite high, a limited number of patients fall in this category (7 percent, according to Ikegami et al. (2011)). Since income is not recorded in the Survey of Medical Care Activities in Public Health Insurance, which I use to derive monthly out-of-pocket expenditures, I compute expenditures considering a "normal" family. See Section A1 in the Online Appendix for details.

${ }^{9}$ The national schedule is usually revised biennially by the Ministry of Health, Labour and Welfare, through negotiations with the Central Social Insurance Medical Council. The latter includes representatives of the public, payers, and providers. See Ikegami and Campbell (1995) for details.
} 
between these two services in 2008. Figure 1 shows that the price schedule for those above 70 always lies below that of those below 70, suggesting that for any given medical expenditures, the out-of-pocket payment for those above 70 was always smaller than that for those below 70 in 2008 .

Unfortunately, information concerning actual out-of-pocket expenditure of the general population is only available for year 2007, and these data do not distinguish between outpatient visits and inpatient admissions. However, I have access to individual level insurance claim data for outpatient visits and inpatient admissions, which summarizes the monthly medical expenditures claimed for insurance reimbursement to medical institutions (called the Survey of Medical Care Activities in Public Health Insurance). Since a portion of this monthly total medical expenditure is paid as patient cost sharing according to the formula in Table 1, I can compute the out-of-pocket medical expenditures for each insurance claim.

Table 2 summarizes the actual average monthly out-of-pocket expenditures of a 69-year-old and the counterfactual monthly out-of-pocket medical expenditures for a 70-year-old. For those aged 70 , since the observed out-of-pocket medical expenditures already reflect the change in cost sharing (i.e., out-of-pocket medical expenditures are endogenous), I compute their counterfactual out-ofpocket expenditures by applying the cost sharing rules of Elderly Health Insurance to utilization by an average 69-year-old. See Section A1 in the Online Appendix for details on these derivations.

In the main analysis, I do not exploit the year-to-year variation in cost sharing, and instead, I pool all the survey rounds to increase the statistical power and smooth out cohort size effects. ${ }^{10}$ As a robustness check, I run separate regressions for periods before and after 2002. I choose 2002 since the price schedule for those above age 70 changes from flat monthly or daily copayment to coinsurance with stop-loss (as shown in Table 1), which could generate quite different utilization incentives. Overall, out-of-pocket medical expenditure, conditional on using health care services in Table 2, is the weighted average of out-of-pocket medical expenditure across all survey years, using the population of 69-year-olds in each survey year as weights.

Table 2 reveals a couple of interesting facts. First, out-of-pocket medical expenditures, especially from inpatient admissions, can pose a substantial financial burden on the near elderly (those just below age 70). Since the average annual income for a 69 -year-old is 1,822 thousand Yen (or roughly 18,220 US dollars), out-of-pocket medical expenditures for inpatient admissions can reach as much as 27 percent of a person's average monthly income. ${ }^{11}$ On the other hand, once the patient turns 70 , the counterfactual ratio of medical expenditures to average monthly income is reduced to as little as 8.6 percent. $^{12}$

One complication in the abovementioned calculations is the nonlinearity imposed by the stoploss, which is a classic, but important, challenge in estimating elasticities and dates back to the

\footnotetext{
${ }^{10}$ Due to the smaller sample size, the estimates from each year are noisy and do not have any consistent pattern. Also, these results should be viewed with caution, since fluctuations in cohort size due to events like the Spanish Flu pandemic and World War I may heavily affect the estimates in this RD framework, which are based on counts instead of rate. These results are available from the author upon request.

${ }^{11}$ One thousand Yen is roughly equal to 10 US dollars. The rate of 27 percent was calculated by the author using the Comprehensive Survey of Living Conditions (CSLC), i.e., 41.7/(1822/12) $=0.27$.

${ }^{12}$ This rate was calculated by the author using the CSLC, i.e., $13.0 /(1822 / 12)=0.086$.
} 
RAND HIE (Keeler, Newhouse, and Phelps, 1977; Ellis, 1986). The problem is that although in many cases, medical expenditure is caused by unpredictable illnesses, economically rational individuals who anticipate spending beyond the stop-loss may spend more when the price is low (Keeler and Rolph, 1988). The size of the difference between true and nominal out-of-pocket prices depends on the probability that the individual will subsequently exceed the stop-loss. Indeed, under fairly restrictive assumptions, it can be shown that the effective price before the stop-loss is reached takes the simple form $(1-x) P$, where $P$ is the nominal price, and $x$ is the probability of exceeding the stop-loss (Keeler and Rolph, 1988).

Accounting for nonlinearity associated with the stop-loss is challenging, since to fully understand the size of the difference between the true price and the nominal price, I may need data on episodes of illness rather than monthly aggregated data. I argue that the effect of the stop-loss on overutilization is probably much smaller in my case, unlike the RAND HIE, for the following two reasons. First, the probability of reaching the stop-loss is not high even for inpatient admissions14 percent for those admitted (see Column (4) in Table 2) and 2 percent for the non-conditional population. Second, the stop-loss is set monthly in Japan, rather than annually like for the RAND HIE and most health insurances in the US. To the extent that illnesses are unpredictable, this shorter interval may make it harder for people to time and overuse medical services. In fact, even under an annual stop-loss, Keeler and Rolph (1988) empirically showed that people in the RAND HIE responded myopically to the stop-loss, i.e., people do not appear to change the timing of their medical purchases to reduce costs. ${ }^{13}$

Nonetheless, to partially account for this effect, I simply apply the formula $\left(1-x_{t}\right) P_{t}$ for those whose out-of-pocket medical expenditures exceed the median in each survey year $t$, since this problem is most relevant for consumers who are close to reaching the stop-loss. Since the probability of reaching the stop-loss is not high even for inpatient admissions, the nominal price (38.0 thousand Yen) for those just below age 70 is not so different from the true price (35.3 thousand Yen). Therefore, the bias coming from the nonlinearity associated with the stop-loss may be negligible in this case.

\section{Data and Identification}

I use one of the most comprehensive health-related data sources ever assembled on Japan. In this section, I summarize the most important datasets used in the study. Further details on the same appear in Section A3 in the Online Appendix. My main outcomes are health care, health outcomes, and out-of-pocket expenditures.

\footnotetext{
${ }^{13}$ Aron-Dine et al. (2012) also showed that while there are some forward-looking aspects in health care utilization, individuals' behavior is much closer to full myopia, such that they respond only to the spot price instead of looking forward as individuals responding only to the future price. See also Kowalski (2012) and Marsh (2012) on the recent application of nonlinear budget set estimation to analyze the effect of health insurance contracts.
} 


\subsection{Data}

The dataset for health care utilization is the Patient Survey, a nationally representative repeated cross-sectional survey that collects administrative data from hospitals and clinics. Since the survey is conducted every three years, I have individual patient-level data for nine rounds of surveys between 1984 and 2008. One of the biggest advantages of this survey relative to usual hospital discharge data is that it also includes information on outpatient visits, unlike most existing datasets that capture either outpatient visits or inpatient admissions. In fact, the Agency for Healthcare Research and Quality (AHRQ) has recognized the need to develop a methodology for studying preventive care in an outpatient setting by using inpatient data, to identify avoidable inpatient admissions. In my case, I directly look at changes in the number of patients for beneficial and preventive care in the outpatient setting. The disadvantage of this data is that like most discharge data, it only includes limited individual demographics, such as gender and place of residence. There is no record of education and income.

The Patient Survey consists of two types of data: outpatient data and discharge data. I use the former to examine outpatient visits, and the latter, inpatient admissions. Outpatient data are collected during one day in the middle of October of the survey year and provide information on all patients who made outpatient visits to the surveyed hospitals and clinics on the day of the survey. ${ }^{14}$ These data include patients' exact dates of birth and the survey dates, which is equivalent to the exact dates of the visits. The discharge data contain the records of all patients who were discharged from surveyed hospitals and clinics in September of the survey year. The discharge data report the exact dates of birth, admission, surgery, and discharge, which enable me to compute age at admission. ${ }^{15}$

As health outcomes, I examine both mortality and morbidity. I examine mortality, since it is one of the few objective and well-measured health outcomes, the data for which are often easily available and comparable across different countries. I use the universe of death records between 1984 and 2008, which report the exact dates of birth and death, place of death, and cause of death using the International Classification of Diseases (ICD) 9 or 10. The main advantage of the death records is that they cover all deaths that occur in Japan, unlike hospital discharge records, which only report in-hospital mortality by definition.

I complement the mortality results by examining other morbidity-related measures in the Comprehensive Survey of Living Conditions (CSLC), which is survey of a stratified random sample of the Japanese population conducted every three years between 1986 and 2007, mostly in June. The survey asks questions about insurance coverage, self-reported physical and mental health, stress levels, and so forth. Age is reported by month in this dataset. Descriptive statistics for the Patient Survey, CSLC, and mortality data are reported in Table A in the Online Appendix.

\footnotetext{
${ }^{14}$ Since data concerning outpatient visits are collected on one day only, the survey is susceptible to external factors such as the weather. This short survey period is another reason I do not exploit the year-to-year variation in cost sharing in this paper.

${ }^{15}$ I describe these dates in chorological order for simplicity, but each unit of data is as per the discharge.
} 


\subsection{Identification Strategy}

My identification strategy is very similar to studies from the U.S. that use an RD design to examine the effect of turning 65 (Card, Dobkin, and Maestas, 2004, 2008, 2009; Chay, Kim, and Swaminathan, 2011). However, in Japan, the change at age 70 only reflects increases in benefit generosity rather than the combined effects of change in health insurance coverage and benefit generosity. Moreover, as shown later, turning 70 in Japan does not coincide with changes in any observable factors, such as employment or receiving pension.

Even though the idea behind the identification strategy is the same, for clarity, I write two regression equations, one for the CSLC and the other for the Patient Survey and mortality data. My basic estimation equation for the CSLC is a standard RD model as follows:

$$
Y_{i a t}=f(a)+\beta P_{o s t} 70_{i a t}+X_{i a t}^{\prime} \gamma+\varepsilon_{i a t}
$$

where $Y_{\text {iat }}$ is a measure of morbidity or out-of-pocket medical expenditure for individual $i$ at age $a$ in survey year $t, f(a)$ is a smooth function of age, $X_{i a t}$ is a set of individual covariates, and $\varepsilon_{i a t}$ is an unobserved error component. Post70 iat is a dummy that takes the value one if individual $i$ is over age 70. My parameter of interest is the coefficient $\beta$. Other controls include a set of dummies for gender, marital status, region, birth month, and survey year. I use a quadratic in age, fully interacted with the post dummies as a baseline specification with samples aged 65-75 years. As robustness checks, I limit the sample to a narrower age window (ages 67-73) and add cubic terms in age. To account for common characteristics within cells of the same age, following Lee and Card (2008), the standard errors are clustered at age in months.

Unlike the CSLC in which I see all individuals, the unique features of the Patient Survey and mortality data is that I only observe individuals who are present in the medical institutions or are deceased, respectively. My approach to deal with this issue is to assume that the underlying populations at risk for outpatient visits, inpatient admissions, and deaths trend smoothly with age. Since I pool several years of data, this assumption seems plausible. ${ }^{16}$ Therefore, I use the $\log$ of counts as the dependent variable for these datasets and modify the regression equation as follows:

$$
\log \left(Y_{a t}\right)=f(a)+\beta \text { Post } 0_{a t}+\mu_{a t}
$$

where $Y_{a t}$ indicates the count of patients or deaths at age $a$ in year $t$. Throughout the paper, for regressions where the dependent variable is either binary or log, the coefficients on Post70 and their standard errors are multiplied by 100 to make them easier to interpret as percentage changes.

There is one remaining empirical issue in estimating the equation (2) using the Patient Survey. As seen in Figure A in the Online Appendix, there is substantial seasonality and heaping in the

\footnotetext{
${ }^{16}$ See Card, Dobkin, and Maestas (2004) for formalization of this approach. Since I am using nine rounds of the Patient Survey, the patients at each age in my samples are from nine different age cohorts. This approach should smooth out cohort sizes fluctuations.
} 
reported birthdays of patients observed in the Patient Survey. First, I observe heaping on the first day of the month, which is likely due to reporting. ${ }^{17}$ Second, there are many more births in the first quarter than in the other three quarters throughout the sample period. Some argue that this observation is due to farmers timing births for the winter, when there is less work, but evidence proving this notion is scant (Kawaguchi, 2011).

Whatever the reason, heaping and seasonality in birthdays pose a challenge for estimating the equation (2), since the Patient Survey is only conducted in one day in October for outpatient visits and in one month (September) for inpatient admissions. To account for heaping within the month, I collapse the data into age in months. Since people become eligible for Elderly Health Insurance at the beginning of the next month after their 70th birthday, this approach allows me to code age in months and the post age-70 dummy using dates of birth and dates of visits without error. To account for seasonality in birth distribution, I include the birth month fixed effects in addition to survey year fixed effects in all specifications (see e.g., Barreca et al., 2010; Carneiro et al., 2010). Thus, the cell indicates the birth month for each age for each survey year. There are 120 observations (12 birth months for each year times 10 years of age (65-75) windows) per survey round, and there are nine rounds of surveys. Thus, there are 1,080 cells in the estimation for outpatient visits.

I also try two different approaches to account for the heaping and seasonality. One approach is to collapse the data into age in quarters and then convert the counts into rates, since I have population data by the quarter of the birth month from the population censuses that are conducted every five years. The disadvantage of this approach is that the interpolation of population may introduce additional noise in the estimates. In fact, the estimates from this approach tend to be smaller than those in the main approach, probably due to measurement error in the population estimates. Another approach is to collapse the data into age in days and include 365 day-ofbirth fixed effects as well as year-of-birth fixed effects into the equation (2), so as to account for seasonality and cohort size effects where age in days at the time of the outpatient visit or inpatient admission is the running variable (Gans and Leigh, 2009; Barreca et al., 2010). The disadvantage of this approach is that when I divide the sample into finer subsamples (e.g., by diagnoses), there are many birthdays without any observations, which may introduce noise in the running variable. The approach of using age in months does not suffer much from this problem since I usually observe at least one observation in each month cell. The results using this alternative approach yield similar results as the main approach as long as there are not many zero cells in the data. Since both alternative approaches face different disadvantages, I prefer to take the approach I first described. Some of the results using age in days as the running variable are shown in Table E in the Online Appendix.

The discharge data pose a slightly more complicated problem. Unlike the outpatient data, the admission day can be any day of the year, as long as patients are discharged in September. To

\footnotetext{
${ }^{17}$ For example, individuals (or their designated respondents) who do not know their exact birthday may report the first day of their birth month as their birthday. Other heaps occur at multiples of five and ten days and at the end of the month.
} 
avoid including patients with unusually long hospitals stays, I limit the sample to those admitted within three months from discharge in September (July, August, and September) in the survey year. This approach is reasonable since 90 percent of admissions in my data are concentrated within these three months. Later, I show that the estimates are robust to using different windows from the discharge date. The cell for discharge indicates the year of birth, month of birth, month of admission, and survey year, the latter being identical to the admission year. Since there are 1,080 cells for each admission month, there are a total of 3,240 cells in the estimation of inpatient admissions. The estimations include birth month fixed effects, admission month fixed effects, and survey year fixed effects.

For the mortality data, I estimate the same equation (2), replacing $Y_{a t}$ with death counts. While I observe that deaths occur throughout the year, seasonality remains an issue. As shown in Figure B in the Online Appendix, more births as well as more deaths are observed in winters. Thus, if I just plot the raw number of deaths by age, I mechanically observe more deaths around each patient' birthday. To account for seasonality (as well as heaping in birthdays, similar to the observation made in the Patient Survey), I collapse the mortality data into birth year/birth month/death year/death month (i.e., age in months) and include birth months and death months fixed effects. This approach is analogous to the estimation of inpatient admissions, with the admission month being replaced by the death month. Since mortality data spans 1984-2008, I limit the sample to those born during 1919-1933, so that I can trace the deaths throughout ages $65-75 .{ }^{18}$ There are 21,600 cells. ${ }^{19}$ The main drawback of using death records is that in those records I only observe the exact date of death. In contrast, in the hospital discharge data, I observe the exact date of admission, which (unlike the date of death) determines the price schedule applicable to the patient. Note that this may attenuate the estimates, since people who died immediately after their 70th birthday may not be eligible for Elderly Health Insurance at the time of admission even though I consider them as treated.

Importantly, "age RD design" is distinct from the standard RD design. Because all individuals will eventually age into the program (age 70 in this case), assignment to treatment is inevitable. Therefore, individuals who are likely to anticipate a price change at age 70 may behave in a certain way before treatment is provided (Lee and Lemieux, 2010). This issue is particularly relevant for inpatient admissions, since there is a possibility that people may delay some expensive medical procedures until they become 70 , which may accentuate the size of the discontinuity. ${ }^{20}$

However, the age RD setting allows me to visually examine whether the discontinuity is accentuated; if the increase is transitory rather than permanent, I should observe a tendency to revert to the previous level after age 70 as well as a drop-off just shy of age 70 . Indeed, as I show later, the overall age trend does not seem to display any catch-up effects, but close inspection of

\footnotetext{
${ }^{18}$ The results using all deaths that occurred between the ages of 65 and 75 during $1984-2008$ are quantitatively similar.

${ }^{19}$ This calculation is a result of 15 birth years (1919-1933), 12 birth months, and 12 death months for 10 years of age $(65-75)$ windows $(21600=15 \times 12 \times 12 \times 10)$.

${ }^{20}$ It is not always the case that such anticipation accentuates the magnitude of the discontinuity; it can also mute the discontinuity (Lee and Lemieux, 2010).
} 
inpatient admissions with elective surgery shows some drop-off just below age 70 and a sudden surge just over it. Though not far from perfect, to partially account for the catch-up effect, I run a "donut-hole" RD by excluding a few observations around the threshold (Barreca et al., 2011). The caveat of this methodology is that there is no clear economic or statistical consensus on the optimal size of the donut, and excluding observations near the threshold undermines the virtue of the RD design, that is, comparing outcomes just below and above the threshold. Nonetheless, this donut-hole RD may show whether my RD estimates are sensitive to catch-up effects or intertemporal substitution.

The underlying assumption of a typical RD model still applies to the age RD design; in this case, the assumption is that expected outcomes below and above age 70 are continuous at age 70 (Hahn, Todd, and van der Klaauw, 1999). Continuity requires that all other factors that might affect the outcome of interest trend smoothly at age 70. Following Lee and Lemieux (2010), I simply fit the same models, such as equation (1), for confounding variables and test for discontinuities at age 70 .

Figure $\mathrm{C}$ in the Online Appendix displays the actual and fitted age profiles of employment for the 1986-2007 pooled CSLC sample (age measured in months). These profiles all trend relatively smoothly at age 70 for both genders. ${ }^{21}$ Row (1) in Table B in the Online Appendix confirms that there is no jump in employment at age 70. In the remaining rows in the table, I also investigate age profiles of marriage and income in the CSLC, but neither outcome shows any discontinuities at age 70. Therefore, employment, marriage, and income are unlikely to confound the impact of cost sharing at that age.

\section{Utilization Results}

In this section, I examine the effect of changes in patient cost sharing on utilization. I use the pooled 1984-2008 Patient Survey for people between ages 65 and 75. I examine outpatient visits and inpatient admissions, respectively .

\subsection{Outpatients Visits}

I examine changes in the number and characteristics of outpatient visits at age 70. As I mentioned earlier, I collapse counts of patients by age in months and include birth month fixed effects as well as survey year fixed effects to account for heaping and seasonality in birthdays. Therefore, for most of the graphs shown in this section, the plotted average is residual from a regression of the log counts on birth month fixed effects and survey year fixed effects.

Figure 2A shows the actual and fitted age profiles of outpatient visits based on pooled outpatient data. The markers in the figure represent averages of the log number of outpatient visits (by

\footnotetext{
${ }^{21}$ The mandatory retirement age in Japan used to be either 55 or 60 years. Pension receipts start at either 60 or 65 years, depending on the type of job. Also, long-term care (LTC) health insurance was introduced in Japan in 2000 , but it does not specify the age of eligibility as 70 . Indeed, I do not see any change at age 70 in the probability of receiving LTC, as shown in Table B in the Online Appendix.
} 
age in months). The lines represent fitted regressions from models with a quadratic age profile fully interacted with a dummy for age 70 or older. Overall outpatient visits smoothly increase prior to age 70 and then jump sharply at age 70 . Also, the increase appears to be permanent rather than transitory since I do not observe any tendency after age 70 to revert to the previous level.

Panel A in Table 3 shows that the jump in Figure 2A corresponds to a 10.3 percent increase. The implied elasticity of the outpatient visits is $-0.18(=0.103 /(\log (1.1)-\log (4.0)))$, where the denominator is the log difference in price between ages 69 and 70 from the first row in Table $2 .{ }^{22}$ Since I do not visually observe catch-up effects and stop-loss is rarely reached, the bias on estimating the elasticity of outpatient visits seems minimal.

Panel B divides the sample before and after 2002, when the price schedule for those above age 70 changes from the flat monthly or daily copayment to coinsurance with stop-loss, which could generate quite different utilization incentives. Even though the RD estimates are larger pre 2002 than post 2002 (12.0 vs. 6.9 percent, respectively), the corresponding price elasticity is relatively similar across periods (-0.19 vs. -0.15 , respectively), since price reduction at age 70 was larger in the period before 2002 (see Table K in the Online Appendix). In addition, the null hypothesis that RD estimates are the same for pre and post 2002 cannot be rejected at the conventional level.

Another way to look at more frequent access to outpatient care is to examine the change in the interval since the last outpatient visits. A shorter interval indicates a higher frequency of outpatient visits. As much as 94 percent of patients are repeat visit patients (i.e., visits for the same underlying health conditions and made at the same hospitals or clinics as last time) rather than first-time visitors, as shown in Table A in the Online Appendix. Figure 2B plots the age profile of days from the last outpatient visit for repeat patients. Consistent with the increase in outpatient visits, the duration from the last visit steadily decreases prior to age 70 , and then drops sharply by roughly one day at age 70 .

So far, I find compelling evidence that people use more outpatient care once they turn 70 . Next, I investigate whether the increase in outpatient visits solely reflects moral hazard or increases in beneficial care, although distinguishing between the two is a very difficult task. To investigate this question, I divide the sample into various dimensions in the remaining rows in Table 3. In Panel C, I divide outpatient visits by first visit or a repeat visit. Interestingly, not only repeat visits but first visits also increase by more than 10 percent. ${ }^{23}$ Since repeat visits account for 94 percent of all outpatient visits, the increase in first visits is small in magnitude relative to total outpatient

\footnotetext{
${ }^{22}$ Note that I used the average price rather than the marginal price in the denominator. Thus, the elasticity estimated is with respect to the average price. However, the marginal price and the average price may not differ much. For example, for 2008, the log marginal price difference would be $\log (0.1)-\log (0.3)$ without stop-loss (Table 1), while the $\log$ average price difference is $\log (1.1)-\log (4.0)$ for outpatient visits $\operatorname{and} \log (13.0)-\log (41.7)$ for inpatient admissions (Table 2).

${ }^{23}$ Figure D in the Online Appendix shows the age profiles for first-time and repeat outpatient visits. The age profiles of first visits show a very interesting trend; the number of first visits steadily decreases prior to age 70 , reflecting the trend of deteriorating health as people get older, and then jumps sharply at age 70. The age profiles of repeat visits are very similar to those of total outpatient visits, since most of total outpatient visits are repeat visits.
} 
visits. But the increase in new visits raises the possibility that those receiving outpatient care for the first time may avoid outpatient visits before turning 70 due to their cost.

For repeat visits, Panel D in Table 3 shows that most of the increases are concentrated within a short interval from the last visit. In fact, most of the increase is concentrated among those who received their last outpatient care within 7 days, and the largest increase of 17.9 percent is observed within one day from the last visit, indicating that some of these visits may be less beneficial. ${ }^{24}$ Panels $\mathrm{E}$ and $\mathrm{F}$ show that the increase in outpatient visits is concentrated at clinics and at visits without referrals. Since people have much easier access to small clinics (rather than large hospitals) without referrals, these results imply that these outpatient visits are more discretionary and less serious.

Most of the findings so far suggest that those who visit medical institutions for outpatient care once they turn 70 are less seriously ill than those who visit these institutions at the age of 69 . To further investigate this point, I examine the size of discontinuity at age 70 by type of diagnoses. Panel $\mathrm{H}$ in Table 3 presents the RD estimates for selected diagnoses. Although the majority of large increases are not likely to be for life-threatening diagnoses, these conditions, such as diseases of the skin and genitourinary and musculoskeletal systems, probably require treatment to enhance the quality of life. However, I also find an increase in potentially more serious diagnoses, such as a 15.2 percent increase for cerebrovascular disease and 14.3 percent increase for respiratory disease, both of which are statistically significant at the 1 percent level. Figure 3 displays the age profile for these commonly examined diagnoses (see e.g., Chay, Kim, and Swaminathan, 2010).

Further, I look at diagnoses listed as ACSCs, for which proper and early outpatient care reduces subsequent avoidable admissions. ACSCs are developed by the AHRQ to study preventive care in an outpatient setting using inpatient data and to identify admissions that should not occur in the presence of sufficient preventive care (see Table D in the Online Appendix for a list of ACSCs). ${ }^{25}$ Since I $d o$ have the outpatient datasets, I can directly look at changes in the number of patients for such beneficial and preventive care. In fact, I find a statistically significant 8.2 percent increase in ACSCs. ${ }^{26}$ Panel D in Figure 3 confirms that there is a modest jump at age 70 for ACSCs.

In sum, while I find a modest increase for diagnoses, such as ACSCs, indicating the need for beneficial and preventive care, I find much a larger increase for discretionary diagnoses. However, I need to view this result with considerable caution, since any conclusion based only on the diagnoses is unwarranted, due to the large heterogeneity of severity within the diagnoses.

Table E in the Online Appendix summarizes the results of alternative specifications that use

\footnotetext{
${ }^{24}$ The average number of days from the last outpatient visit for patients aged $65-75$ years is 13.6 days, as shown in Table A in the Online Appendix.

${ }^{25}$ The leading ACSC is hypertension, which is by far the most frequent diagnosis of all outpatient visits (see Table $\mathrm{C}$ in the Online Appendix). Untreated high blood pressure can be an important risk factor for the elderly, and thus, proper treatment may prevent subsequent hospitalization or even death from conditions such as heart failure, cerebrovascular disease or stroke, and heart attacks (Pierdomenico et al., 2009).

${ }^{26}$ I also try to investigate each ACSC separately, but due to smaller sample sizes, I cannot obtain precise estimates for most ACSCs. The two exceptions are Chronic Obstructive Pulmonary Disease (COPD), a progressive disease that makes it hard to breathe, and hypertension. The increase for patients with COPD and hypertension is 17.2 percent $(\mathrm{t}-\mathrm{stat}=2.10)$ and 8.5 percent $(\mathrm{t}$-stat $=3.54)$ respectively.
} 
age in days as the running variable with birthday fixed effects and shows quantitatively similar results for most of the outcomes. ${ }^{27}$ As a falsification test, I also run the same estimation for other ages that should not have any discontinuity (each single age between 66 and 74 years) and do not find any statistically significant changes in them (results available upon request). This result is not surprising, since I do not see any visible discontinuity in other ages in either Figures 2 or 3.

\subsection{Inpatient Admissions}

Figure 4A shows the actual and fitted age profiles of inpatient admissions based on the pooled discharge data for 1984-2008. The plotted average is the residual from a regression of log counts on birth month, admission month, and survey year fixed effects. Overall inpatient admission steadily increases prior to age 70 and then jumps sharply at age 70 . The increase appears to be permanent in this case as well as for outpatient visits, with no tendency to return to prior levels.

Since the sharp change in cost sharing in inpatient admissions coincides with that of outpatient visits, it may be difficult to conclusively distinguish if the change in inpatient admissions for a certain condition is the result of lower inpatient cost sharing per se or of substitution with increased outpatient visits. For example, preventive and beneficial outpatient care may replace avoidable admissions in the future. Alternatively, more frequent checkups at outpatient visits allow detection of serious conditions and, hence, increase subsequent admissions. However, since I do not see a discontinuity with time lag in the graph for inpatient admissions, it is more likely that the jump I observe is the reflection of lower cost sharing rather than any interaction with outpatient visits. I will return to this point in section 6 .

The first entry in Table 4 shows that the jump in overall inpatient admissions in Figure $4 \mathrm{~A}$ corresponds to an 8.2 percent increase. The implied elasticity of inpatient admissions is -0.16 (= $0.082 /(\log (13.0)-\log (41.7)))$, where the denominator is the log difference in price between ages 69 and 70 (from the second row in Table 2). Panel B presents the RD estimates from the sample before and after 2002 (similar to what was done for outpatient visits). While the RD estimates are larger for the period before 2002 than after 2002 (9.6 vs. 5.3 percent, respectively), the corresponding price elasticities become relatively similar across periods ( -0.17 vs. -0.12 , respectively), since price reduction at age 70 was larger in the former period (see Table $\mathrm{K}$ in the Online Appendix). Moreover, the null hypothesis that the RD estimates are the same pre and post 2002 cannot be rejected at the conventional level.

As I discussed earlier, there is a potential bias in estimating elasticity, especially due to the catch-up effect. To account for this effect, I run a donut-hole RD by excluding a few months of observations around the threshold. There is no guide as to the size of the donut-hole statistically or economically, because it is not clear what magnitude of delay is fathomable/medically low-cost for patients. Thus, I experiment with a threshold of zero to six months. However, removing six

\footnotetext{
${ }^{27}$ I choose some outcomes that do not have zero cells for any age in days in Table $\mathrm{E}$ in the Online Appendix. It is conventional to add one or a small positive value before taking the log value of such cells, but zero cells introduce noises and hence, attenuate the estimates. In fact, as the number of zero cells increases, the estimates obtained by using age in days as the running variable start to deviate from those of age in months.
} 
months from either side of age 70 may be too drastic, since it would essentially mean comparing patients aged 69.5 and 70.5. Figure D1 in the Online Appendix shows that the estimates get smaller and the standard errors larger as the hole is expanded. But as long as the removal of the data is within three months of age 70 , the estimates are statistically significant at the 5 percent level. Taking the conservative RD estimate from the three-month donut-hole RD, the lower bound of implied elasticity is $-0.14(=0.072 /(\log (13.0)-\log (41.7)))$, which is not so different from naive elasticity.

Figure D2 in the Online Appendix presents the RD estimates by different windows from the discharge date. Since the applicable price schedule changes monthly in Japan, those who enter the scheme before age 70 and stay until after 70 may see a price reduction in the middle of a spell. This fact implies that the RD estimates may get smaller as I include longer stay, since the expected price for those below age 70 can be lower than the nominal price. However, Figure D2 shows that the results are pretty stable across the length of windows from the discharge date.

Another source of bias due to forward-looking behavior is the timing of admission within a month. To the extent that patients are forward looking, they may time their admissions early in the month to fully exploit the monthly nature of stop-loss, and hence, those who enter hospitals at different times within a month may have different characteristics. To investigate this possibility, I divide the sample into those who are admitted in the first half and the second half of the months, and I run RD regressions separately. Panel C in Table 4 shows that the estimates are very similar and in fact, not statistically distinguishable. Therefore, the timing of the admissions does not seem to affect the compositions of patients and RD estimates.

So far, I have shown that estimates on inpatient admissions are pretty robust. Next, I examine the characteristics of inpatient admissions in the remaining rows in Table 4. First, in Panel D, I divide the sample by whether the patients received surgery. Interestingly, I find that the increase in admissions for people who received surgery is larger than the overall growth in admissions (12.0 percent versus an overall increase of 8.2 percent, respectively), while estimates from non-surgery admissions are smaller in magnitude (6.4 percent). Indeed, close inspection of the age profile of patients with surgery in Figure $4 \mathrm{~B}$ reveals a drop-off just prior to age 70, coupled with a temporary surge shortly after age 70 . This pattern suggests that some people who are close to 70 years of age delay surgery until they become eligible for Elderly Health Insurance, so as to reduce out-of-pocket expenditures.

In Panel E, I further investigate the sizes of discontinuities across types of surgeries. Unfortunately, this information was only collected in the most recent four survey years (1999, 2002, 2005, and 2008), and the categorization is quite coarse. Therefore, it is difficult to obtain precise estimates. While the estimates on any procedures are positive, I find that open-stomach surgery and intraocular lens implantation, the latter with substantial overlaps with admissions for cataracts (clouding of the lens of the eye), show statistically significant increases at age 70. Figure F in the Online Appendix displays the age profile of inpatient admissions for these two procedures. Similar to the overall age profiles for inpatient admissions with surgery, I find a drop-off just prior to age 70 coupled with a temporary surge shortly after age 70 for both procedures. These results are 
plausible since on the one hand, these procedures such as cataract surgeries are easily deferred, and on the other, they may substantially improve the quality of life (Card, Dobkin, and Maestas, 2008).

These findings raise two possibilities for physicians' and patients' roles in the demand for health care services. First, it may imply that physicians may consider the financial effects of treatments on patients, since there are no financial incentives for physicians to delay surgeries until age 70, because reimbursements do not differ by patient age. Alternatively, it may raise the possibility of patients playing a more active role in determining their treatments. Indeed, Hai and Rizzo (2009) pointed out that recent organizational changes (e.g., alternative sources of medical information such as the internet, health care report cards, and direct-to-consumer advertising of pharmaceuticals) might have fostered patient-initiated requests for specific treatments.

Next, I examine patients' heterogeneous responses by the severity of the conditions. Figure 5 plots the RD estimates at age 70 on the $y$-axis and the severity measure on the $x$-axis. While there is no perfect measure of the severity of an illness, following Dobkin (2003), I use the fraction of weekend admissions as a severity measure. ${ }^{28}$ The idea behind this measure is that if the condition is urgent and serious, admission occurs even during the weekend without triage, and thus, weekend admissions tend to be higher for these diagnoses. Since three digits of ICD9 are insufficient in providing precise RD estimates for each diagnosis, I group diagnoses into roughly 60 groups based on the Basic Tabulations of Diagnoses (see Table G in the Online Appendix for lists of diagnosis groups). I omit diagnosis groups with less than 1 percent of total observations, because such sample sizes are too small to provide credible estimates. This leaves me with roughly 20 diagnosis groups. The graph presents a clear negative relationship: the higher the severity, the smaller the RD estimates, suggesting that patients are less price sensitive for more serious conditions.

Panel G in Table 4 presents the RD estimates for selected diagnoses. ${ }^{29}$ Interestingly, the observed patterns by admission diagnoses are similar to the findings in Card, Dobkin, and Maestas (2008), which examined Medicare eligibility at age 65; they found smaller increases for conditions typically treated with medication or bed rest (heart failure, bronchitis, and pneumonia) and large increases for those treated with specific procedures (chronic ischemic heart disease and osteoarthrosis). While I do not find an increase in admissions for respiratory diseases and the ACSCs that are typically treated with medication, I do find increases for cataracts, cerebral infarction, and (chronic) ischemic heart disease, which may require procedures, such as intraocular lens implantation, open-head surgery, and open-heart surgery, respectively. ${ }^{30}$ These results imply that diagnoses that are treated with expensive but elective procedures are quite price sensitive, probably due to their large cost, and hence, patients delay treatment so as to reduce out-of-pocket expenditures.

\footnotetext{
${ }^{28}$ Unfortunately, the discharge data in the Patient Survey do not record whether the admission was elective, urgent, or for emergency care.

${ }^{29}$ Table $\mathrm{C}$ in the Online Appendix lists the top 5 diagnoses in 3-digit ICD9 codes and the corresponding RD estimates. Also, Figure G in the Online Appendix displays the age profile of inpatient admissions for the commonly examined broad set of diagnoses.

${ }^{30}$ Note that estimates on ischemic heart disease are mostly driven by chronic, rather than acute, heart attacks (clinically referred to as an acute myocardial infarction or AMI).
} 
Finally, I also examine the interaction between outpatient visits and inpatient admissions by looking at the route before admission to hospitals. Panel E in Table 4 shows that there is a statistically significant 9.7 percent increase in admissions that come from outpatient visits to the same hospitals, implying that patients wait to switch from outpatient visits to inpatient admissions within the hospital till they reach the age of 70 .

Table $\mathrm{F}$ in the Online Appendix shows the results of alternative specifications for selected outcome variables. The results are quite robust to different specifications, such as limiting the sample to a narrower age window (ages 67-73) and including a cubic polynomial in age fully interacted with a dummy for age 70 or older. However, specifications with a cubic polynomial in age sometimes give larger estimates due to a drop-off in the number of inpatient admissions just prior to age 70 .

\section{Benefits}

To investigate the benefit side of cost sharing, I first explore whether lower cost sharing benefits the health of those above age 70, and then, I examine risk reduction.

\section{$5.1 \quad$ Health Outcomes}

A priori, the impact of cost sharing on mortality is ambiguous. On the one hand, cheaper access to health care services may reduce mortality. On the other hand, lower cost sharing may increase mortality if those who are just below 70 delay life-saving treatment. Most importantly, if the marginal patient is not severely ill, I may find no effects on mortality.

Figure 6 shows the actual and fitted age profiles of the log of overall deaths among those aged between 65 and 75 using pooled mortality data from 1987-2008. The plotted average is the residual from a regression of log outcome on birth month and death month fixed effects. The first entry in Panel $\mathrm{A}$ in Table 5 shows that the estimate (-0.2 percent) is not statistically significant at the conventional level. The remaining columns in Panel A present similar results from different specifications. It is important to note that while none of the point estimates are statistically significant, the 95 percent confidence interval for the mortality effects includes declines of elderly mortality up to 2.6 percent (based on the first entry in Panel A). In addition, Panel G (Table 3), Panel F (Table 4), and Panel B (Table 5) are stratified by gender, but none of the estimates are statistically different from each other between male and female patients. ${ }^{31}$

Further, I examine cause-specific deaths for three leading causes of death among the elderly in Japan (cancer, heart disease, and cerebrovascular disease) and also respiratory disease. ${ }^{32}$ Figure $\mathrm{H}$ in the Online Appendix shows the there are no discernible patterns for any causes of death. Panel $\mathrm{C}$ in Table 5 confirms that there is no clear change in cause-specific mortality at age 70.

\footnotetext{
${ }^{31}$ Unfortunately, as the Patient Survey and mortality data only include limited individual demographics except for gender, I could not examine heterogeneous effects based on individual characteristics.

${ }^{32}$ The corresponding 3-digit ICD9 codes are as follows: cancer (140-208), heart disease (390-398, 402, 404, 410429), cerebrovascular disease (430-434, 436-438), and respiratory disease (460-519).
} 
These results are, to some extent, expected; in general, it is hard to detect the effect on health in an RD framework, because health is stock (Grossman, 1972). Thus, it may take a while for the most observable effects to be realized, unless the causes of death are acute, such as heart attacks or strokes (see e.g., Card, Dobkin, and Maestas, 2009; Chay, Kim, and Swaminathan, 2010). Following Card, Dobkin, and Maestas (2009), I also examine nondeferrable conditions (those with very similar weekend and weekday admission rates), but I do not find any discernible patterns in the age profile (results available upon request).

I also examine trends in self-reported physical and mental health as a morbidity measure before and after age 70, but I do not find any evidence that lower cost sharing leads to a discrete jump in morbidity as well (see Figure I and Table $\mathrm{H}$ in the Online Appendix). ${ }^{33}$ These results are not surprising, since the findings in the utilization imply that the marginal patient receiving health care because of lower cost sharing is not severely ill, and also, it is unlikely that people delay life-saving procedures. ${ }^{34}$

It is worthwhile mentioning that the available health measures here are limited. In fact, several of the procedures that show large increases at age 70 are likely to yield substantial health benefits. For example, cataract surgeries may improve peoples' vision and reduce injury (Desapriya et al., 2010). While self-reported health measures should capture such health improvements, I may still underestimate the overall health benefit.

\subsection{Risk Reduction}

Other than improved health, another benefit of lower cost sharing is a lower risk of unexpected outof-pocket medical spending. As Finklestein and McKnight (2008) pointed out, this benefit is often overlooked in the literature. Some claim that protection against large medical expenditure risk is arguably the primary purpose of health insurance (e.g., Zeckhauser, 1970). Indeed, for risk-averse individuals, the largest welfare gains from lower cost sharing come from reducing catastrophic negative shocks to consumption.

To examine the effect of cost sharing on risk reduction, I use self-reported out-of-pocket medical expenditure in the CSLC. Unfortunately, the CSLC started collecting this information in 2007. Thus, I only have one survey year of individual out-of-pocket expenditures. Out-of-pocket medical expenditures include any medical expenses, such as over-the-counter drug spending, which is not covered by health insurance, and this expenditure does not distinguish between outpatient visits and inpatient admissions. With these caveats in mind, my primary interest is to examine total individual out-of-pocket medical expenditures, regardless of how they were spent. Therefore, in the analysis in this section, I focus on data for 2007. My analysis is based on 66,112 individuals aged between 65 and 75 years, with non-missing out-of-pocket medical expenditure. The average

\footnotetext{
${ }^{33}$ See also Nishi et al. (2012) on mental health.

${ }^{34}$ In contrast, Card, Dobkin, and Maestas (2009) showed that Medicare eligibility has a modest positive effect on the health of those above age 65 . The difference in the two results is probably because supply side incentives differ significantly at age 65 in the US. In fact, Card, Dobkin, and Maestas (2008) showed that both supply side incentives and shifts in insurance characteristics play an important role for the utilization of health care services at age 65 in the US.
} 
annual out-of-pocket spending among those aged 65-69 is 142 thousand Yen (1,420 US dollars), while the median out-of-pocket medical expenditure is 48 thousand Yen (480 US dollars). ${ }^{35}$

I first present an RD estimate at the mean on out-of-pocket medical expenditures by estimating equation (1), where the model assumes quadratic in age fully interacted with a Post70 dummy. On average, lower cost sharing is associated with decline in out-of-pocket medical expenditure by 52 thousand Yen (520 US dollars). The estimate is close to the conventional level, but it is not marginally statistically significant $(\mathrm{t}$-stat $=-1.47)$. However, the mean impact may miss the distributional impact of lower cost sharing. As is well known, the distribution of out-of-pocket spending is highly right-skewed. Among those aged 65-69, the top 5 percent of spenders account for almost 40 percent of out-of-pocket medical spending, while 72 percent of the sample has outof-pocket spending below 100 thousand Yen (1,000 US dollars) in a year.

Figure 7A shows the age profiles of out-of-pocket medical expenditures at the 75th, 90th, and 95th percentiles. Out-of-pocket medical expenditures steadily increase prior to age 70, reflecting worse health as people age. Then, they decline sharply at age 70 at all three percentiles, with the largest decline at the highest percentile. ${ }^{36}$ This result is consistent with other studies in the US that showed a pronounced decline in the right tail of the distribution of out-of-pocket medical expenditures through Medicare Parts A and B (Finkelstein and McKnight, 2008), Medicare Part D (Englehardt and Gruber, 2011), and Medicaid (Finkelstein et al., 2011). As noted previously, these studies looked at the effect of insurance coverage rather than changes in generosity.

To gauge the magnitude of the decline, I estimate equation (1) for each quantile $q$, where the outcome is out-of-pocket medical expenditure. Figure 7B plots the RD estimates at age 70 on each quantile, along with their 95 percent confidence interval. The standard error is computed based on the empirical standard deviation of 200 bootstrap repetitions of quantile treatment estimates. ${ }^{37}$ Note that the coefficient and standard errors on the Post70 dummy are not multiplied by 100, because the outcome variable is a level rather than a log. The units for this coefficient are thousand Yen.

The graph shows that lower patient cost sharing at age 70 is associated with declines in out-ofpocket spending at almost all (nonzero) quantiles of the distribution. While lower cost sharing has a very small effect at low quantiles, it grows consistently with baseline spending. At the median, the impact on out-of-pocket spending is a reduction of 23.5 thousand Yen; at the 95th quantile,

\footnotetext{
${ }^{35}$ The data record out-of-pocket payments in the last month (May), whereas the survey is conducted in June. I multiply the data by 12 to convert the value to "annual" out-of-pocket costs. Note that seasonality in medical spending may introduce a measurement error. Moreover, this may overstate the likelihood of very high out-of-pocket payments if few patients visit a hospital every month.

${ }^{36}$ Figure $\mathrm{J}$ in the Online Appendix compares the whole distribution of out-of-pocket medical expenditure in 2007 for different age groups.

${ }^{37}$ See Frandsen, Froelich, and Melly (2010), which proposed the nonparametric estimator for quantile treatment effects in an RD design. Recognizing the potential bias due to the misspecification, I choose to use the parametric approach, since I also want to obtain the coefficients on other control variables used to derive the distribution of out-of-pocket medical expenditure at each quantile, conditional on individual characteristics later in the welfare analysis in Section A2 in the Online Appendix. In fact, I also estimate the proposed nonparametric estimators and compare them to the parametric ones. The estimates are quite similar throughout the percentile, except for a slight deviation among the top 3 percentile. The results are available from the author.
} 
it grows to 107 thousand Yen, a 26 percent decline from the value just below age 70 (see Table I in the Online Appendix). These results show that patients at the right tail of the distribution in particular are substantially benefited from lower cost sharing, since the reduction in price at age 70 overwhelms offsetting increases in utilization.

\section{Discussion}

\subsection{Implications of Price Elasticities}

I estimated the price elasticities of outpatient and inpatient care separately, since the price schedule of patient cost sharing differs for the two services. The data I use in this paper do not generally allow me to distinguish own- from cross-price effects, because the prices of outpatient and inpatient care both drop by roughly 70 percent at age 70 . Thus, the behavioral responses of roughly 10 percent increases in visits for both outpatient and inpatient care may be driven in principle by both effects. ${ }^{38}$ However, for some diagnosis groups, cross-price effects should be nearly zero, because for these diagnosis groups nearly all treatment is outpatient or nearly all treatment is inpatient.

Figures K1 and K2 in the Online Appendix show RD estimates by diagnosis group (see Table $\mathrm{G}$ in the Online Appendix for the list) as they relate to the fraction of visits in each group using outpatient or inpatient care at age 69 , respectively. In each figure, the RD estimates are generally driven by both own- and cross-price effects. However, the right-hand limit of each figure covers diagnosis groups where nearly all patients use outpatient or inpatient care, respectively. For these diagnosis groups, the RD effects should be driven almost entirely by own-price effects. The bottom line is that these own-price effects are about 10 percent, which is in line with the total effects given in Table 3 and Table 4.

Specifically, the diagnosis group with highest fraction of outpatient care in Figure K1 is hypertensive disease (diagnosis group 26), where the fraction is 94.2 percent. In fact, hypertension, which is included in this diagnosis group, is the leading cause for outpatient visits at the 3-digit ICD9 level (see Table C1 in the Online Appendix). The RD estimate for this diagnosis group is 8.2 percent, and it is not statistically different from the overall estimate of 10.3 percent (see Panel A in Table 3).

I conduct the same exercise for inpatient care. The diagnosis group with the highest fraction of inpatient care in Figure K2 is benign neoplasm (diagnosis group 15), with a fraction of 78.5 percent. Compared to the result for outpatient care, the claim that nearly all patients are treated as inpatients does not really fit - nearly a quarter of patients in this group are outpatients. The $\mathrm{RD}$ estimate for this diagnosis group is 11.7 percent, while the overall estimate is 8.2 percent (see Panel A in Table 4). Here, we see that the overall estimate is somewhat lower than the estimate for

\footnotetext{
${ }^{38}$ Whether outpatient and inpatient care are substitutes or complements is an important, but unsettled, question. Most of the literature, including that pertaining to the RAND HIE, has found that outpatient and inpatient care are complements (e.g., Kaestner and Lo Sasso, 2012). A recent study by Chandra, Gruber, and McKnight (2010) is an exception: it found evidence of substitution effects, namely that while the copayment increase in outpatient visits reduces the number of such visits, it leads to an increase in subsequent hospitalizations.
} 
this diagnosis group (although not statistically significantly different). Taken together, the results for inpatient and outpatient care show that for diagnosis groups where cross-price effects are $a$ priori small, the overall behavioral effect of the price change (RD estimate) is an approximately 10 percent increase in visits, which is similar to the overall estimate, which includes both cross- and own-price effects. To the extent that the magnitude of own-price effects is similar across diagnosis groups, this suggests that own-price effects are the dominant factor in the RD estimates presented in this paper.

\subsection{Comparison to Prior Literature}

While the elderly are the most intensive consumers of health care, credible evidence on price elasticities for this group is very scarce. As Finkelstein (2007) argues, it is not clear a priori whether the elderly are expected to have larger or smaller price elasticities of demand for health care services than the non-elderly. The former's price elasticities may be larger if they are poorer or more credit-constrained than the latter and smaller if their health problems are more severe than those of the latter.

One notable exception is Chandra, Gruber, and McKnight (2010), which examined the price elasticity of physician office visits among the recipients of a supplemental Medicare insurance policy in the US. My estimate for outpatient visits (-0.16) is slightly larger than the estimates in Chandra et al. (-0.07 to -0.10). Also, while individuals over the age 62 are excluded from the RAND HIE, my estimate is similar to the estimates found therein for the non-elderly (roughly -0.2). ${ }^{39}$ In any case, my estimate is within the range of similar estimates in prior literature.

Nevertheless, I need to view these comparisons with considerable caution since there are many institutional differences between Japan and the US. For example, the ratio of medical expenditure to GDP was 6.5 percent in 1984 and 8.6 percent in 2008 in Japan, while the corresponding figures in the US were much higher, namely 10.2 percent and 16.6 percent, respectively (OECD, 2012). In fact, in 2008, Japan's ratio was the lowest (20th) among the OECD countries. This fact is interesting because given Japan's universal coverage without the need to go through a gatekeeper or a referral system, Japan has the highest per-capita number of physician visits among all OECD countries. Physician consultations per-capita per year number 13.2 in Japan, which is more than twice as large than that in the US (3.9). Some argue that Japan's low medical spending is achieved through low reimbursements to hospitals, controlled by the stringent national fee schedule (e.g., Ikegami and Campbell, 1995).

Interestingly, while there is a five-year age difference between the Medicare population in the US (those over age 65) and individuals covered under Elderly Health Insurance in Japan (those over age 70), there is some indication that the underlying population may be similar. In fact, in 2008, the life expectancy at birth was 82.7 in Japan and 78.1 in the US (OECD, 2012). Conditional on surviving until the eligibility age for public insurance for the elderly is reached, these figures

\footnotetext{
${ }^{39}$ In addition, see Aron-Dine, Einav, and Finkelstein (2013), which reexamined the core findings of the RAND HIE, including the well-known elasticity estimate of -0.2. Chandra, Gruber, and McKnight (forthcoming) found price elasticities of about - 0.16 - similar to my estimates - for a low-income population sample in Massachusetts.
} 
for life expectancy are not much different.

\subsection{Cost-benefit Analysis}

Finally, I conduct a simple cost-benefit analysis associated with the change in the price of health care services at age 70. The details are summarized in Section A2 in the Online Appendix. Since I needed to make a number of assumptions, the results from this exercise are mostly speculative. The social cost is the combination of the deadweight loss of program financing and the moral hazard, while the benefit is risk protection against unexpected out-of-pocket medical spending. My estimates suggest that the welfare gain of risk protection from lower patient cost sharing is comparable to the total social cost, indicating that the welfare gain from risk protection may fully cover the total social cost in this setting. One limitation of this welfare analysis is that it does not incorporate welfare gains from health improvements. While I do not find any short-term reduction in mortality or improvement in any self-reported health measures, it is possible that preventive care induced by lower cost sharing at age 70 may prevent severe future health events, thus improving health in the long run. It is infeasible to estimate long-run effects in this framework, because individuals eventually age into treatment.

\section{Conclusion}

Previous studies of patient cost sharing have had difficulty separating its effect on patients from the responsive behavior by medical providers and insurers. In addition, the estimates are confounded by the joint effects of changes in health insurance coverage and benefit generosity. This paper attempted to overcome these limitations by examining a sharp reduction in patient cost sharing at age 70 in Japan, using an RD design. I find that the implied price elasticities are -0.2 for both outpatient visits and inpatient admissions. While I did not detect any effects on health, I did find reduced cost sharing benefits for patients at the right tail of the out-of-pocket distribution, lowering it by roughly 30 percent. One limitation of the paper is that I cannot take long-run health benefits into account in this empirical framework. Estimating the long-term effect of patient cost sharing on health is beyond the scope of the current paper, but it clearly remains an important topic for future research.

\section{References}

Aron-Dine, Aviva, Liran Einav, and Amy Finkelstein. 2013. "The RAND Health Insurance Experiment, Three Decades Later." Journal of Economic Perspectives 27(1): 197-222.

Aron-Dine, Aviva, Liran Einav, Amy Finkelstein, and Mark Cullen. 2012. "Moral Hazard in Health Insurance: How Important is Forward Looking Behavior?" National Bureau of Economic Research Working Paper No. 17802. 
Barreca, Alan, Melanie Guldi, Jason M. Lindo, and Glen R. Waddell. 2011. "HeapingInduced Bias in Regression-Discontinuity Designs." National Bureau of Economic Research Working Paper No. 17408.

Card, David, Carlos Dobkin, and Nicole Maestas. 2004. "The Impact of Nearly Universal Insurance Coverage on Health Care Utilization and Health: Evidence from Medicare." National Bureau of Economic Research Working Paper No. 10365.

Card, David, Carlos Dobkin, and Nicole Maestas. 2008. "The Impact of Nearly Universal Insurance Coverage on Health Care Utilization: Evidence from Medicare." American Economic Review 98(5): 2242-2258.

Card, David, Carlos Dobkin, and Nicole Maestas. 2009. "Does Medicare Save Lives?" Quarterly Journal of Economics 124(2): 597-636.

Carneiro, Pedro, Katrine V. Loken, and Kjell G. Salvanes. 2010. "A Flying Start? Long Term Consequences of Maternal Time Investments in Children During Their First Year of Life." IZA Discussion Paper No. 5362.

Carpenter, Christopher, and Carlos Dobkin. 2009. "The Effect of Alcohol Consumption on Mortality: Regression Discontinuity Evidence from the Minimum Drinking Age." American Economic Journal: Applied Economics 1(1): 164-182.

Centers for Medicaid and Medicare Services. 2005. National Health Expenditures. www.cms.hhs.gov/NationalHealthExpendData/04_NationalHealthAccountsAgePHC.asp (accessed Aug 7, 2013)

Chandra, Amitabh, Jonathan Gruber, and Robin McKnight. 2010. "Patient Cost-Sharing and Hospitalization Offsets in the Elderly." American Economic Review 100(1): 193-213.

Chandra, Amitabh, Jonathan Gruber, Robin McKnight. (forthcoming). "The impact of patient cost-sharing on LOW-INCOME POPULATIONS: Evidence from Massachusetts." Journal of Health Economics.

Chay, Kenneth Y., Daeho Kim, and Shailender Swaminathan. 2010. "Medicare, Hospital Utilization and Mortality: Evidence from the Program's Origins." Unpublished.

Congressional Budget Office. 2011. CBO's 2011 Long-Term Budget Outlook. http://www.cbo.gov/publication/41486 (accessed Aug 7, 2013)

Cutler, David M. 1998. "Cost Shifting or Cost Cutting?: The Incidence of Reductions in Medicare Payments." Tax Policy and the Economy 12: 1-27.

Desapriya, Ediriweera, Sayed Subzwari, Giulia Scime-Beltrano, Lionel A. Samayawardhena, and Ian Pike. 2010. "Vision improvement and reduction in falls after expedited cataract surgery: Systematic review and metaanalysis." Journal of Cataract and Refractive Surgery 36(1): 13-19. 
Dobkin, Carlos. 2003. "Hospital Staffing and Inpatient Mortality." Unpublished.

Ellis, Randall. 1986. "Rational Behavior in the Presence of Coverage Ceilings and Deductibles." RAND Journal of Economics 17(2): 158-175.

Engelhardt, Gary V., and Gruber, Jonathan. 2011. "Medicare Part D and the Financial Protection of the Elderly." American Economic Journal: Economic Policy 3(4): 77-102.

Feldstein, Martin, and Jonathan Gruber. 1995. "A Major Risk Approach to Health Insurance Reform." Tax Policy and the Economy 9: 103-130.

Finkelstein, Amy. 2007. "The Aggregate Effects of Health Insurance: Evidence from the Introduction of Medicare." Quarterly Journal of Economics 122 (3), 1-37.

Finkelstein, Amy, and Robin McKnight. 2008. "What Did Medicare Do? The Initial Impact of Medicare on Mortality and Out of Pocket Medical Spending." Journal of Public Economics 92(7): 1644-1668.

Finkelstein, Amy, Sarah Taubman, Bill Wright, Mira Bernstein, Jonathan Gruber, Joseph P. Newhouse, Heidi Allen, Katherine Baicker, and The Oregon Health Study Group. 2012. "The Oregon Health Insurance Experiment: Evidence from the First Year." Quarterly Journal of Economics 127(3): 1057-1106.

Frandsen, Brigham, Markus Frolich, and Blaise Melly. 2010. "Quantile Treatment Effects in the Regression Discontinuity Design." Unpublished.

Gans, Joshua S., and Andrew Leigh. 2009. "Born on the First of July: An (Un)natural Experiment in Birth Timing." Journal of Public Economics 93(1-2): 246-263.

Grossman, Michael. 1972. "On the Concept of Health Capital and the Demand for Health." Journal of Political Economy 80(2): 223-255.

Hahn, Jinyong, Petra Todd, and Wilbert van der Klaauw. 2001. "Identification and Estimation of Treatment Effects with a Regression-Discontinuity Design." Econometrica 69(1): 201-209.

Hai Fang, and John A. Rizzo. 2009. "Competition and Physician-enabled Demand: The Role of Managed Care." Journal of Economic Behavior and Organization 72(1): 463-474.

Ikegami, Naoki, and John C. Campbell. 1995. "Medical Care in Japan." New England Journal of Medicine 333: 1295-1299.

Ikegami, Naoki, Byung-Kwang Yoo, Hideki Hashimot, Masatoshi Matsumoto, Hiroya Ogata, Akira Babazono, Ryo Watanabe, Kenji Shibuya, Bong-Min Yang, Michael R Reich, and Yasuki Kobayashi. 2011. "Japanese Universal Health Coverage: Evolution, Achievements, and Challenges." The Lancet 378(9796): 1094-1105. 
Imbens, Guido W., and Thomas Lemieux. 2008. "Regression Discontinuity Designs: A Guide to Practice." Journal of Econometrics 142(2): 615-635.

Kaestner, Robert, and Anthony T. Lo Sasso. 2012. "Does Seeing the Doctor More Often Keep You Out of the Hospital?" National Bureau of Economic Research Working Paper No. 18255.

Kawaguchi, Daiji. 2011. "Actual Age at School Entry, Educational Outcomes, and Earnings." Journal of the Japanese and International Economies 25(2): 64-80.

Keeler, Emmett B., Joseph P. Newhouse, and Charles E. Phelps. 1977. "Deductibles and the Demand for Medical Care Services: The Theory of a Consumer Facing a Variable Price Schedule Under Uncertainty." Econometrica 45(3): 641-656.

Keeler, Emmett, and John E. Rolph. 1988. "The Demand for Episodes of Treatment in the Health Insurance Experiment." Journal of Health Economics 7(4): 337-367.

Kondo, Ayako, and Hitoshi Shigeoka. 2013. "Effects of Universal Health Insurance on Health Care Utilization and Supply-Side Responses: Evidence from Japan." Journal of Public Economics, 99: $1-23$.

Kowalski, Amanda. 2012. "Estimating the Tradeoff between Risk Protection and Moral Hazard with a Nonlinear Budget Set Model of Health Insurance." National Bureau of Economic Research Working Paper No.18108.

Lee, David S., and David Card. 2008. "Regression Discontinuity Inference with Specification Error." Journal of Econometrics 142(2): 655-674.

Lee, David S., and Thomas Lemieux. 2010. "Regression Discontinuity Designs in Economics." Journal of Economic Literature 48: 281-355.

Manning, Willard G., Joseph P. Newhouse, Naihua Duan, Emmett B. Keeler, and Arleen Leibowitz. 1987. "Health Insurance and the Demand for Medical Care: Evidence from a Randomized Experiment." American Economic Review 77(3): 251-277.

Ministry of Health, Labour and Welfare. 2010. Estimates of National Medical Care Expenditure. http://www.e-stat.go.jp/SG1/estat/List.do?lid=000001058043 (accessed Aug 21, 2011)

Ministry of Health, Labour and Welfare. 2009. Report on Health Service for Elderly (Rojin Iryo Jigyo Houkoku) (In Japanese). http://www.mhlw.go.jp/bunya/iryouhoken/database/seido/roujin_houkoku.html_(accessed May 5, 2013)

Newhouse, Joseph, and the Insurance Experiment Group. 1993. Free for All? Lessons from the RAND Health Insurance Experiment. Harvard University Press. 
Nishi, Akihiro, Michael J McWilliams, Haruko Noguchi, Hideki Hashimoto, Nanako Tamiyae, and Ichiro Kawachi. 2012. "Health benefits of reduced patient cost sharing in Japan." Bulletin of the World Health Organization, 90(6): 426-435A.

Marsh, Christina. 2012. "Estimating Demand Elasticities using Nonlinear Pricing." Unpublished.

Okamura, Shinichi, Ryota Kobayashi, and Tetsuo Sakamaki. 2005. "Case-mix Payment in Japanese Medical Care." Health Policy 74: 282-286.

Organisation for Economic Co-operation and Development. 2012. OECD Health Data. http://www.oecd.org/els/health-systems/oecdhealthdata2012-frequentlyrequesteddata.htm (accessed May 21, 2013)

Pierdomenico, Sante D., Marta Di Nicola, Anna L. Esposito, Rocco Di Mascio, Enzo Ballone, Domenico Lapenna and Franco Cuccurullo. 2009. "Prognostic Value of Different Indices of Blood Pressure Variability in Hypertensive Patients." American Journal of Hypertension 22: $842-847$.

Zeckhauser, Richard. 1970. "Medical Insurance: A Case Study of the Tradeoff between Risk Spreading and Appropriate Incentives." Journal of Economic Theory 2: 10-26. 
Figure 1: Patient Cost Sharing Below 70 and Above 70 (2008)

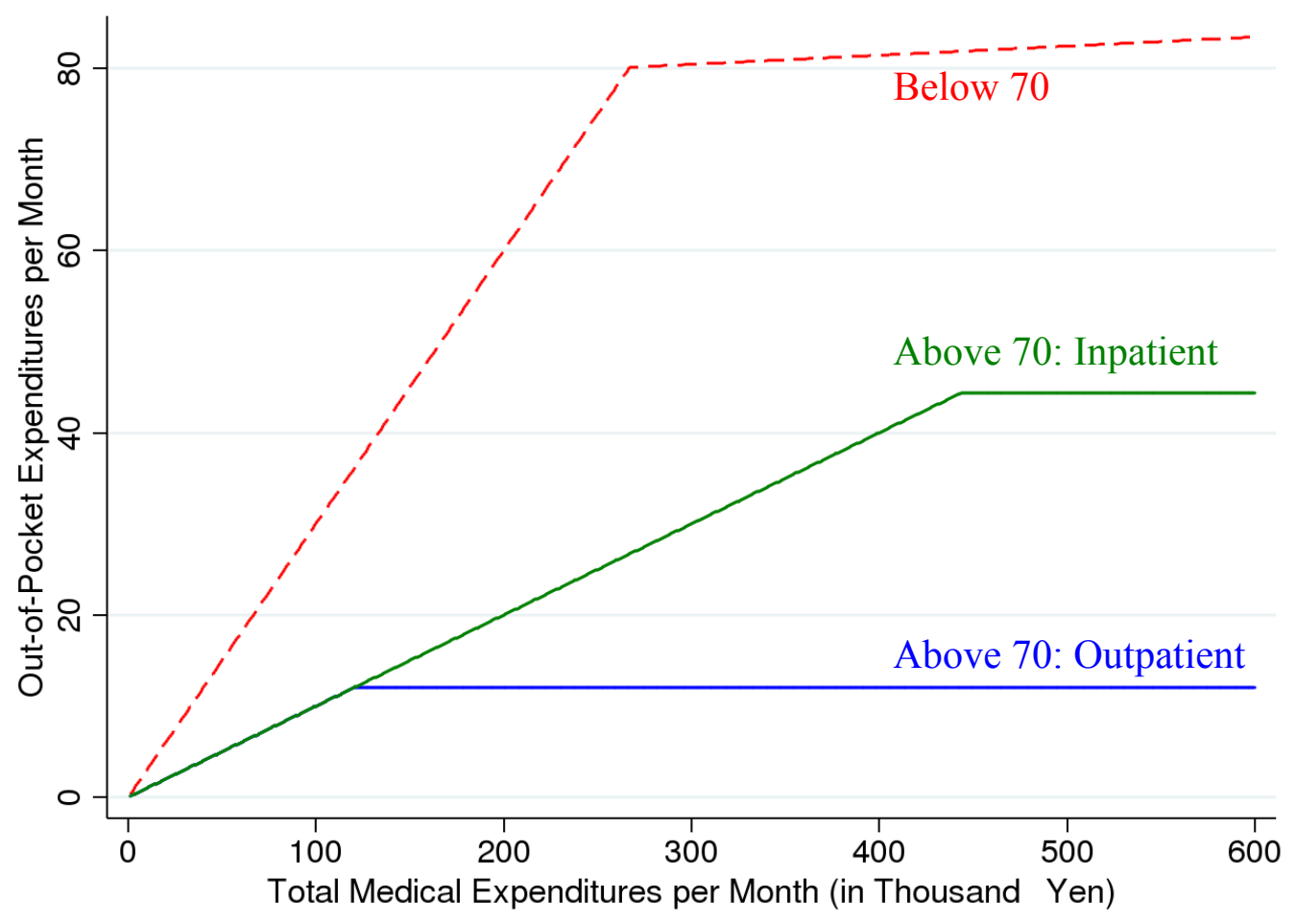

Note: See Table 1 for the formula used to calculate patient cost sharing. For those above age 70 , since the coinsurance rate and stop loss differs by outpatient visits and inpatient admissions, I show two separate lines for each service. For those below 70, there was no distinction between outpatient visits and inpatient admissions in year 2008. One thousand Yen roughly equaled 10 US dollars in 2008. 
Figure 2: Age Profile for Outpatient Visits

2A. Overall Outpatient Visits (Log Scale)

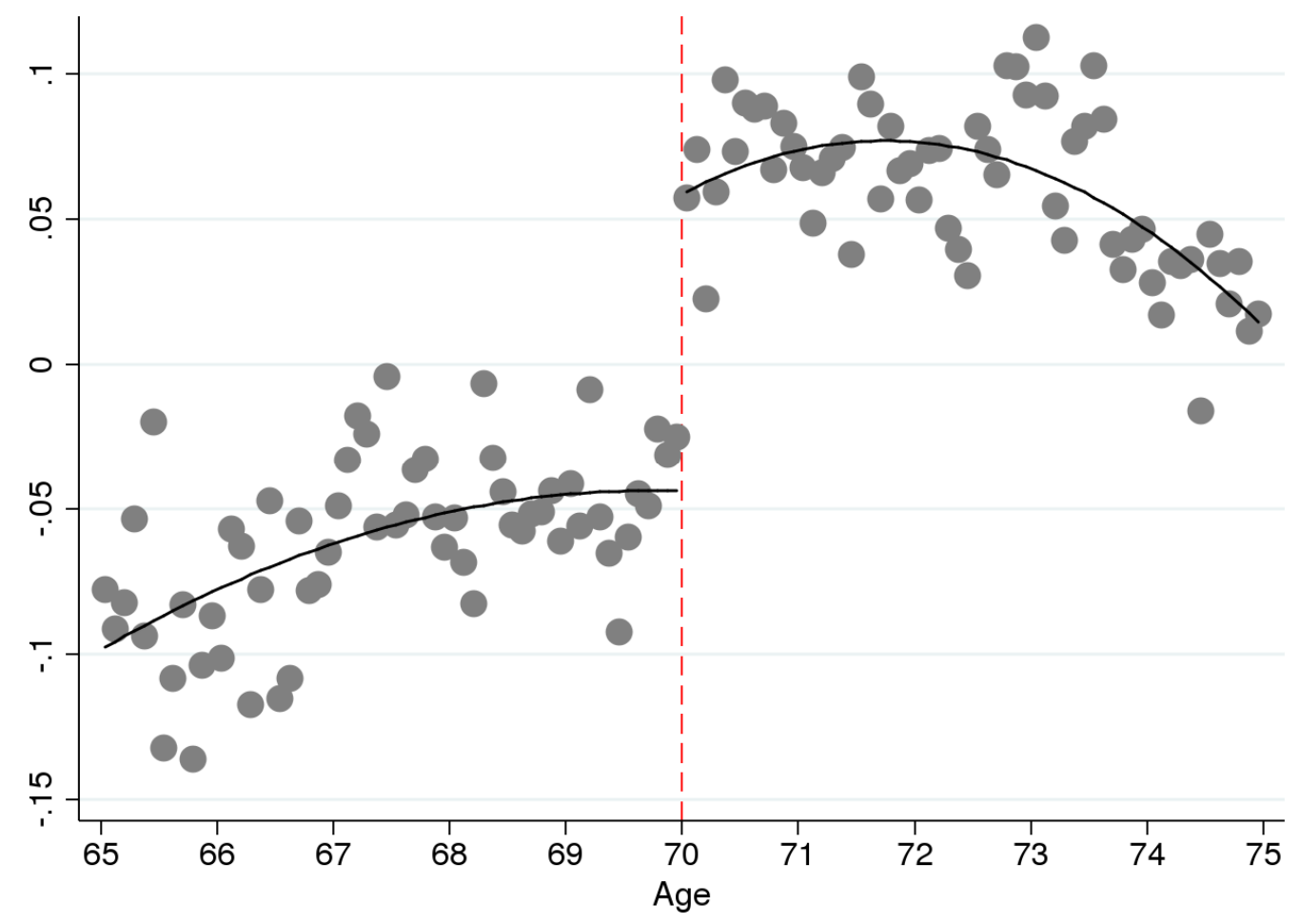

2B. Days from Last Outpatient Visit for Repeat Patients

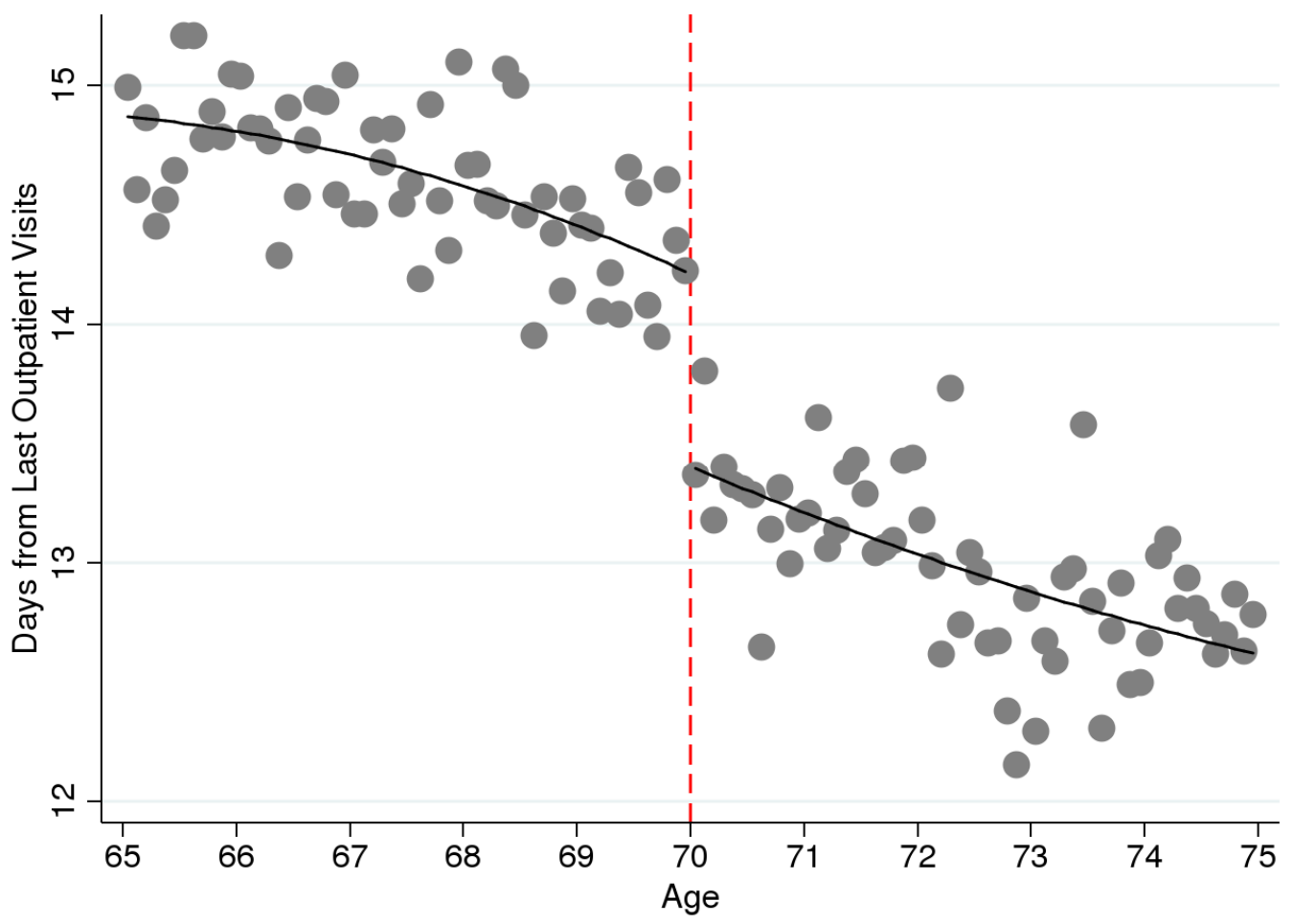

Note: I pool outpatient data for 1984-2008 from the Patient Survey. The markers in 2A represent the averages of residuals from regressions of log outcomes on birth month fixed effects and survey year fixed effects (aggregated by age in months). The markers in $2 \mathrm{~B}$ represent the simple average. The lines represent fitted regressions from models that assume a quadratic age profile, fully interacted with a dummy for age 70 or older. 
Figure 3: Age Profile for Outpatient Visits for Selected Diagnoses (Log Scale)
A. Heart Disease
C. Respiratory Disease
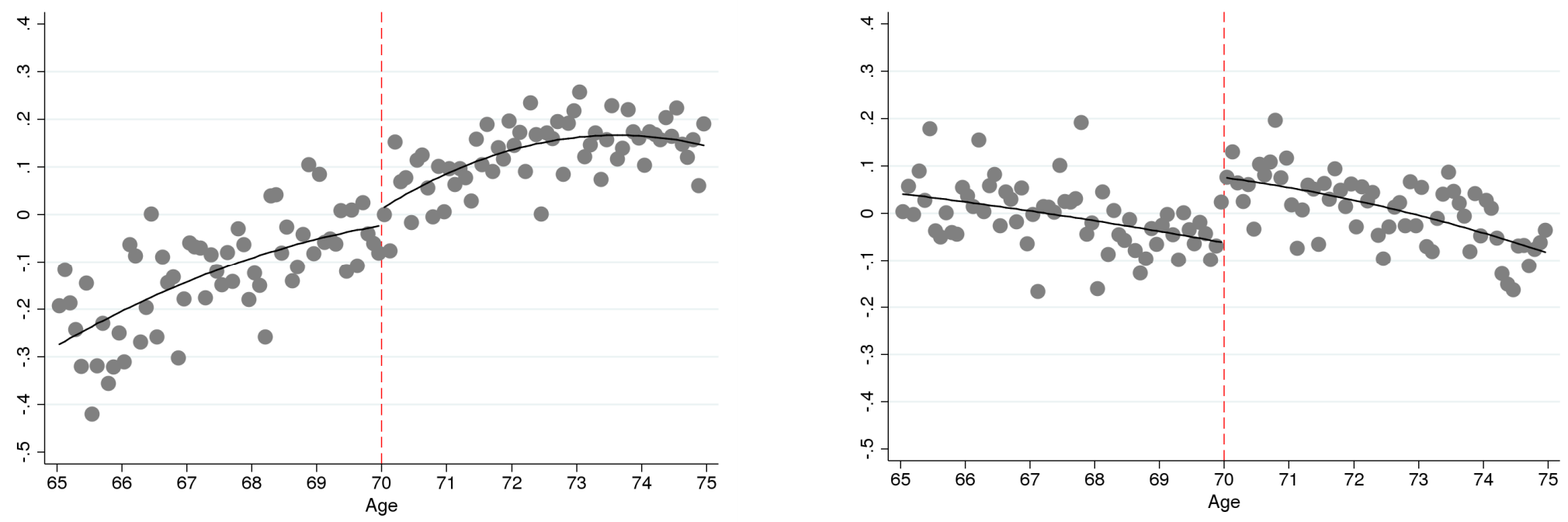

B. Cerebrovascular Disease

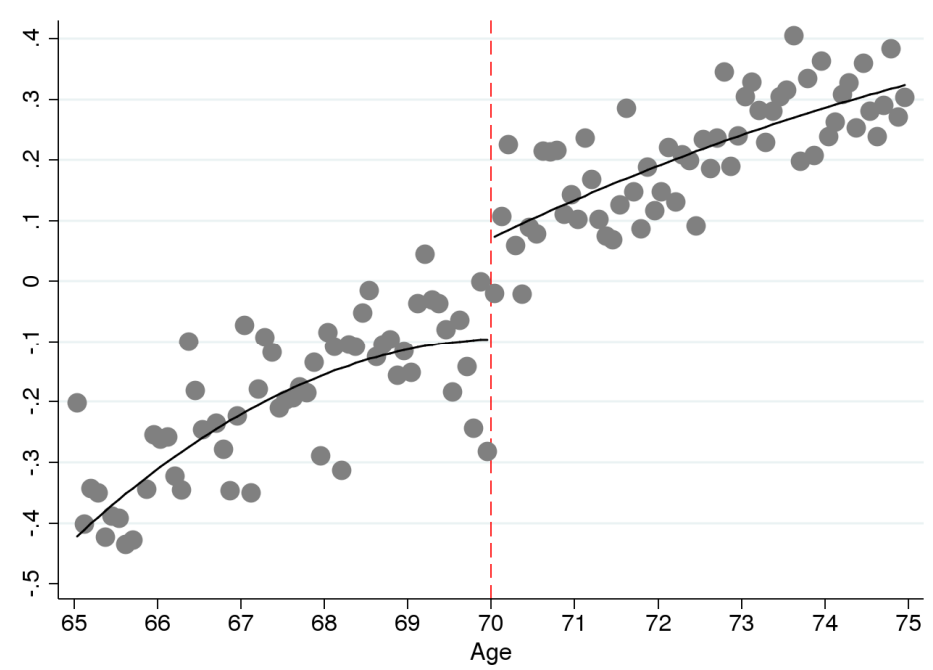

D. ACSCs

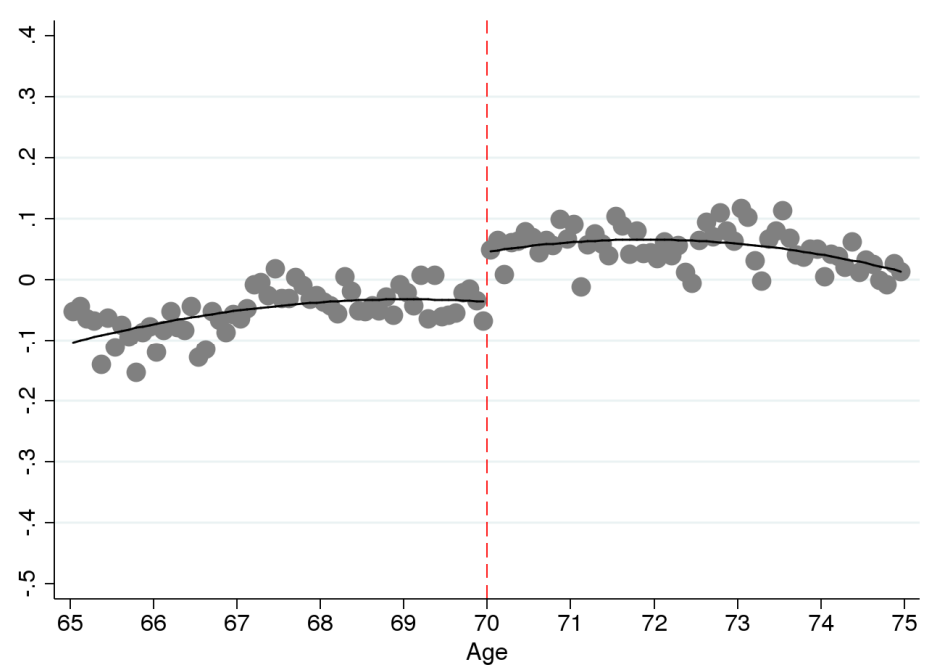

Note: I pool outpatient data for 1984-2008 from the Patient Survey. Except for Panel A, the corresponding RD estimates at age 70 are statistically significant at the 5 percent level. The markers represent the averages of residuals from regressions of log outcomes on birth month fixed effects and survey year fixed effects (aggregated by age in months). The lines represent fitted regressions from models that assume a quadratic age profile, fully interacted with a dummy for age 70 or older. "ACSCs" stands for Ambulatory Care Sensitive Conditions developed by the Agency for Healthcare Research and Quality (AHRQ). See Table D in the Online Appendix for the list of ACSCs. 
Figure 4: Age Profile for Inpatient Admissions (Log Scale)

4A. Overall

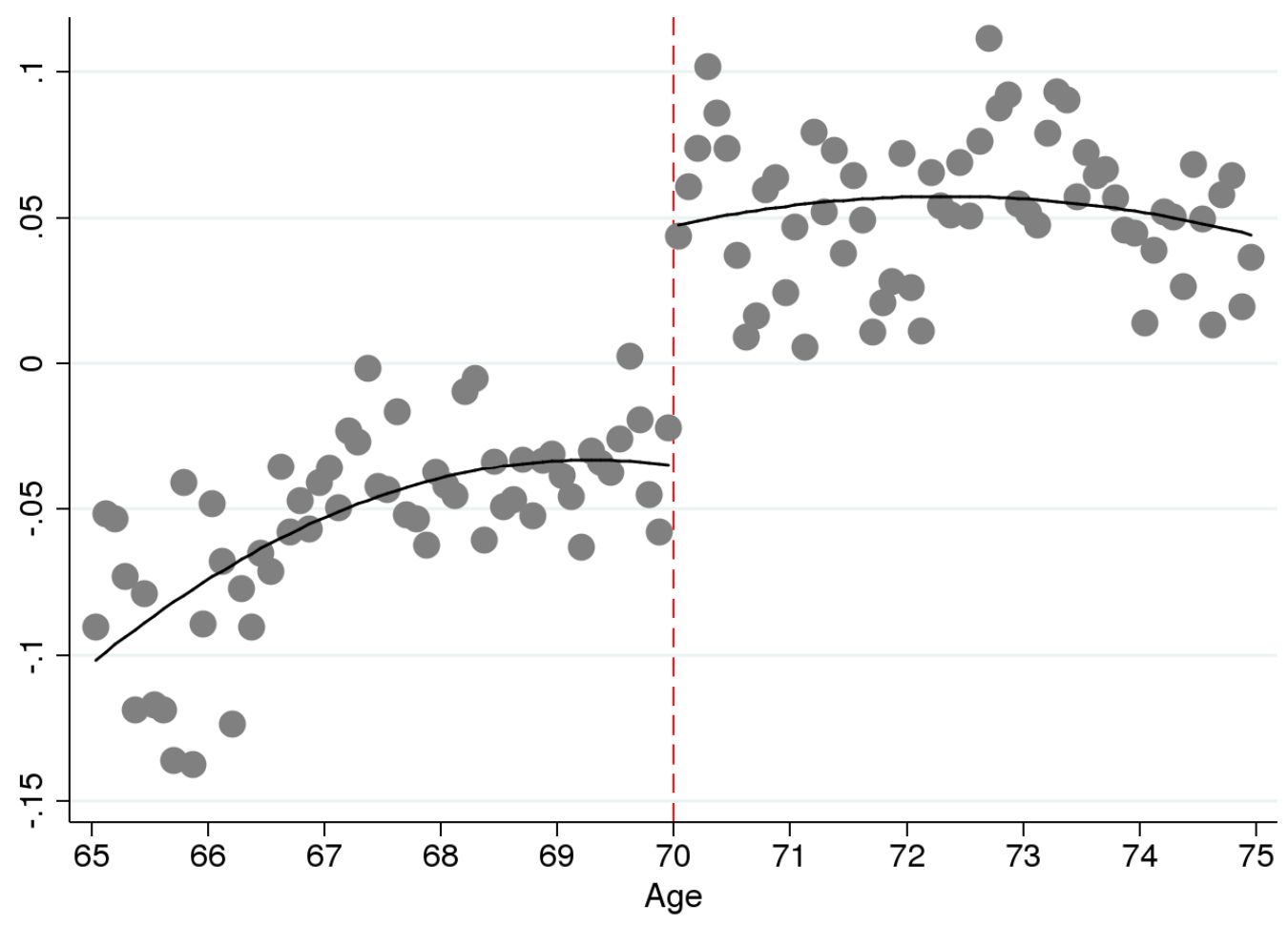

4B. With Surgery

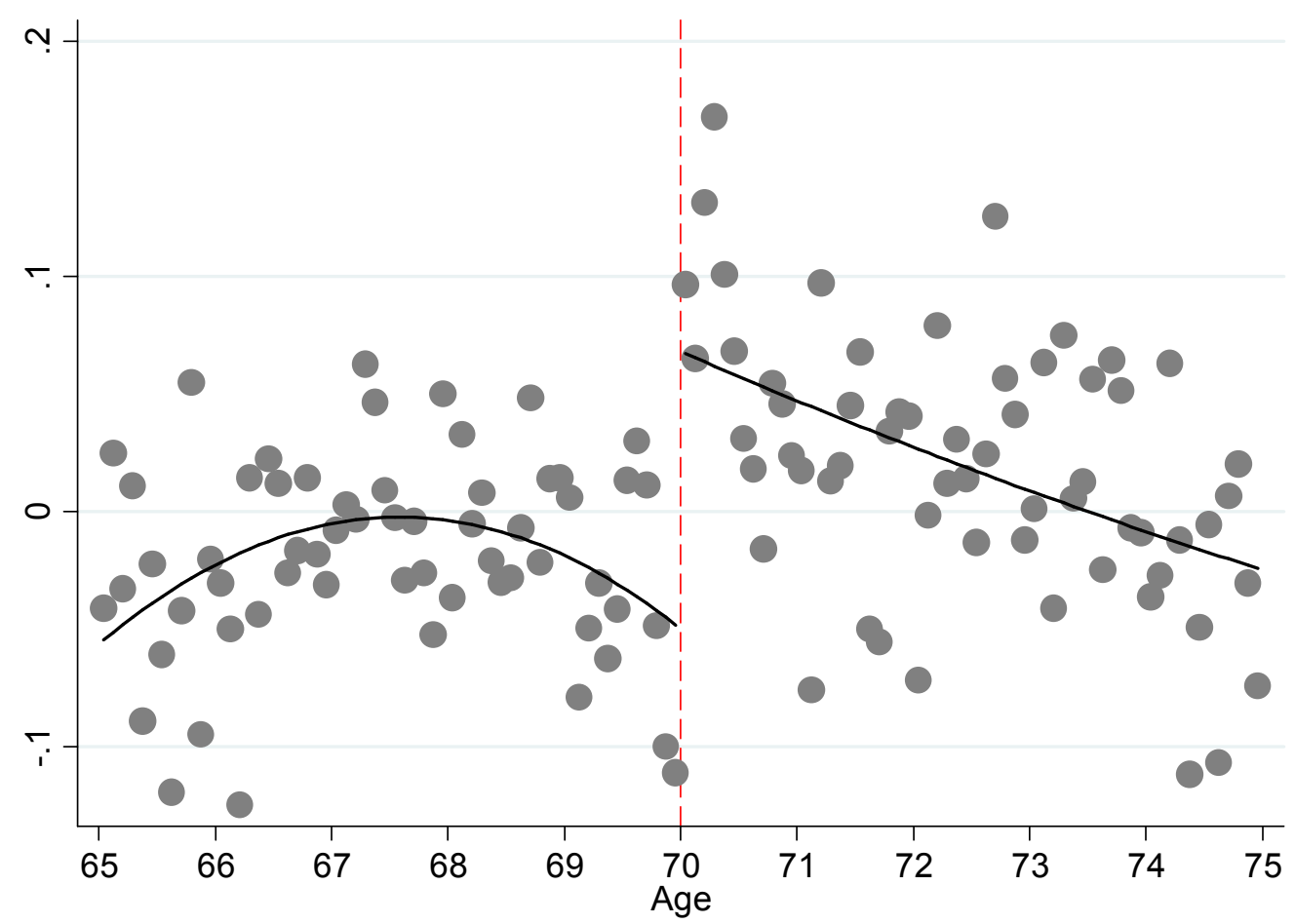

Note: I pool discharge data for 1984-2008 from the Patient Survey. The markers represent the averages of residuals from regressions of log outcomes on birth month fixed effects, admission month fixed effects, and survey year fixed effects (aggregated by age in months). The lines represent fitted regressions from models that assume a quadratic age profile, fully interacted with a dummy for age 70 or older. 


\section{Figure 5: RD Estimates and Fraction of Weekend Admissions}

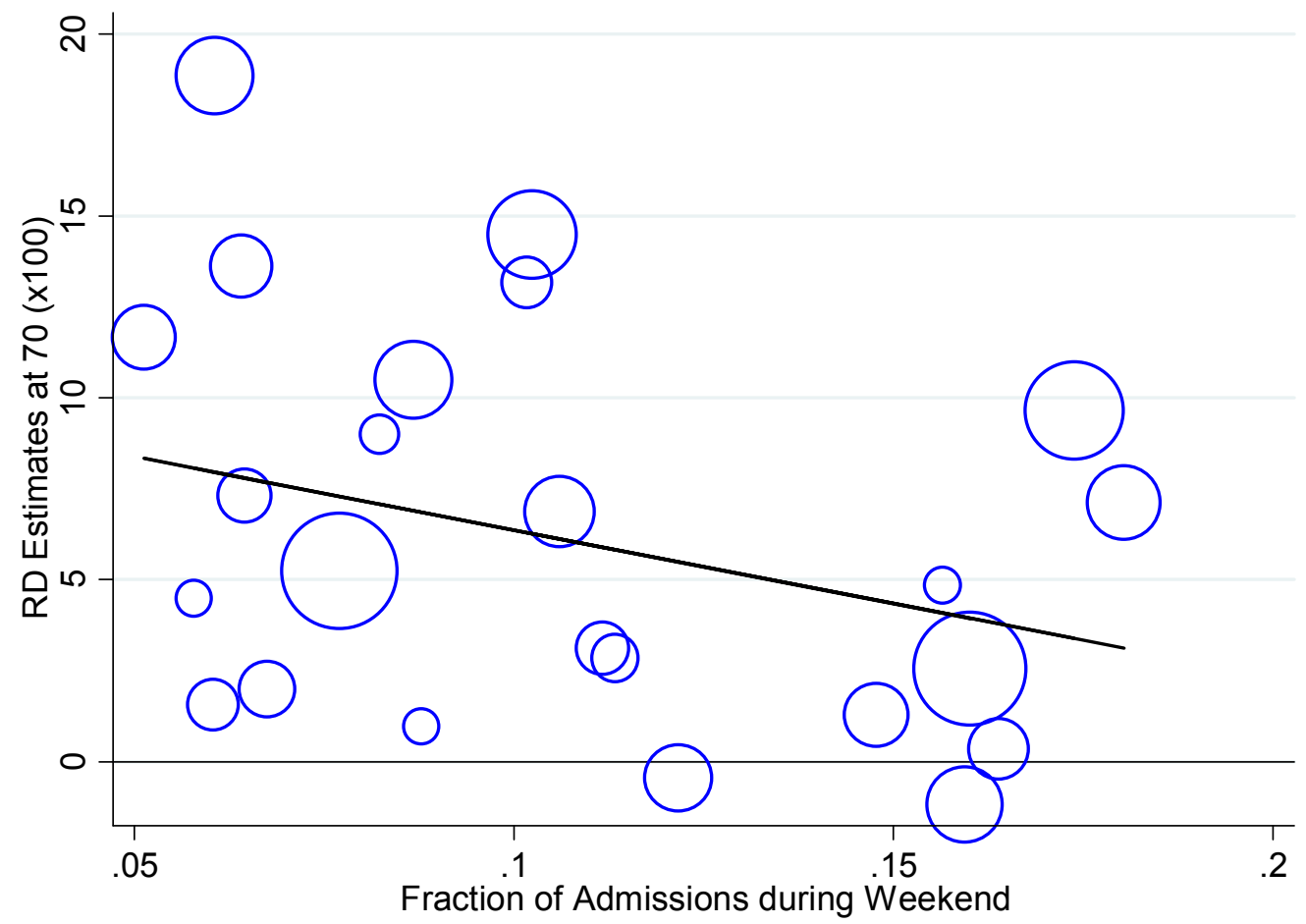

Note: I pool discharge data for 1984-2008 from the Patient Survey. The $y$-axis represents the RD estimates at age 70 , and the $x$-axis is the fraction of admissions during weekends for each diagnosis group. The size of each dot reflects the number of observations in the discharge data for the control group (those aged 69). See Table $G$ in the Online Appendix for the list of diagnosis groups. I omit diagnosis groups with less than 1 percent of the total observations, because their sample sizes are too small to provide credible estimates. The solid line is a linear fit, using the reciprocal of the variance of each RD estimate as weight for the observation.

Figure 6: Age Profile of Overall Mortality

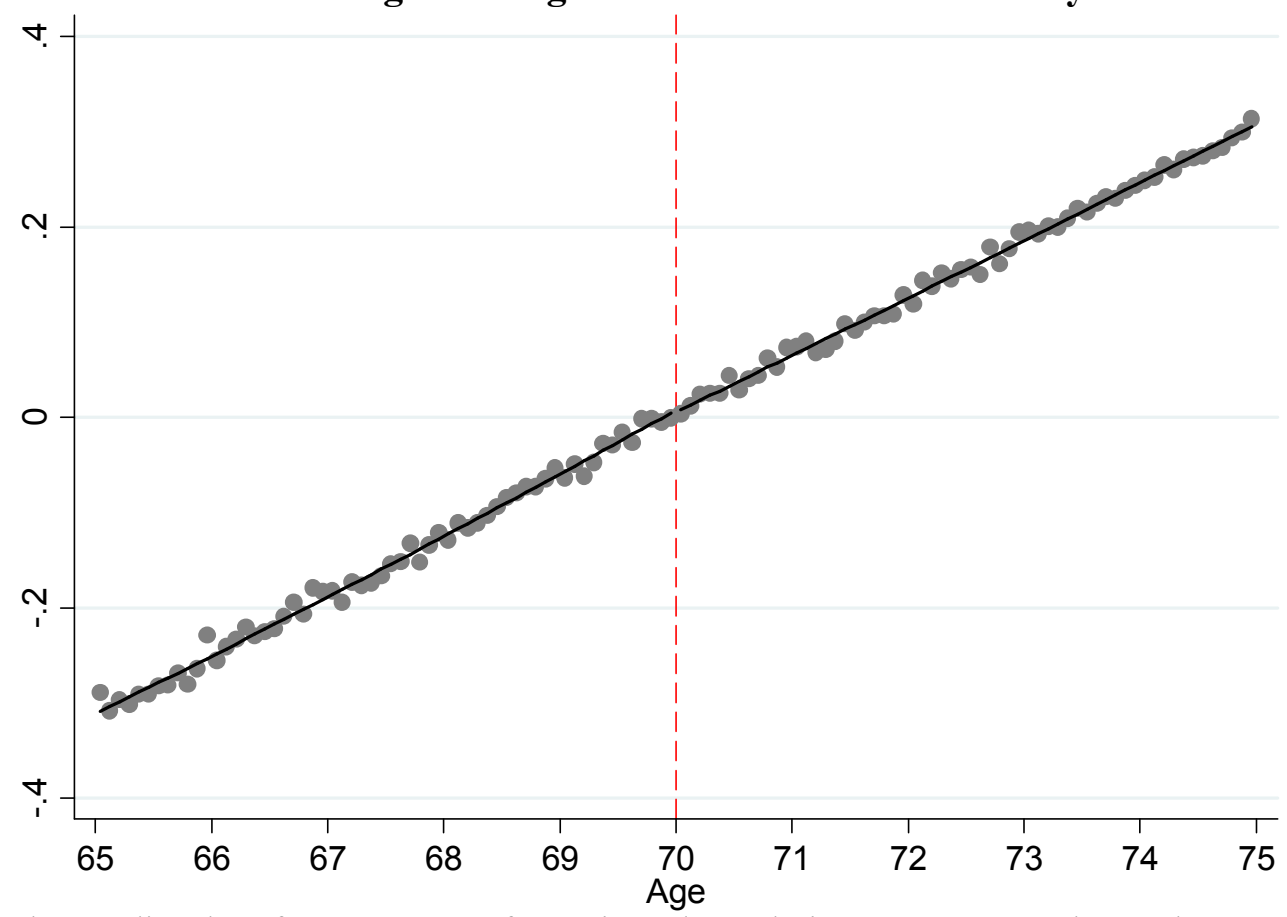

Note: I pool mortality data for 1984-2008 for patients born during 1919-1933. The markers represent the averages of residuals from regressions of log outcomes on birth month fixed effects and death month fixed effects (aggregated by age in months). The lines represent fitted regressions from models that assume a quadratic age profile, fully interacted with a dummy for age 70 or older. 
Figure 7: Age Profile of Out-of-pocket Medical Expenditures (2007)

7A. At the 75th, 90th, and 95th Percentile

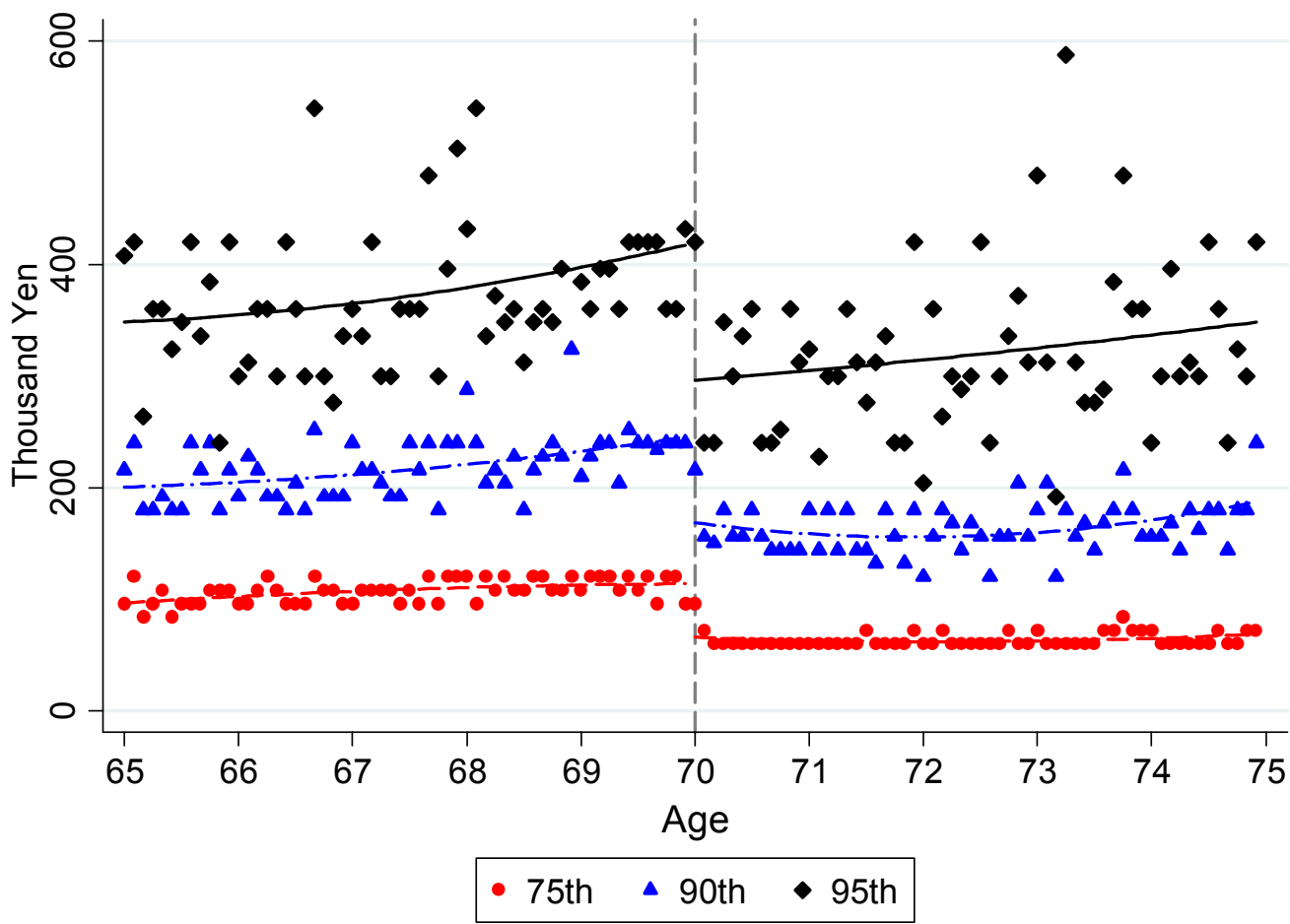

7B. RD Estimates at Each Quantile

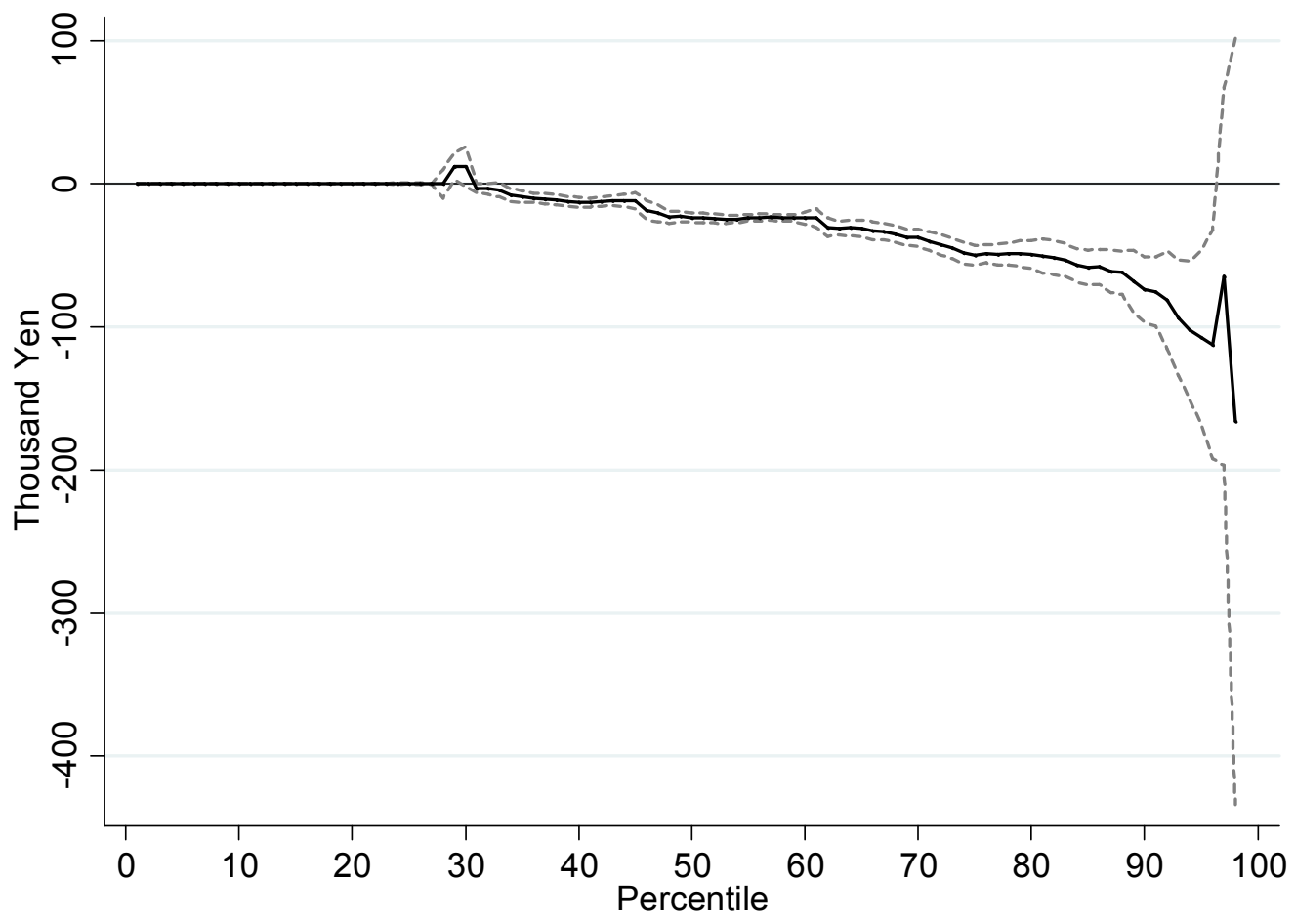

Note: The data are sourced from the Comprehensive Survey of Living Conditions for 2007. I multiply the monthly out-of-pocket expenditures by 12 to convert the values to an annual basis. One thousand Yen roughly equaled 10 US dollars in 2007. The markers in Figure 7A represent actual averages (age measured in months), and the lines represent fitted regressions from models that assume a quadratic age profile, fully interacted with a dummy for age 70 or older. Figure 7B plots the RD estimates at each quantile along with their 95 percent confidence interval. The confidence interval for the 99th percentile $(-989.38,-9.25)$ is not shown on the graph. 
Table 1: Formula for Patient Cost Sharing Below and Above Age 70

A. Outpatient Visits

\begin{tabular}{|c|c|c|c|c|c|c|}
\hline \multirow[b]{3}{*}{ Year } & \multicolumn{4}{|c|}{ Below 70} & \multicolumn{2}{|c|}{ Above 70} \\
\hline & \multicolumn{3}{|c|}{ Coinsurance } & \multirow[b]{2}{*}{$\begin{array}{c}\text { Stop-loss } \\
\text { (thousand Yen) }\end{array}$} & Coinsurance & \multirow[b]{2}{*}{$\begin{array}{c}\text { Stop-Loss } \\
\text { (thousand } \\
\text { Yen) }\end{array}$} \\
\hline & $\begin{array}{c}\text { NHI } \\
\text { (percent) }\end{array}$ & $\begin{array}{c}\text { Employment- } \\
\text { based } \\
\text { (Employee, } \\
\text { Percent) }\end{array}$ & $\begin{array}{c}\text { Employment- } \\
\text { based } \\
\text { (Dependent, } \\
\text { Percent) }\end{array}$ & & All & \\
\hline 1984 & $30^{(1)}$ & 10 & 30 & 51.0 & $0.4 /$ month & - \\
\hline 1987 & $30^{(1)}$ & 10 & 30 & 54.0 & $0.8 /$ month & - \\
\hline 1990 & $30^{(1)}$ & 10 & 30 & 57.0 & $0.8 /$ month & - \\
\hline 1993 & $30^{(1)}$ & 10 & 30 & 63.0 & $1.0 /$ month & - \\
\hline 1996 & $30^{(1)}$ & 10 & 30 & 63.0 & $1.02 /$ month & - \\
\hline 1999 & $30^{(1)}$ & 20 & 30 & 63.6 & $0.53 /$ day $^{(2)}$ & - \\
\hline 2002 & $30^{(1)}$ & 20 & 30 & $\begin{aligned} 63.6 & +(\mathrm{TC}-318) \\
\times & 0.01\end{aligned}$ & 10 & 12.0 \\
\hline 2005 & 30 & 30 & 30 & $\begin{array}{c}72.3+(\mathrm{TC}-241) \\
\times 0.01\end{array}$ & 10 & 12.0 \\
\hline 2008 & 30 & 30 & 30 & $\begin{array}{c}80.1+(\mathrm{TC}-267) \\
\times 0.01\end{array}$ & 10 & 12.0 \\
\hline
\end{tabular}

Note: (1) Among the retired, former employees pay 20 percent, and their dependents, 30 percent. (2) Up to four times per month. TC stands for total cost per month. All monetary values (i.e., values not expressed as percent) are in thousand Yen (roughly 10 US dollars in 2008).

B. Inpatient Admissions

\begin{tabular}{|c|c|c|c|c|c|c|}
\hline \multirow[b]{3}{*}{ Year } & \multicolumn{4}{|c|}{ Below 70} & \multicolumn{2}{|c|}{ Above 70} \\
\hline & \multicolumn{3}{|c|}{ Coinsurance } & \multirow[b]{2}{*}{$\begin{array}{c}\text { Stop-Loss } \\
\text { (thousand Yen) }\end{array}$} & \multirow{2}{*}{$\begin{array}{c}\text { Coinsurance } \\
\text { All }\end{array}$} & \multirow[b]{2}{*}{$\begin{array}{c}\text { Stop-Loss } \\
\text { (thousand } \\
\text { Yen) }\end{array}$} \\
\hline & $\begin{array}{c}\text { NHI } \\
\text { (percent) }\end{array}$ & $\begin{array}{l}\text { Employment- } \\
\text { based } \\
\text { (Employee, } \\
\text { Percent) }\end{array}$ & $\begin{array}{c}\text { Employment- } \\
\text { based } \\
\text { (Dependent, } \\
\text { Percent) }\end{array}$ & & & \\
\hline 1984 & $30^{(1)}$ & 10 & 20 & 51.0 & $0.4 /$ day $^{(2)}$ & - \\
\hline 1987 & $30^{(1)}$ & 10 & 20 & 54.0 & $0.4 /$ day & - \\
\hline 1990 & $30^{(1)}$ & 10 & 20 & 57.0 & $0.4 /$ day & - \\
\hline 1993 & $30^{(1)}$ & 10 & 20 & 63.0 & $0.7 /$ day & - \\
\hline 1996 & $30^{(1)}$ & 10 & 20 & 63.0 & $0.71 /$ day & - \\
\hline 1999 & $30^{(1)}$ & 20 & 20 & 63.6 & $1.2 /$ day & - \\
\hline 2002 & $30^{(1)}$ & 20 & 20 & $\begin{array}{c}63.6+(\mathrm{TC}-318) \\
\times 0.01\end{array}$ & 10 & 37.2 \\
\hline 2005 & 30 & 30 & 30 & $\begin{array}{c}72.3+(\mathrm{TC}-241) \\
\times 0.01\end{array}$ & 10 & 40.2 \\
\hline 2008 & 30 & 30 & 30 & $\begin{aligned} 80.1 & +(\mathrm{TC}-267) \\
& \times 0.01\end{aligned}$ & 10 & 44.4 \\
\hline
\end{tabular}

Note: (1) Among the retired, both former employees and their dependents pay 20 percent. (2) Up to two months. TC stands for total cost per month. All monetary values (i.e., values not expressed as percent) are in thousand Yen (roughly 10 US dollars in 2008). 
Table 2: Estimated Out-of-pocket Medical Expenditure per Month

\begin{tabular}{|c|c|c|c|c|c|}
\hline \multirow[b]{2}{*}{ Type of Service } & \multicolumn{3}{|c|}{$\begin{array}{l}\text { Out-of-pocket Medical Expenditure } \\
\text { (thousand Yen) }\end{array}$} & \multicolumn{2}{|c|}{$\begin{array}{l}\text { Percent Reached } \\
\text { Stop-loss among } \\
\text { Insurance Claims }\end{array}$} \\
\hline & $\begin{array}{c}\text { Below } 70 \\
\text { (1) }\end{array}$ & $\begin{array}{c}\text { Above } 70 \\
\text { (2) }\end{array}$ & $\begin{array}{c}\text { Percent } \\
\text { Reduction } \\
((1)-(2)) /(3)\end{array}$ & $\begin{array}{c}\text { Below } 70 \\
\text { (4) }\end{array}$ & $\begin{array}{c}\text { Above } 70 \\
\text { (5) }\end{array}$ \\
\hline \multicolumn{6}{|l|}{ Outpatient Visits } \\
\hline & 4.0 & 1.1 & 73 & 0.1 & 0.6 \\
\hline & 41.7 & 13.0 & 69 & 14.6 & 0.0 \\
\hline
\end{tabular}

Note: All monetary values (i.e., values not expressed as percent) are in thousand Yen (roughly 10 US dollars in 2008).

Table 3: RD Estimates on Outpatient Visits at Age 70

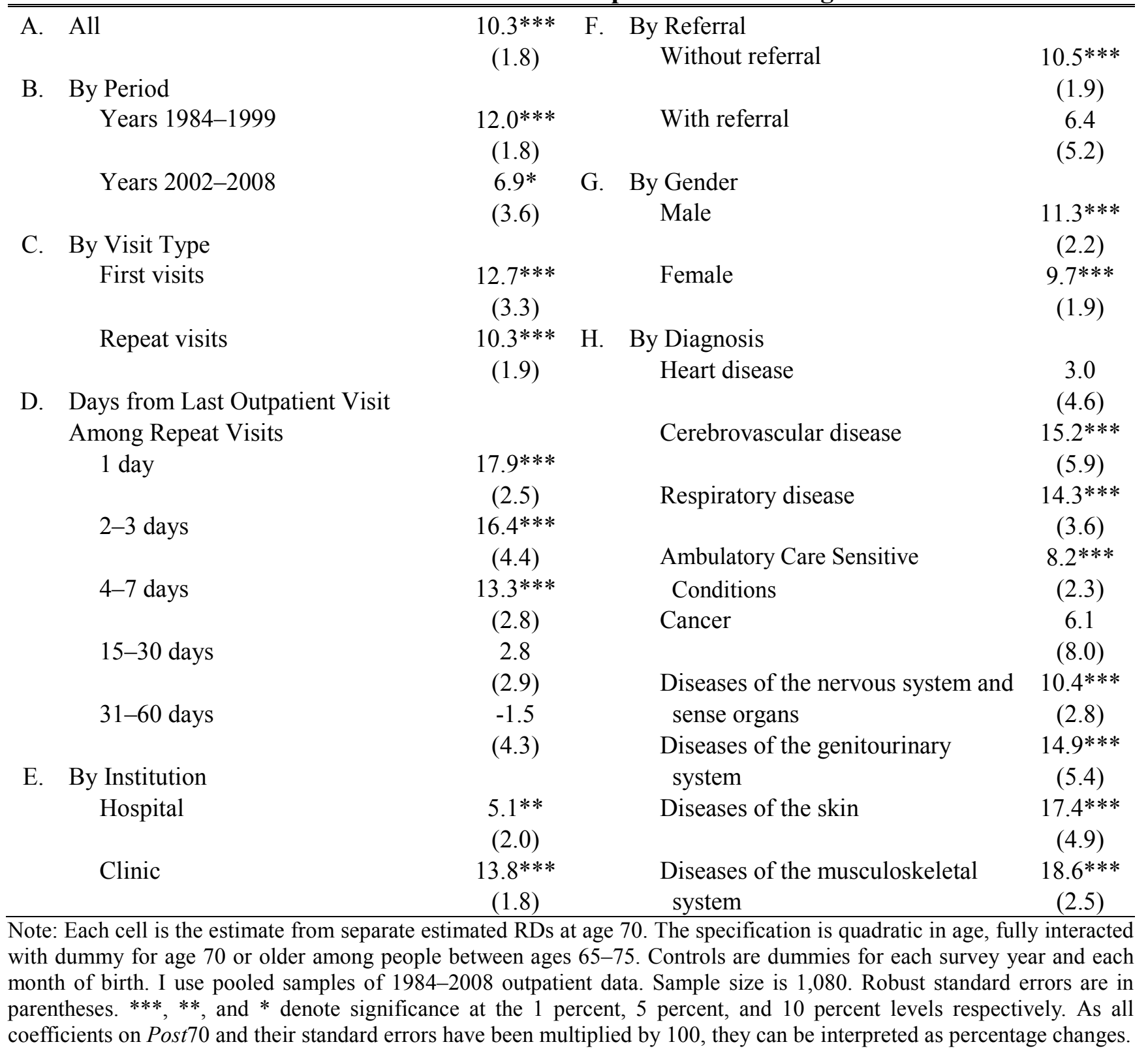


Table 4: RD Estimates on Inpatient Admissions at Age 70

\begin{tabular}{|c|c|c|c|c|c|}
\hline \multirow[t]{2}{*}{ A. } & All & $8.2 * * *$ & F. & Gender & \\
\hline & & $(2.6)$ & & Male & $8.1 * * *$ \\
\hline \multirow[t]{4}{*}{ B. } & By period & & & & $(2.8)$ \\
\hline & Years 1984-1999 & $\begin{array}{c}9.6^{* * * *} \\
(2.2)\end{array}$ & & Female & $\begin{array}{c}9.0 * * * \\
(2.8)\end{array}$ \\
\hline & Years 2002-2008 & $5.3 * *$ & G. & By Diagnosis & \\
\hline & & $(2.6)$ & & Heart disease & $11.4^{* *}$ \\
\hline \multirow[t]{3}{*}{ C. } & By admission day & & & & $(5.7)$ \\
\hline & First half of the month & $\begin{array}{c}9.8 * * * \\
(2.8)\end{array}$ & & Hypertensive disease & $\begin{array}{c}4.8 \\
(5.5)\end{array}$ \\
\hline & Second half of the month & $\begin{array}{c}8.7 * * * \\
(3.2)\end{array}$ & & Ischemic heart disease & $\begin{array}{c}14.5^{* *} \\
(7.1)\end{array}$ \\
\hline \multirow[t]{5}{*}{ D. } & Surgery & & & Cerebrovascular disease & $10.5^{* * *}$ \\
\hline & Without surgery & $6.4^{* *}$ & & & $(3.9)$ \\
\hline & & $(2.6)$ & & Intracerebral hemorrhage & 8.0 \\
\hline & With surgery & $12.0 * * *$ & & & $(6.1)$ \\
\hline & & $(3.5)$ & & Cerebral infarction & $12.8 * * *$ \\
\hline \multirow[t]{8}{*}{ E. } & Type of Surgery & & & & $(4.6)$ \\
\hline & Open-head surgery & $\begin{array}{l}11.3 \\
(7.9)\end{array}$ & & Respiratory Diseases & $\begin{array}{c}6.9 \\
(4.8)\end{array}$ \\
\hline & Open-heart surgery & $\begin{array}{c}8.1 \\
(8.0)\end{array}$ & & Ambulatory Care Sensitive Conditions & $\begin{array}{c}5.6 \\
(5.2)\end{array}$ \\
\hline & Open-stomach surgery & $\begin{array}{c}12.6^{* * *} \\
(5.3)\end{array}$ & & Cancer & $\begin{array}{c}6.5 \\
(4.6)\end{array}$ \\
\hline & Musculoskeletal surgery & $\begin{array}{c}5.6 \\
(5.0)\end{array}$ & & Cataract & $\begin{array}{c}22.6 * * * \\
(6.5)\end{array}$ \\
\hline & Endoscopic surgery: stomach & $\begin{array}{c}8.7 \\
(7.1)\end{array}$ & $\mathrm{H}$. & $\begin{array}{l}\text { Location Before Admission } \\
\text { Outpatients in the same hospital }\end{array}$ & $9.7 * * *$ \\
\hline & Intraocular lens implantation & $22.9 * * *$ & & & $(2.9)$ \\
\hline & & $(5.2)$ & & Other & $\begin{array}{c}4.3 \\
(2.7)\end{array}$ \\
\hline
\end{tabular}

Note: Each cell is the estimate from separate estimated RDs at age 70. The specification is quadratic in age, fully interacted with a dummy for age 70 or older among people between ages 65-75. Controls are dummies for each survey year, each month of birth, and each month of admission. I use pooled samples of 1984-2008 discharge data. Sample size is 3,240 excluding Panels E and H. Sample size for Panel E is 1,440 (4 years, 1999-2008) and that for Panel H is 1,800 (5 years, 1996-2008), since these data were only collected in later years. Robust standard errors are in parentheses. ***,**, and * denote significance at the 1 percent, 5 percent, and 10 percent levels respectively. As all coefficients on Post 70 and their standard errors have been multiplied by 100 , they can be interpreted as percentage changes. 
Table 5: RD Estimates on Mortality at Age 70

\begin{tabular}{|c|c|c|c|c|}
\hline & & Basic & $\begin{array}{l}67-73 \\
\text { years }\end{array}$ & Cubic \\
\hline & & (1) & (2) & (3) \\
\hline A. & All & -0.2 & 0.1 & 0.0 \\
\hline & & $(1.1)$ & $(0.8)$ & $(0.9)$ \\
\hline B. & Gender & & & \\
\hline & Male & -0.2 & 0.3 & 0.1 \\
\hline & & $(1.3)$ & $(1.1)$ & $(1.2)$ \\
\hline & Female & -0.2 & 0.1 & -0.1 \\
\hline & & $(1.2)$ & $(0.9)$ & $(1.0)$ \\
\hline $\mathrm{C}$. & By Diagnosis & & & \\
\hline & Cancer & -0.6 & -0.6 & -0.5 \\
\hline & & $(1.3)$ & $(1.3)$ & $(1.4)$ \\
\hline & Heart diseases & 0.3 & 0.0 & 0.0 \\
\hline & & $(1.6)$ & $(1.4)$ & $(1.5)$ \\
\hline & Cerebrovascular diseases & 0.3 & 1.2 & 2.1 \\
\hline & & $(1.6)$ & $(1.6)$ & $(1.7)$ \\
\hline & Respiratory diseases & 1.5 & 1.9 & 0.0 \\
\hline & & $(2.4)$ & $(2.6)$ & $(2.7)$ \\
\hline
\end{tabular}

Note: Each cell is the estimate from separate estimated RDs at age 70. The dependent variable is the log of the number of deaths. I use pooled 1984-2008 mortality data for patients born during 1919-1933. Sample size is 21,600. Robust standard errors are in parentheses. ${ }^{* *}, * *$, and $*$ denote significance at the 1 percent, 5 percent, and 10 percent levels respectively. As all coefficients on Post 70 and their standard errors have been multiplied by 100 , they can be interpreted as percentage changes. 


\title{
The Effect of Patient Cost Sharing on Utilization, Health, and Risk Protection
}

\author{
Hitoshi Shigeoka
}

\section{A Online Appendix}

\section{A.1 Derivation of Out-of-pocket Health Expenditures}

This section describes how I convert the cost sharing formula in Table 1 into actual monthly outof-pocket health expenditures in Table 2. Ideally, I would like to have access to information on actual out-of-pocket expenditures at the individual level (like Medical Expenditure Panel Survey in the US). In the absence of such data, I attempt to derive the same.

Fortunately, I know the exact formula for cost sharing (Table 1) and have access to individuallevel insurance claim data, which is the monthly summary of medical expenditures claimed for insurance reimbursement to medical institutions (called the Survey of Medical Care Activities in Public Health Insurance). Since a portion of this monthly total medical expenditure is paid as patient cost sharing, using the formula in Table 1, I can compute the average out-of-pocket medical expenditures at each age for each survey year of the Patient Survey. ${ }^{1}$

The insurance claim data are monthly, since reimbursements to the medical institutions are conventionally paid monthly in Japan. Thus, the stop-loss is set monthly, rather than annually, unlike the US. The age of patients is measured in years in this data.

The steps used to compute the average monthly out-of-pocket expenditures are as follows. Note that the cost sharing formula differs by outpatient visits and inpatient admissions; since inpatient admissions are more expensive and put more financial burden on patients, the coinsurance rate of inpatient admissions tends to be set lower than that of outpatient visits.

\footnotetext{
${ }^{1}$ The remaining medical expenditures are paid by insurance societies, the source of this money being a fund of pooled premiums of insured members and assistance from the government.
} 


\section{A.1.1 Patients below age 70}

First, I compute the average monthly out-of-pocket health expenditures for 69-year-old patients. For those below age 70, the coinsurance rate is determined by the type of health insurance: National Health Insurance (NHI), employees in employment-based health insurance, and dependents of employees in employment-based health insurance. Among those subscribing to NHI, the coinsurance rate differs among those who are still employed, retired former employees, and dependents of retied employees. I use information from the Comprehensive Survey of Living Conditions (CSLC) to compute the rate of those employed among the NHI recipients. Also, assuming that males who are not employed are retired former employees and that females who are not employed are dependents of retired employees, I compute the weighted average of the coinsurance rate for NHI. This assumption does not make any major difference to this computation since the fraction of retired former employees is quite small. In fact, the coinsurance rate for only outpatient visits during 1984-2002 differs by 10 percent between retired former employees and dependents of retired employees, and the computed weighted coinsurance rate for NHI is around 28 percent, which is very close to the coinsurance rate for the employed and dependents of retired employees subscribing to NHI (30 percent). For inpatient admissions, this assumption plays no role, since the coinsurance rate for inpatient admissions is the same (20 percent) for retired former employees and their dependents.

Then, actual out-of-pocket medical expenditures, $A M_{i p t}$, for individual $i$ whose health insurance plan is $p$ ( $p=1-3$, where 1: NHI, 2: employees in employment-based health insurance, and 3: dependents of employees in employment-based health insurance), and who use service $j$ ( $j=1-2$, where 1: inpatient admissions, 2: outpatient visits) in survey year $t$, is given as follows:

$$
A M_{i p t}=\min \left(E M_{i j p t}, S L_{j p t}\right)
$$

where $E M_{i j p t}$ is the expected payment without stop-loss (or the maximum amount of out-of-pocket expenditure), and $S L_{j p t}$ is the stop-loss for each plan $p$ and each service use $j$ in survey year $t$.

Suppose there is an individual whose total medical expenditure for inpatient use in June 2008 is 1 million Yen, and the coinsurance rate is 30 percent. This indicates an $E M_{i j p t}$ of 300 thousand Yen. On the other hand, $S L_{j p t}$ is 87,430 Yen $(80,100+(1,000,000-267,000) \times 0.01$, according to the formula in Table 2). Since $S L$ is smaller than $E M, A M$ is 87,430 Yen. I compute $A M$ for 
each individual-level claim data and take the simple average to compute the average expenditure $A M_{j p t}$ by each plan type $p$, for each service $j$ in survey year $t$.

Finally, I take a weighted average of each insurance type $W_{p t}$ obtained from the CSLC. Therefore, the average monthly out-of-pocket medical expenditure $A M$ for age 69 is

$$
A M_{j t}(\text { age } 69)=\sum_{p=1}^{3}\left(W_{p t} \times A M_{j p t}\right)
$$

for use of service $j$ in each survey year $t$ of the Patient Survey. I take $W_{p t}$ for each year $t$ from the CSLC in year $t-1$, since the CSLC is conducted a year before the Patient Survey. The exception is the Patient Survey for 1984, for which I use the fraction from 1987 of the CSLC as a weight, since it is the closest year for which information is available. The majority of 69 year-olds (roughly 70-80 percent) subscribe to NHI, and the rest to employment-based health insurance.

\section{A.1.2 Patients above age $\mathbf{7 0}$}

Next, I compute the average out-of-pocket health expenditures for 70-year-old patients, all of whom receive Elderly Health Insurance. Since the utilization is endogenous (i.e., the observed out-ofpocket medical expenditure already reflects the change in cost sharing), I compute a counterfactual out-of-pocket expenditure for 70-year-old patients assuming that they have the same amount of utilization as the average 69-year-old. I compute the average monthly frequency of outpatient visits and the average length of stay for inpatient admissions for age 69 . Then, I apply the formula for age 70 to compute the monthly average out-of-pocket medical expenditures in the same manner as I have done for age 69.

Finally, the overall out-of-pocket medical expenditure in Table 2 is the weighted average of the out-of-pocket medical expenditure across all survey years for outpatient visits and inpatient admissions, using the populations at age 69 in each survey year as the weights. Table $\mathrm{K}$ in the Online Appendix shows the estimated out-of-pocket medical expenditure for each survey year.

It is worth mentioning that these figures are a rough estimate of actual out-of-pocket medical expenditures, since the actual cost sharing is slightly more complicated. For example, different coinsurance rates are applied to specific populations, and there is another way to reduce out-ofpocket medical expenditures. For example, in October 2002, the coinsurance rate for those over age 70 with high income -7 percent of the population, according to Ikegami et al. (2011) — was 
raised from 10 percent to 20 percent. Also, for all ages, the stop-loss is set lower for people with very low income. Nonetheless, since most of the patients are covered under the basic cost sharing formula, the cost sharing I estimate should be within an acceptable range.

\section{A.2 Cost-Benefit Analysis}

In this section, I conduct a simple cost-benefit analysis. Since it requires making a number of assumptions, the results are more speculative. Nonetheless, the exercise provides a rough estimate on the social costs and benefits of the marginal change in cost sharing at age 70 .

To understand the costs and benefits in this framework, I first describe the items of social costs and benefits associated with the change in the price of health care services at age 70 . The program incurs two types of costs. The first entails extra spending for mechanical reasons, i.e., the government has to bear additional payments due to higher reimbursements for consumers above 70 (I denote this as item \#1). The second refers to efficiency costs from the moral hazard on increased health spending (I denote this as item \#2). The sum of items \#1 and \#2 is the amount of increased spending by the government. Since marginal costs are associated with raising public revenue, these numbers have to be multiplied by the marginal cost of funds (MCF) to estimate the total social cost. On the benefit side, there are two benefits. The first concerns the mechanical gain by lower cost sharing accrued to consumers, which is exactly the mirror image of the increase in government reimbursement (i.e., item \#1). The other benefit is risk protection against unexpected out-of-pocket medical spending, which I explain at length later on in this Appendix (I denote this as item \#3). Note that since I did not find any short-term health effects, the social benefit does not include a health benefit. Thus, the net benefit can be written as follows.

$$
\begin{aligned}
\text { Net Benefit } & =(\text { Total Benefit })-(\text { Total Cost }) \\
& =(\# 3+\# 1)-M C F \times(\# 1+\# 2) \\
& =\# 3-(M C F-1) \times \# 1-M C F \times \# 2
\end{aligned}
$$

Note that the mechanical cost is multiplied by (MCF-1), which is the excess burden of the public fund or dead weight loss, while the moral hazard is multiplied by MCF, since there is no benefit accrued by consumers to offset the cost. Next, I estimate each component (items \#1, \#2, and \#3). 


\section{A.2.1 Social Cost}

The first cost is the mechanical cost. Since the out-of-pocket medical expenditures reported in the CSLC do not distinguish between outpatient visits and inpatient admissions, I need to make an assumption to estimate the out-of-pocket spending distribution that mechanically adjusts for what the Elderly Health Insurance would have covered if it were applied to those just below age 70. Since the coinsurance rate for both inpatient admissions and outpatient visits was 30 percent for those below 70, and 10 percent for those above 70 in 2007, I assume that two-thirds of the out-of-pocket medical expenditures just below age 70 is the mechanical cost. ${ }^{2}$ Since the average out-of-pocket medical expenditure just below age 70 is 152 thousand Yen (see the first row of Table I in the Appendix), the average mechanical cost is 102 thousand Yen (1,020 US dollars).

Second, there are efficiency costs from the moral hazard on increased health spending. As seen from the results on utilization, most of the increased spending may have been socially inefficient. However, it is difficult to pinpoint exactly what may be considered as socially efficient use of medical services. By treating the entire increase in utilization as a social cost, I provide an upper bound on the efficiency costs of lowered cost sharing. The difference between the counterfactual and actual out-of-pocket medical expenditure just above age 70 should be the moral hazard. The first row in Column (1) in Table I in the Appendix indicates that the counterfactual mean value of the out-of-pocket medical expenditure is 51 thousand Yen $(=152 / 3)$. The actual out-of-pocket medical expenditure just above the cut-off is 100 thousand Yen (152 - 52), and therefore, the moral hazard is 49 thousand Yen.

\section{A.2.2 Social Benefit: Welfare Gains from Risk Protection}

To estimate the reduction in risk exposure, I combine the expected utility framework with the quantile RD estimates and calculate the change in the risk premium associated with out-of-pocket expenditure as a measure of the welfare gain from lower cost sharing at age $703^{3}$

Specifically, I assume that each individual has utility $U(C)$, which is the function of net nonhealth consumption $C$. I then assume the individual must satisfy a budget constraint for each

\footnotetext{
${ }^{2}$ This assumption is reasonable since only 2 percent of those aged 65-69 pay beyond the stop-loss in the sample. Note that Table 2 shows that 14.6 percent of those aged 65-69 reach the stop-loss conditional on being admitted.

${ }^{3}$ This approach is akin to that used in Feldstein and Gruber (1995), Finkelstein and McKnight (2008), and Englehardt and Gruber (2011). My welfare estimates may be bound to be lower than those in the US, since it is much less likely to have catastrophic health expenses in Japan due to the government's stringent control over national fee schedules (Ikegami and Campbell, 1995).
} 
period $C=Y-M$, where $Y$ denotes per-period income, and $M$ is the individual's out-of-pocket medical expenditure. $M$ is a random variable with the probability density function $f(M)$ with support $[0, \bar{M}]$.

I calculate the change in the risk premium associated with lower cost sharing by computing the risk premium for both just below (denoted as zero) and above age 70 (denoted as one). For those just below age 70 , the risk premium (or certainty equivalence) $\pi_{0}$ can be defined by a fixed amount such that

$$
U\left(Y-\pi_{0}\right)=\int_{0}^{\bar{M}} U\left(Y-M_{0}\right) f\left(M_{0}\right) d M_{0} .
$$

The expression measures the amount a risk-averse individual would be willing to pay to insure against random variation in out-of-pocket spending.

For those just above age 70 , lower cost sharing at age 70 reduces not only the variance but also the mean of the out-of-pocket spending distribution. However, since the difference between the mean values of $M_{0}$ and $M_{1}$ is simply a transfer between the insured and insurers (or the government), I calculate the certainty equivalence for the out-of-pocket risk distribution just above age 70 with an adjustment to make the mean of the risk distribution just above age 70 equal to that of just below age 70 (i.e., I evaluate the mean-preserving spread in risk).

Thus, I define the risk premium $\pi_{1}$ for those just above age 70 as

$$
U\left(Y-\pi_{1}\right)=\int_{0}^{\bar{M}} U\left(Y-M_{1}+\mu_{1}-\mu_{0}\right) f\left(M_{1}\right) d M_{1}
$$

where $\mu_{0}$ and $\mu_{1}$ are the mean of $M_{0}$ and $M_{1}$ respectively.

A decrease in risk exposure just above 70 to just below 70 is reflected as a decline in the risk premium; the absolute value of this decline $\Delta$ provides a measure of the insurance value, and hence, the welfare gain of lower cost sharing. Thus,

$$
\Delta=\left|\pi_{1}-\pi_{0}\right|
$$

In practice, I measure $\Delta$ in the three steps. First, I estimate the following equation for each quantile $q$

$$
M_{i}^{q}=\alpha_{0}^{q}+\alpha_{1}^{q} \operatorname{Post}_{i}+f^{q}(a)+X_{i}^{\prime} \gamma^{q}+\varepsilon_{i}
$$


where $M_{i}^{q}$ is the out-of-pocket medical expenditure at quantile $q$, and $f^{q}(a)$ is a quantile-specific smooth function of age, where age $a$ is normalized to zero at age 70. $X_{i}^{\prime}$ are demographic controls in the form of dummy variables for marital status, gender, region and birth month. Note that Figure 5 in the main text plots $\alpha_{1}^{q}$, along with their 95 percent confidence interval.

Second, I use these quantile estimates to calculate for each individual $i$ in the sample the quantiles of the out-of-pocket spending distribution $\hat{M}_{i}^{q}$, conditional on the individual's characteristics $X_{i}^{\prime}$ just below and above age 70 . Specifically, for each $i=1, \ldots, N$ in the sample, $\hat{M}_{i 0}^{q}$ for those below age 70 can be written as

$$
\hat{M}_{i 0}^{q}=\hat{\alpha}_{0}^{q}+X_{i}^{\prime} \hat{\gamma}^{q}
$$

for $q=1, \ldots, 99$, where $\hat{\alpha}_{0}^{q}$ and $\hat{\gamma}^{q}$ come from equation (4) at each quantile $q$ as above.

For those above age 70, I compute the counterfactual out-of-pocket spending distribution the individual faces once the quantile treatment estimates of lower cost sharing estimated in equation (4) are applied. Therefore, $\hat{M}_{i 1}^{q}$ for those above age 70 can be written as

$$
\hat{M}_{i 1}^{q}=\hat{M}_{i 0}^{q}+\hat{\alpha}_{1}^{q}
$$

where $\hat{\alpha}_{1}^{q}$ is the RD estimate from equation (4) for each quantile $q$.

Because there are 99 quantile estimates for each individual $i$, to ensure that the sum of the probabilities is one, I set conditional out-of-pocket spending at the very bottom of the distribution to zero, or $q=0$, i.e., $\hat{M}_{i 1}^{0}=\hat{M}_{i 0}^{0}=0$. I now have 100 points of equal probability of occurrence in the out-of-pocket spending distribution for each individual. Following Finkelstein and McKnight (2008) and Englehardt and Gruber (2011), I truncate predicted out-of-pocket spending from below at zero and from above at 80 percent of individual income as a benchmark.

Finally, I calculate the risk premium $\pi_{0 i}$ for those below age 70 for each individual $i$ by solving

$$
U\left(Y-\pi_{0 i}\right)=\frac{1}{100}\left[\sum_{q=1}^{99} U\left(Y_{i}-\hat{M}_{0 i}\right)+U_{0}\right],
$$

where $U_{0}=U\left(Y_{i}\right)$, and the right-hand side is the average utility, given its income $Y_{i}$ for each individual. In a similar vein, I calculate the risk premium $\pi_{1 i}$ for individuals just above age 70 by solving

$$
U\left(Y-\pi_{1 i}\right)=\frac{1}{100}\left[\sum_{q=1}^{99} U\left(Y_{i}-\hat{M}_{1 i}+\hat{\mu}_{1}-\hat{\mu}_{0}\right)+U_{1}\right],
$$


where $U_{1}=U\left(Y_{i}+\hat{\mu}_{1}-\hat{\mu}_{0}\right)$, and I make an adjustment by subtracting from the individual's income the average difference in out-of-pocket expenditures between the 100 estimates for the original distribution just below age $70\left(\hat{\mu}_{0}\right)$ and the 100 estimates for the counterfactual distribution $\left(\hat{\mu}_{1}\right)$.

Following the literature, I specify the constant relative risk aversion (CRRA) utility function $U(C)=-\frac{1}{\phi-1} C^{1-\phi}$, which implies the Arrow-Pratt measure of relative risk aversion of $\phi=-\frac{C U^{\prime \prime}}{U^{\prime}}$. For a typical risk aversion of 3 in the CRRA utility function (see e.g., McClellan and Skinner, 2006), I estimate that this decline in risk premium, or welfare gain, is 37 thousand Yen (370 US Dollars) per person. This is less than the average cost of the moral hazard.

However, it is important to note that the previous estimate on the decline in risk exposure is understated, since the out-of-pocket expenditures include the behavioral response of increased utilization of health care services. Here, I once again assume that cost sharing would have been one-third if Elderly Health Insurance was mechanically applied to those just below age 70. For a typical risk aversion $(=3)$ in the CRRA utility function, using this mechanically adjusted out-ofpocket spending, I estimate that this decline in risk premium is doubled from 37 to 98 thousand Yen per person.

Table $\mathrm{J}$ in the Online Appendix shows the sensitivity of the welfare gain to two particular assumptions: risk aversion and maximum level of out-of-pocket medical expenditures as a share of income. In fact, the estimates are quite sensitive to these two assumptions. First, Panel A shows that compared to an estimated welfare gain of 98 thousand Yen per person with a relative risk aversion of 3 , the welfare gain falls to about 8 thousand Yen with a relative risk aversion of 1 and rises to 306 thousand Yen with a relative risk aversion of 5 (assuming the cap on out-of-pocket spending is 80 percent of income). Next, if I replace my baseline 80 percent cap on out-of-pocket medical expenditures as a share of income with a cap of 60 percent, the estimated welfare gain falls from 98 thousand Yen to 33 thousand Yen, and if I impose a cap of 90 percent, the welfare estimate rises to 203 thousand Yen (assuming a relative risk aversion of 3). Finally, Panel B shows the risk premium at other percentiles. The median is 85 thousand Yen, and the 95th percentile is 214 thousand Yen, suggesting the welfare gains are skewed.

\section{A.2.3 Discussion}

My central estimate of risk reduction is 98 thousand Yen per person (980 US Dollars). One way to gauge the size of the estimate is to simply plug estimated benefits and costs into equation (1) 
and calculate the MCF such that the two are equal. Since I have the estimated values for all components (items \#1, \#2, and \#3), it is straightforward that the MCF is 1.32 , or in other words, the MCF should be less than 1.32 to have positive net benefits. This value is very close to some of the estimates of the MCF in the 1990s (e.g., 1.3; see Poterba, 1996)..$^{4}$

Put differently, assuming the MCF is 1.3, the sum of the program financing costs and moral hazard suggests that the total annual social cost was 94.3 thousand Yen $(102 \times 0.3+49 \times 1.3)$ per elderly beneficiary. Here, the deadweight loss and moral hazard associated with program financing was responsible for one-third and two-thirds of the total cost. My estimate of risk reduction (98 thousand Yen per person) suggests that the welfare gain of risk protection from lower patient cost sharing is comparable to the total social cost, indicating that the welfare gain of risk protection may fully cover the total social cost in this setting.

Although somewhat speculative, a simple cost-benefit analysis shows that the welfare gain of risk protection from lower cost sharing is on the same order of magnitude as the total social cost. However, there are a number of caveats to my welfare calculation. On the one hand, the stylized welfare calculations may overstate the welfare gains, since the use of a one-period model ignores the possibility that individuals can use savings or other mechanisms to smooth expenditure risk over several periods, thus potentially leading me to overstate the welfare gains from lower cost sharing. This may indeed be the case, since the elderly seem to have some savings $!^{5}$ On the other hand, the welfare gains may be understated because the calculations were based on an annual, rather than lifetime, measure of medical expenditure risk. In fact, there is some evidence that out-of-pocket medical expenditures are positively serially correlated (Feenberg and Skinner, 1994; French and Jones, 2004). These studies suggest that the lifetime distribution of out-of-pocket spending may be even more right-skewed than the annual distribution; therefore, the reduction in risk exposure in the lifetime scale may be even greater ${ }^{6}$ Furthermore, my welfare calculation does not incorporate the welfare gains from health improvements. While I do not find any short-term reduction in

\footnotetext{
${ }^{4}$ There is no consensus estimate for the MCF, since it depends on behavioral responses to taxation and may differ by country at any given point in time. Nonetheless, to have a rough estimate, I focus on income tax, since it is a major source of taxes. The simplest formula is $\frac{1}{\left(1-\rho *\left(\frac{t}{1-t}\right)\right)}$ where $\rho$ is the elasticity of taxable income and $t$ is the income tax rate (Kopczuk, 2005). Assuming that both the elasticity of taxable income and the tax rate are 0.4 , the MCF would be 1.36, which is close to the value I use (1.3).

${ }^{5}$ The average net savings at age 69 is 5,418 thousand Yen, which is roughly two and half times the average annual income (1,860 thousand Yen). Since saving and debt are only reported at the household level, I divide the net saving (i.e., saving - debt) by the number of household members.

${ }^{6}$ Further, the stylized model treats medical expenditures as affecting the budget constraint only and does not allow for any utility change from increased medical expenditures.
} 
mortality or improvement in any self-reported health measures, it is possible that preventive care induced by lower cost sharing at age 70 may prevent future severe health events and thus improve health in the long run. It is infeasible to estimate long-run effects in this framework, because individuals eventually age into treatment.

\section{A.3 Data Appendix}

In this study, I use a variety of datasets collected mainly by the Ministry of Health, Labour and Welfare. A brief description of each dataset is provided in this data appendix. The English to Japanese translations of the dataset titles can be found at the website of the Ministry of Health, Labour and Welfare (http://www.mhlw.go.jp/toukei/itiran/eiyaku.html).

\begin{tabular}{|c|c|c|c|}
\hline & Name of Dataset & Period & Interval \\
\hline 1 & Patient Survey & $1984-2008$ & $\begin{array}{l}\text { Every three year } \\
\text { ( } 9 \text { rounds in total) }\end{array}$ \\
\hline 2 & Comprehensive Survey of Living Conditions & $1986-2007$ & $\begin{array}{l}\text { Every three year } \\
\text { ( } 8 \text { rounds in total) }\end{array}$ \\
\hline 3 & $\begin{array}{l}\text { Survey of Medical Care Activities in Public Health } \\
\text { Insurance }\end{array}$ & 1984-2008 & Every year \\
\hline 4 & Vital Statistics: Mortality data & 1984-2008 & Every year \\
\hline
\end{tabular}

\section{Patient Survey}

Source: http://www.mhlw.go.jp/english/database/db-hss/dl/sps_2008_06.pdf

Started in 1948, the Patient Survey is a national sample survey of hospitals and clinics that gathers information on the utilization of medical institutions in Japan. The comprehensive version of the Patient Survey has been conducted every three years since 1984. It covers roughly 2,000-7,000 hospitals and 3,000-6,000 clinics per survey year. It collects information on the International Classification of Diseases (ICD) codes, patients' principal sources of payment, and limited sociodemographic characteristics such as gender and patients' place of residence. Individual-level patient microdata files are available from 1984 onwards.

There are two datasets in the Patient Survey, namely outpatient data and discharge data, which I use to examine outpatient visits and inpatient admissions respectively.

\subsection{Outpatient Data}

The outpatient data in the Patient Survey is collected on one day in mid-October (normally a weekday in the second week) and includes information on all patients who visit hospitals or clinics as outpatients (i.e., visits to hospitals or clinics not culminating in hospitalization). The datasets 
contain 75,000-100,000 individuals/outpatient visitors. This data include the exact dates of birth and the survey, the latter being equivalent to the exact dates of visits. This enables me to compute age in days at the time of the outpatient visit. The sample size of the outpatient data is about 500,000-1,500,000 per survey year.

\subsection{Discharge Data}

The discharge data in the Patient Survey report details of all the inpatients discharged from the surveyed hospitals and clinics in the month of September of the survey year. The datasets contain about 180,000-970,000 inpatient records per survey year. The sample size has become larger in more recent years. The data include the exact dates of birth, admission, discharge, and surgery. The data also contain information about whether the patient needed surgery and the types of main surgeries conducted (collected from 1999 onwards). Unlike the CSLC, the discharge data include patients who die in the surveyed hospitals and clinics.

2. Comprehensive Survey of Living Conditions

Source: http://www.mhlw.go.jp/english/database/db-hss/cslc.html

The CSLC is a nationwide repeated cross-section survey of households that has been gathering information on the health of the Japanese people since 1986. The CSLC collects information on sociodemographic characteristics and health-related topics. The long version of CSLC (used in this study) is conducted every three years. Individuals are sampled randomly from 3000-5000 districts from the National Census, which is conducted every five years. The microdata files are available from fiscal year 1986 onwards. The survey reports the month of birth. Knowing the month the survey was conducted in, I use this information to compute the age in months. The long version of the CSLC consists of three questionnaires: household, health, and income and savings. A long-term care questionnaire was added in 2004. I mainly use the data pertaining to the health questionnaire that collects information on self-reported physical and mental health and limitations in individuals' daily activities.

I also use the information concerning insurance in the household questionnaire to compute the average health insurance coverage of each health insurance type. I map the same to the Survey of Medical Care Activities in Public Health Insurance to derive out-of-pocket medical expenditures. The household forms also include basic individual sociodemographic information, such as gender, marital status, employment, and household size. The income and savings questionnaire records the amounts of income, savings, and debt as well as the source of income. Information on out-of-pocket 
medical expenditures at the individual level was collected in 2007 alone. I use individual income and out-of-pocket medical expenditures to compute the welfare gains from risk reduction.

The survey typically covers 240,000-290,000 households and 740,000-800,000 household members in each round. The income and savings questionnaire is conducted for approximately only 15 percent of the whole sample.

3. Survey of Medical Care Activities in Public Health Insurance

Source: http://www.mhlw.go.jp/english/database/db-hss/dl/shw-03.pdf

The Survey of Medical Care Activities in Public Health Insurance is a survey of health insurance claims data, which gathers yearly information on detailed statements of medical fees. I use this information to derive the average monthly out-of-pocket medical expenditures for those who use medical institutions as described in Appendix Section A1.

Due to the monthly reimbursements to medical institutions, the claim data are a summary of the medical expenditures per month per individual using these institutions in June of the survey year. The data are collected from the prefectural branches of the Social Insurance Medical Fee Payment Fund for employment-based health insurance recipients and the Federation of National Health Insurance for NHI recipients. Health insurance claim data from society-managed employmentbased health insurance recipients has been collected since 1999. The individual's age is recorded in years.

\section{Vital Statistics: Mortality Data}

Source: http://www.mhlw.go.jp/english/database/db-hw/outline/index.html

The 1984-2008 National Mortality Details Files is an annual census of deaths in Japan. The data contain the universe of deaths and information on the deceased's dates of birth and death, which enables me to compute age in days at the time of death. The data also include gender, nationality, place of death, and cause of death, the latter being classified according to the ICD. In Japan, the ICD9 classification was used till 1994, after which it adopted ICD10.

\section{References}

[1] Engelhardt, Gary V., and Gruber, Jonathan. 2011. "Medicare Part D and the Financial Protection of the Elderly." American Economic Journal: Economic Policy 3(4): 77-102. 
[2] Feenberg, Daniel, and Jonathan Skinner. 1994. "The Risk and Duration of Catastrophic Health Expenditures." Review of Economics and Statistics 76(4): 663-647.

[3] Feldstein, Martin, and Jonathan Gruber. 1995. "A Major Risk Approach to Health Insurance Reform." Tax Policy and the Economy 9: 103-130.

[4] Finkelstein, Amy, and Robin McKnight. 2008. "What Did Medicare Do? The Initial Impact of Medicare on Mortality and Out of Pocket Medical Spending." Journal of Public Economics 92(7): 1644-1668.

[5] French, Eric, and John Bailey Jones. 2004. "On the Distribution and Dynamics of Health Care Costs." Journal of Applied Econometrics 19(6): 705-721.

[6] Ikegami, Naoki, and John C. Campbell. 1995. "Medical Care in Japan," New England Journal of Medicine, 333: 1295-1299.

[7] Ikegami, Naoki, Byung-Kwang Yoo, Hideki Hashimot, Masatoshi Matsumoto, Hiroya Ogata, Akira Babazono, Ryo Watanabe, Kenji Shibuya, Bong-Min Yang, Michael R Reich, and Yasuki Kobayashi. 2011. "Japanese Universal Health Coverage: Evolution, Achievements, and Challenges." The Lancet 378(9796): 1094-1105.

[8] Kopczuk, Wojciech. 2005. "Tax Bases, Tax Rates and the Elasticity of Reported Income." Journal of Public Economics 89(11-12): 2093-2119.

[9] Poterba, James. 1996. "Government Intervention in the Markets for Education and Health Care: How and Why?" in Individual and Social Responsibility Victor Fuchs (ed). University of Chicago Press. 


\section{$\underline{\text { Appendix Figures and Tables }}$}

\section{FIGURES}

\section{Figure A: Seasonality in Day of Birth in the Patient Survey Data}

This figure shows that there is substantial seasonality and heaping in the reported birthdays of patients observed in the Patient Survey. First, heaping on the first day of the month is observed, which is likely due to reporting. Second, there are many more births in the first quarter than in the other three quarters throughout the sample period.

\section{Figure B: Seasonality in the Mortality Data}

Figures B1 and B2 show seasonality in the mortality data. Figure B1 shows seasonality in the reported birthdays of those deceased, and this pattern is very close to that observed in the Patient Survey in Figure A. Figure B2 plots the reported death dates, and there is substantial seasonality in the death dates also. First, heaping on the first day of the month is observed, which is likely due to reporting. Second, there are many more deaths in the winter than in the summer, and the highest number of deaths is observed in January.

\section{Figure C: Age Profile of Employment by Gender}

This figure displays the actual and fitted age profiles of employment for the 1986-2007 pooled Comprehensive Survey of Living Conditions (CSLC) sample (age measured in months). These profiles all trend relatively smoothly through age 70 for both genders.

\section{Figure D: Age Profiles for First-time and Repeat Outpatient Visits}

Figures D1 and D2 display the age profiles for first-time and repeat outpatient visits, respectively. Figure D1 shows that the number of first-time visits decreases steadily prior to age 70, reflecting the trend of deteriorating health as people get older, and then, it jumps sharply at age 70. Figure D2 shows that the age profiles of repeat visitors are very similar to those of overall outpatient visits, since 94 percent of total outpatient visits are repeat visits.

\section{Figure E: Robustness of Results on Inpatient Admissions}

Figures E1 and E2 show the robustness of the estimates on inpatient admissions. Figure E1 shows the results on the donut-hole RD, by excluding a few months of observations around the threshold. The figure shows that the estimates get smaller and the standard errors larger as the "hole" is expanded. However, as long as the removal of the data is within a three-month period from both sides of age 70, the estimates are statistically significant at the 95 percent level. Figure E2 shows that the results on inpatient admissions are not driven by how I limit the sample by admission dates. The results are pretty robust to the length of the windows from the discharge date. Note that more than 90 percent of inpatient admissions occurred within three months from the date of discharge.

\section{Figure F: Age Profile for Inpatient Admissions for Selected Surgery}

This figure displays the age profile of inpatient admissions for two procedures: open-stomach surgery (Figure F1) and intraocular lens implantation (Figure F2). I find a drop-off just prior to age 70, coupled with a temporary surge shortly after age 70 for both procedures. This pattern suggests that some people who are close to 70 delay surgery until they become eligible for Elderly Health Insurance, in order to reduce out-of-pocket expenditures.

\section{Figure G: Age Profile of Inpatient Admissions for Selected Diagnoses}

These graphs display the age profile of inpatient admissions for the following selected diagnoses: heart disease, cerebrovascular disease, respiratory diseases, and Ambulatory Care Sensitive Conditions (ACSCs) (see Table D in the Appendix for the list of ACSCs). Figures G1 and G2 show that there are 
sharp increases in the number of inpatient admissions for heart disease and cerebrovascular disease, and they are statistically significant (as shown in Table 4). While there are slight increases for respiratory diseases and ACSCs in Figures G3 and G4 respectively, they are not statistically significant at the conventional levels.

\section{Figure H: Age Profile for Cause-specific Mortality}

This figure plots age profiles for mortality from cause-specific deaths for three broad leading causes of death among the elderly (cancer, heart disease, cerebrovascular disease), and also respiratory diseases. These figures show that there are no discernible patterns for any of the selected causes of deaths.

\section{Figure I: Age Profiles for Fraction in Good or Very Good Health}

Respondents to the Comprehensive Survey of Living Conditions (CSLC) report health on a five-point scale (very poor, poor, fair, good, or very good). This figure shows the age profiles of the fraction of people who report themselves to be in good or very good health (cumulatively 31 percent of the population), based on pooled 1986-2008 CSLC samples. The graph shows that health gradually declines with age, but I do not find any observable change in self-reported health at age 70 . Table I in the Appendix confirms this age pattern.

\section{Figure J: Out-of-pocket Medical Expenditures}

Figure J1 compares the distribution of out-of-pocket medical expenditures in 2007 for 65-69 year-olds (not covered by Elderly Health Insurance) and 70-74 year-olds (covered by Elderly Health Insurance). The graph reveals that 70-74 year-olds at the top of the distribution spend substantially less than 65-69 year-olds, despite the large offsetting increase in utilization among those above 70 . Figure $\mathrm{J} 2$ compares an adjacent age group (age 60-64) to the near-elderly (age 65-69), neither of whom benefit from lower cost sharing. The figure shows that out-of-pocket medical expenditure among 65-69 year-olds is higher than that among 60-64 year-olds, indicating that medical expenditure tends to increase with age. This finding is reassuring; it suggests that Figure $\mathrm{J} 1$ is not measuring any systematic change in spending by age groups.

\section{Figure K: RD Estimates and Fraction of Outpatient or Inpatient Care}

Figure K1 and K2 show the RD estimates by diagnosis group (see Table G for the list) as they relate to the fraction of visits in each group using outpatient or inpatient care at age 69, respectively. The diagnosis group with highest fraction of outpatient care in Figure K1 is hypertensive disease (diagnosis group 26), where the fraction is 94.2 percent. The RD estimate for this diagnosis group is 8.2 percent, and it is not statistically different from overall estimate of 10.3 percent (see Panel A in Table 3 ). Similarly, the diagnosis group with the highest fraction of inpatient care in Figure K2 is benign neoplasm (diagnosis group 15), where the fraction is 78.5 percent. The RD estimate for this diagnosis group is 11.7 percent, and it is not statistically different from overall estimate of 8.2 percent (See Panel A in Table 4). 


\section{TABLES}

Table A: Summary Statistics (Ages 65-75)

This table summarizes descriptive statistics for the Patient Survey (outpatient data and discharge data), CSLC, and mortality data.

Table B: RD Estimates on Employment and Family Structure at Age 70

This table shows the RD estimates at age 70 on a variety of demographic outcomes in the CSLC. None of these outcomes show any discontinuities at age 70 .

Table C: Top 5 Diagnoses and RD Estimates

This table lists the top 5 diagnoses for outpatient visits and inpatient admissions and their corresponding RD estimates.

\section{Table D: List of Ambulatory Care Sensitive Conditions (ACSCs)}

This table lists the ACSCs developed by the Agency for Healthcare Research and Quality (AHRQ), for which proper and early treatment can reduce subsequent avoidable admissions.

\section{Table E: Robustness of RD Estimates on Outpatient Visits for Selected Outcomes}

This table reports alternative specifications for RD models of outpatient visits for selected outcomes. There are three alternative estimates of the RD at age 70: (1) the basic RD estimates from the main tables in the paper, (2) an RD estimate from a model fit to data for people who are 67-73 years old, (3) an RD estimate from a cubic polynomial in age, fully interacted with a dummy for age 70 or older. Both age in months as well as age in days are used as the running variables. Outcomes are selected so that there are no zero cells for any age in days for these outcomes.

\section{Table F: Robustness of RD Estimates on Inpatient Admissions for Selected Outcomes}

This table reports alternative specifications for RD models of inpatient admissions for selected outcomes. There are three alternative estimates of the RD at age 70: (1) the basic RD estimates from the main tables in the paper, (2) an RD estimate from a model fit to data for people who are 67-73 years old, (3) an RD estimate from a cubic polynomial in age, fully interacted with a dummy for age 70 or older.

\section{Table G: List of Diagnosis Groups}

This table lists the diagnosis groups used for Figure 5.

\section{Table H: RD Estimate on Morbidity at Age 70}

This table reports RD estimates on morbidity using 1986-2007 CSLC data. Column (2) presents estimates from linear probability models for the probability that people report their health as good or better. Column (4) reports estimates from a simple linear regression for the mean assessment of health (assigning 1 to poor health and 5 to very good health). In the remaining columns, I also look at the mental health, but I do not find any changes in mental health outcomes either. Overall, I do not find any evidence that lower cost sharing leads to a discrete jump in morbidity measures.

\section{Table I: RD Estimates on Out-of-pocket Medical Expenditures at Age 70}

This table reports the RD estimates on out-of-pocket medical expenditures in 2007 at each tenth centile above the 40th percentile and at the 95th and 99th percentile in Column (2), with a mean value just below age 70 in Column (1). This table corresponds to Figure 7B.

\section{Table J: Sensitivity of Welfare Gain from Risk Protection}

This table shows the sensitivity of welfare gain to two particular assumptions: risk aversion and 
maximum level of out-of-pocket medical expenditures as a share of income.

\section{Table K: Estimated Out-of-pocket Medical Expenditure per Month across Survey Years}

This table reports the estimated out-of-pocket medical expenditure per month across survey years using Survey of Medical Care Activities in Public Health Insurance (see Section A3 in the Online Appendix). The number used to compute the elasticity in the main text is the weighted average of the out-of-pocket medical expenditure across all survey years for outpatient visits and inpatient admissions, using the populations at age 69 in each survey year as weights. See Section A1 in the Online Appendix for details. 
Figure A: Seasonality in Day of Birth in the Patient Survey Data

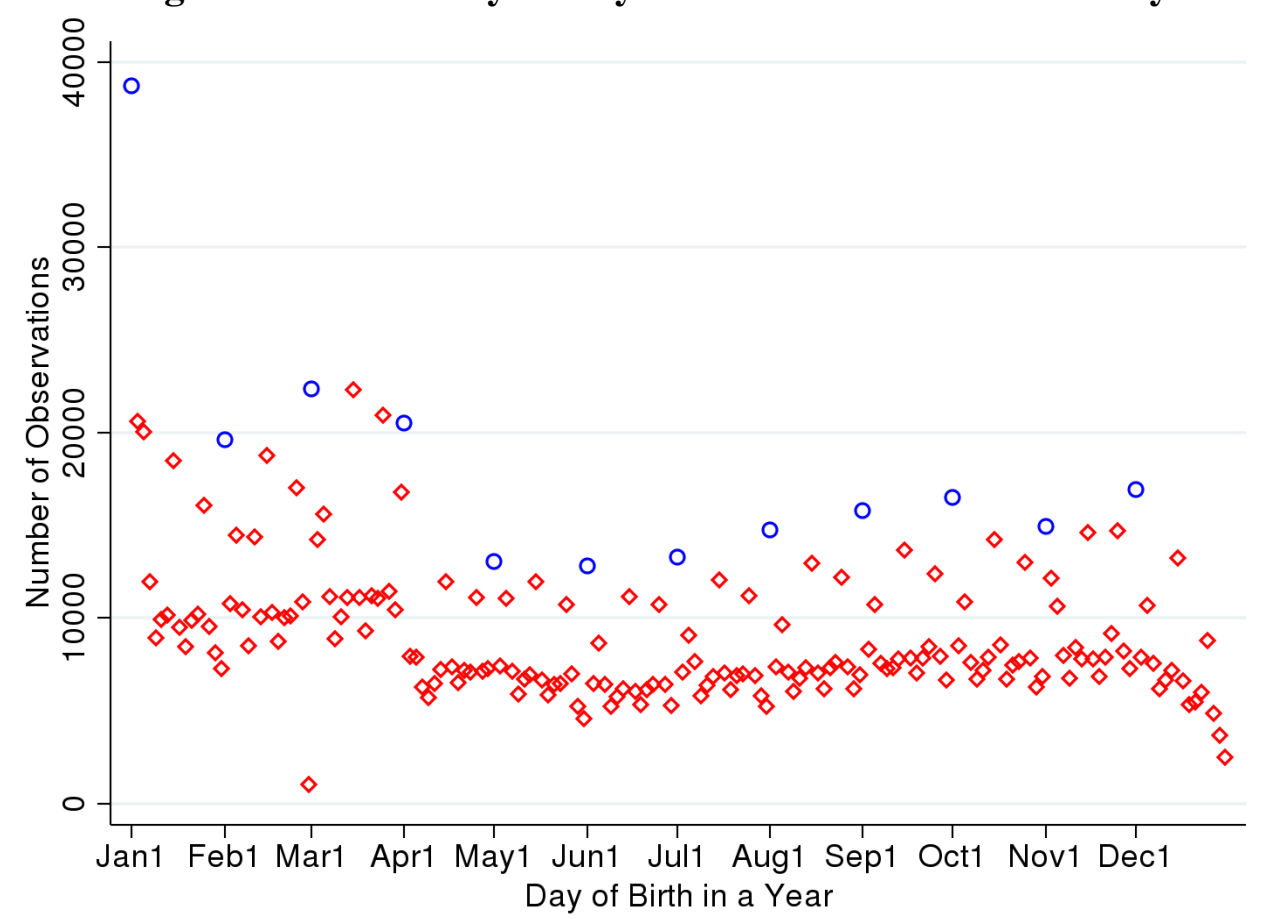

Note: I pool outpatient data for 1984-2008 from the Patient Survey. The circles indicate the first day of the month. 
Figure B: Seasonality in the Mortality Data

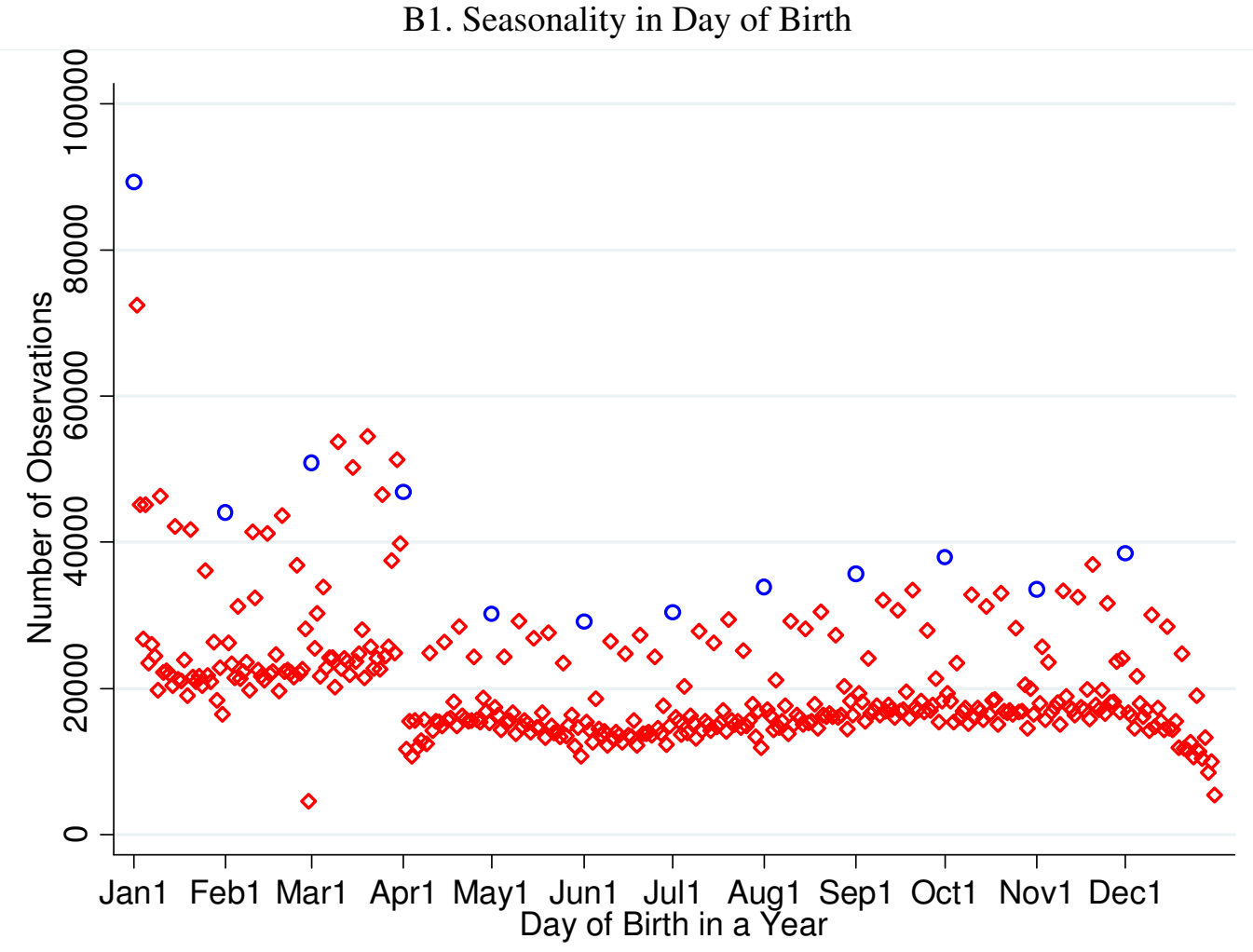

B2. Seasonality in Day of Death

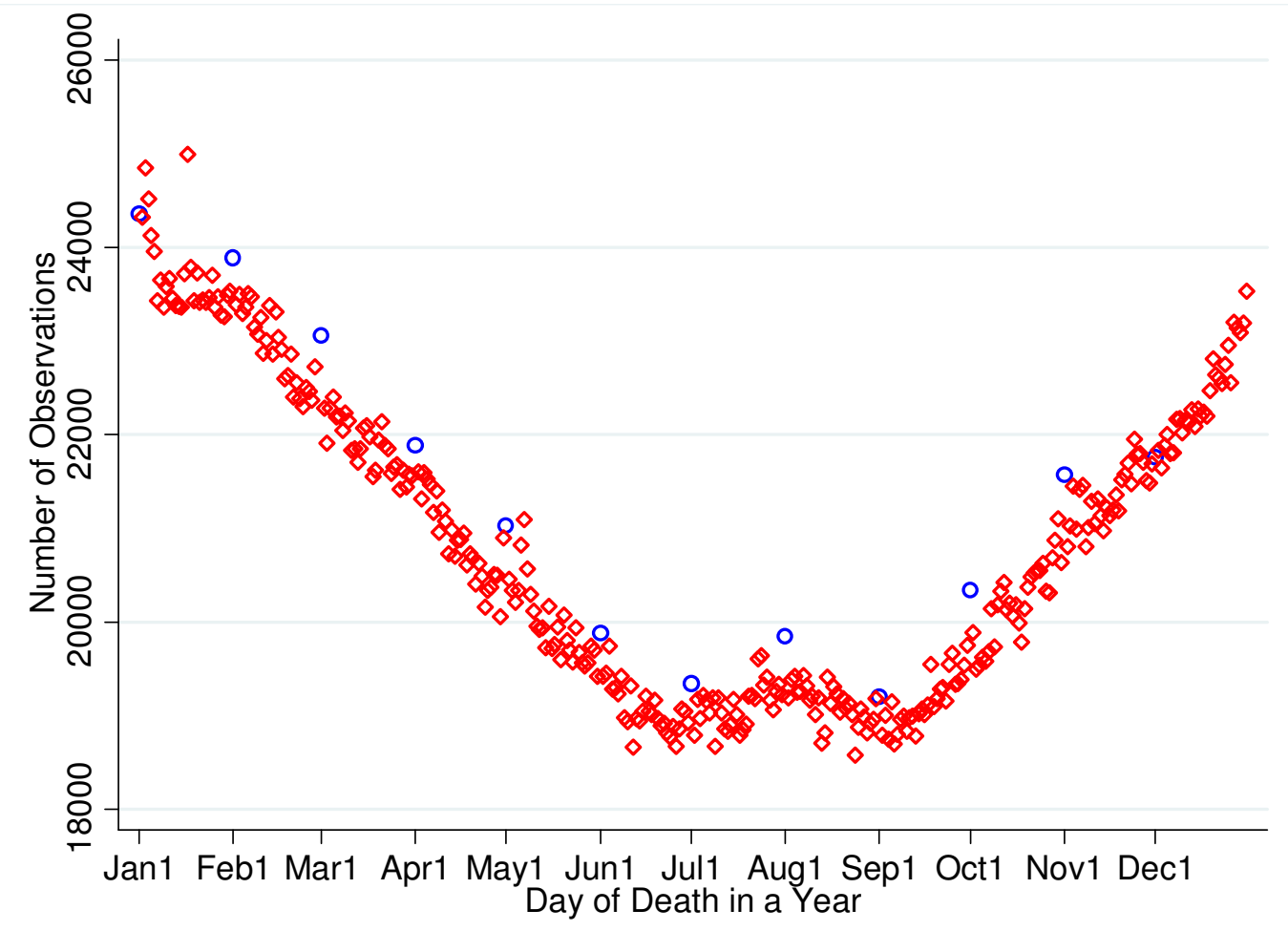

Note: I pool mortality data from among those born during 1919-1933 for 1984-2008. The circles indicate the first day of the month. 
Figure C: Age Profile of Employment by Gender (1987-2007 CSLC)

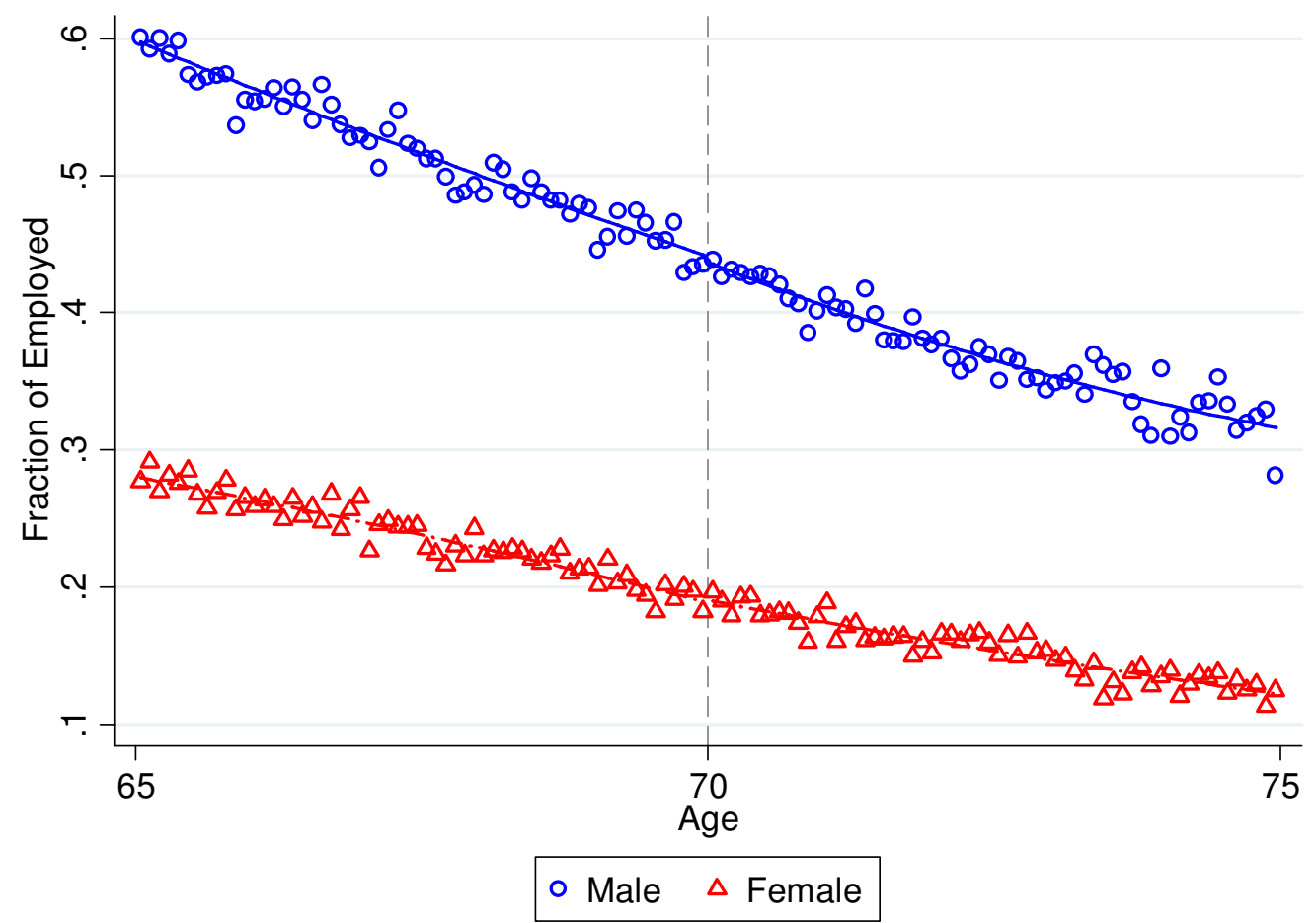

Note: I pool outpatient data for 1986-2007 from the CSLC. The markers represent actual averages (age in months), and the lines represent fitted regressions from models that assume a quadratic age profile, fully interacted with a dummy for age 70 or older, separately for male and female patients. 
Figure D: Age Profiles for First-time and Repeat Outpatient Visits (Log Scale)

D1. First-time Visits

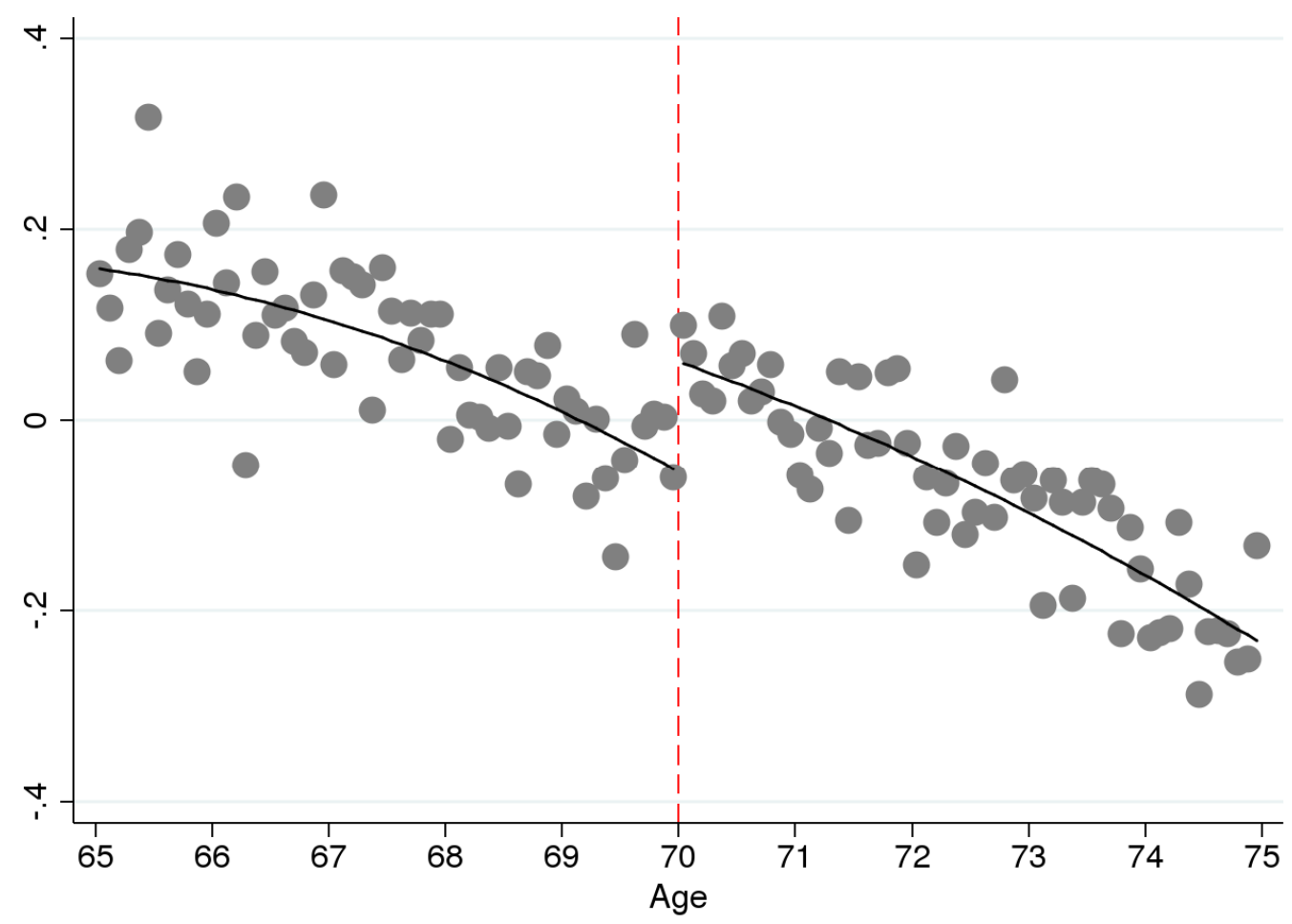

D2. Repeat Visits

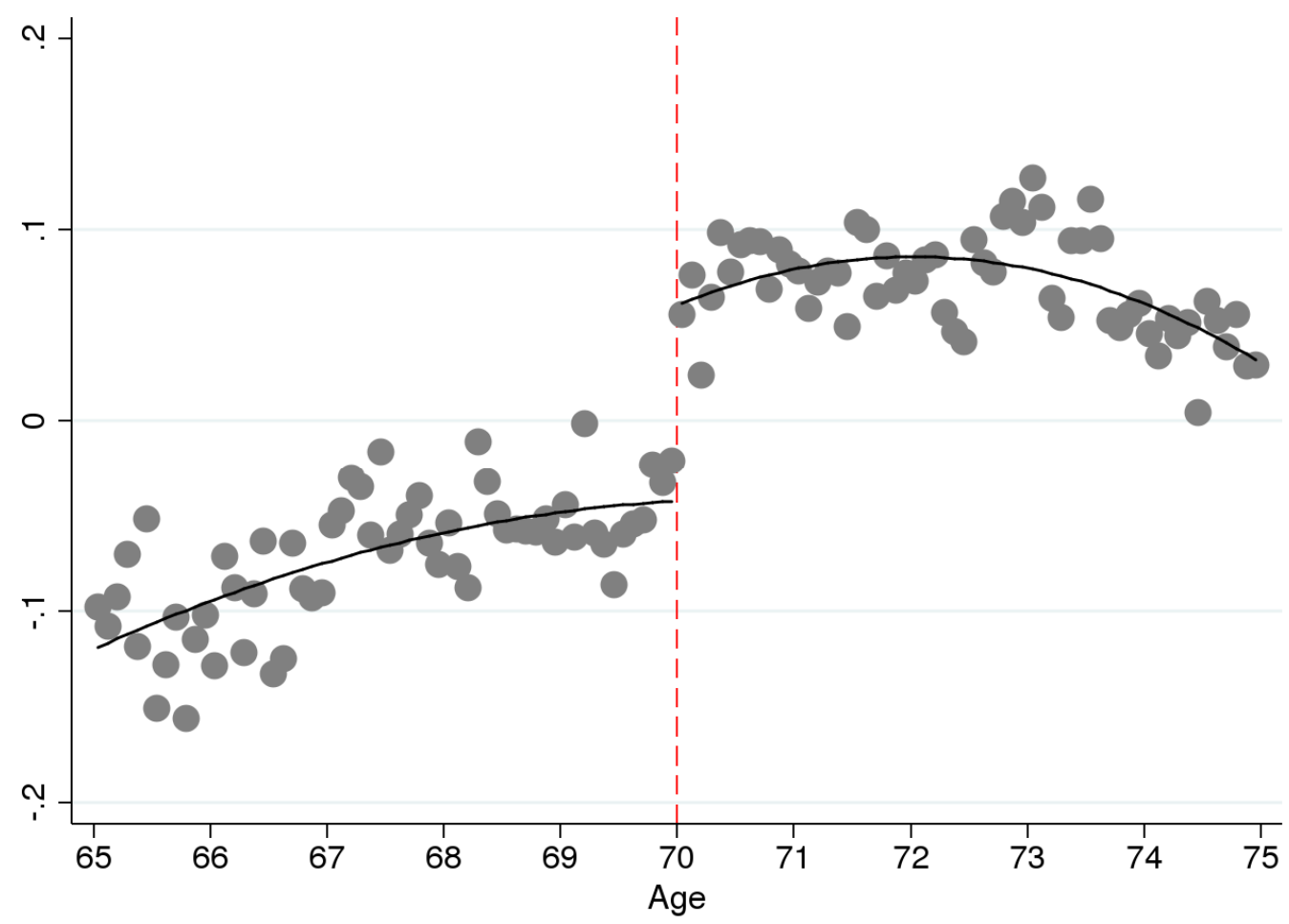

Note: I pool outpatient data for 1984-2008 from the Patient Survey. The markers represent averages of the residuals of log outcomes regressed by birth month fixed effects and survey year fixed effects, to partial out the seasonality in birth and the underlying common shocks in the survey year, respectively. The lines represent fitted regressions from models that assume a quadratic age profile, fully interacted with a dummy for age 70 or older. 
Figure E: Robustness of Results on Inpatient Admissions

E1. Estimates from the "Donut-hole" RD

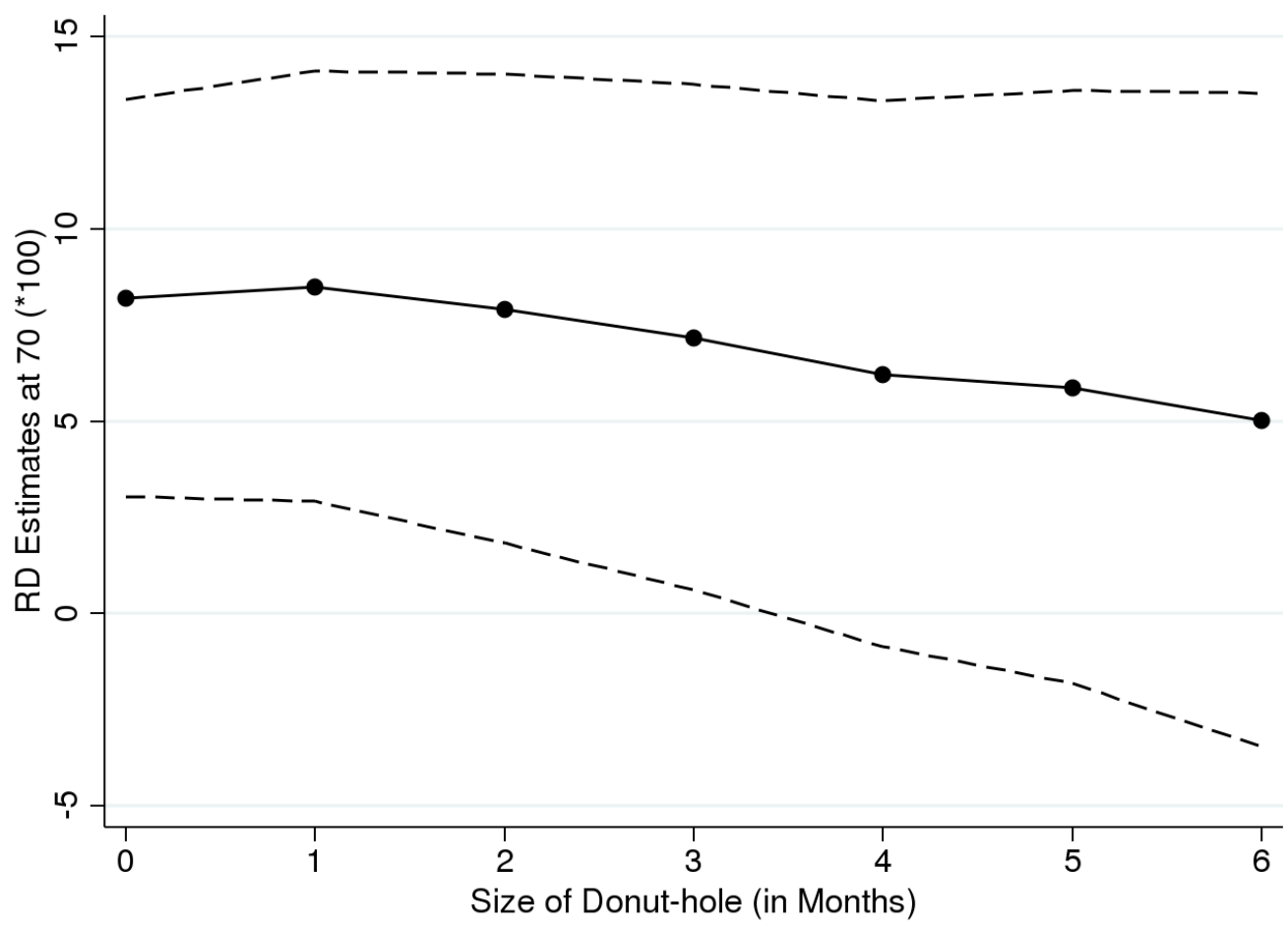

E2. Limiting the Sample by Different Windows from Discharge

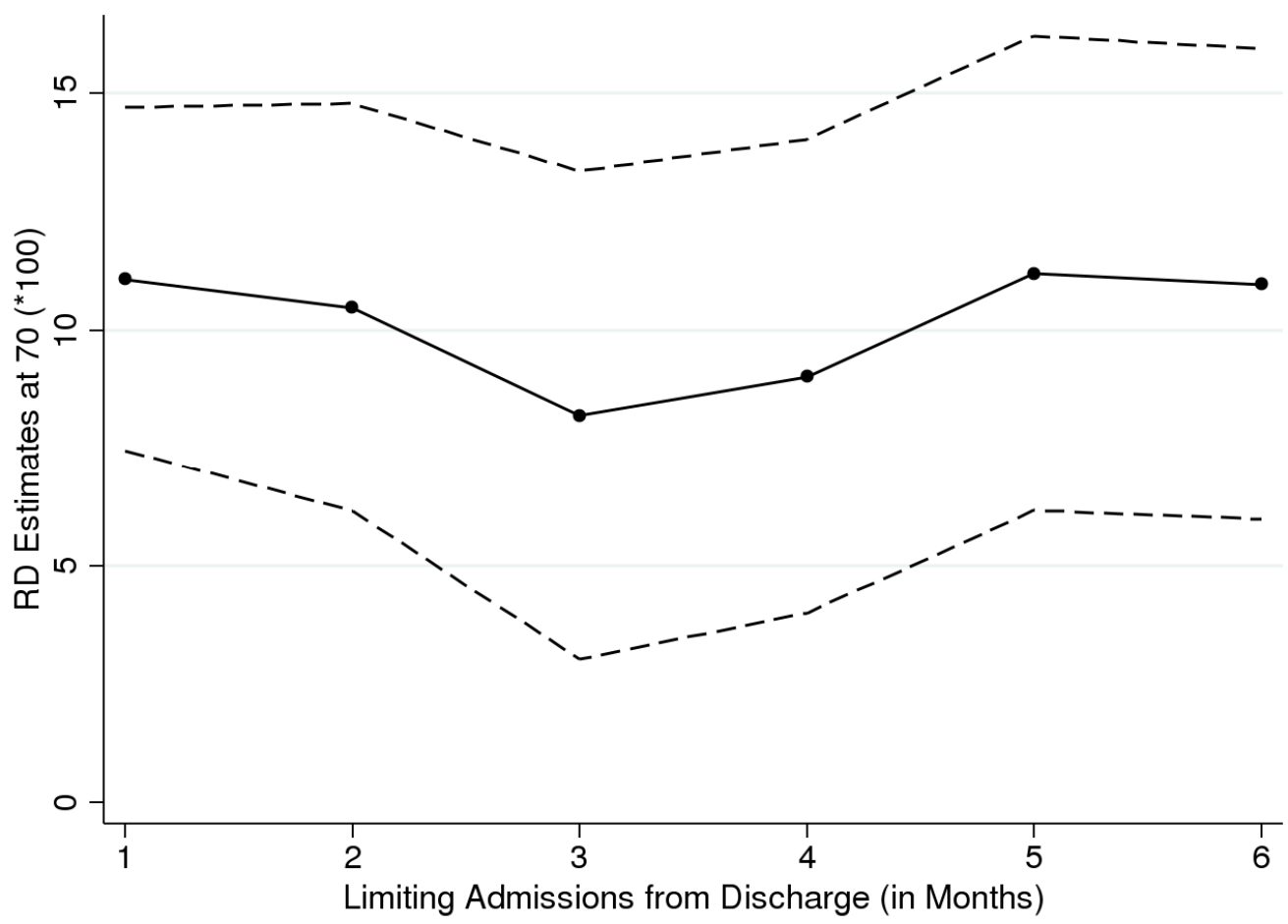

Note: I pool discharge data for 1984-2008 from the Patient Survey. The model here is a quadratic age profile, fully interacted with a dummy for age 70 or older. The dashed line indicates the 95 percent confidence interval. 
Figure F: Age Profile for Inpatient Admissions for Selected Surgery (Log Scale)

F1. Open-stomach Surgery

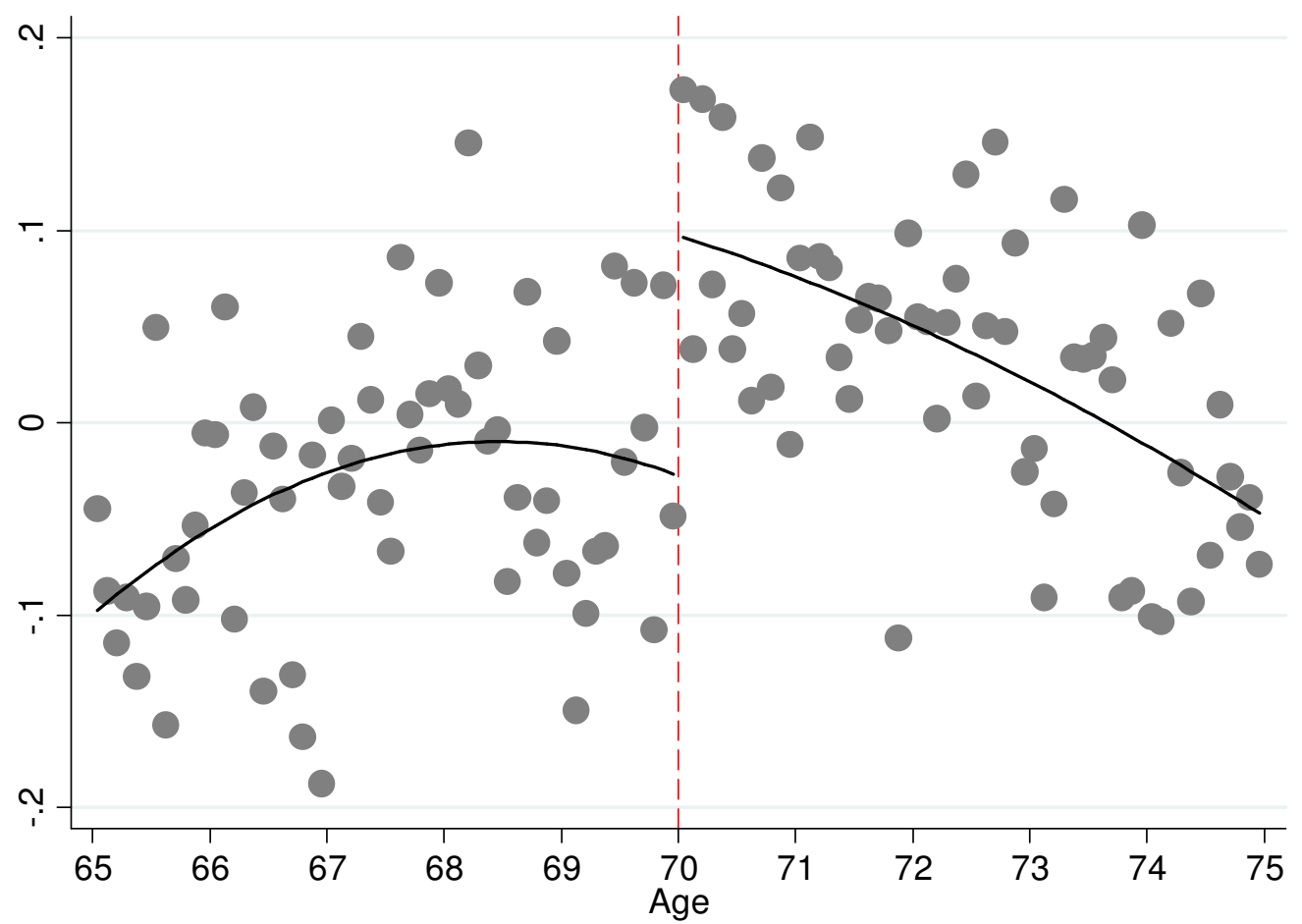

F2. Intraocular Lens Implantation

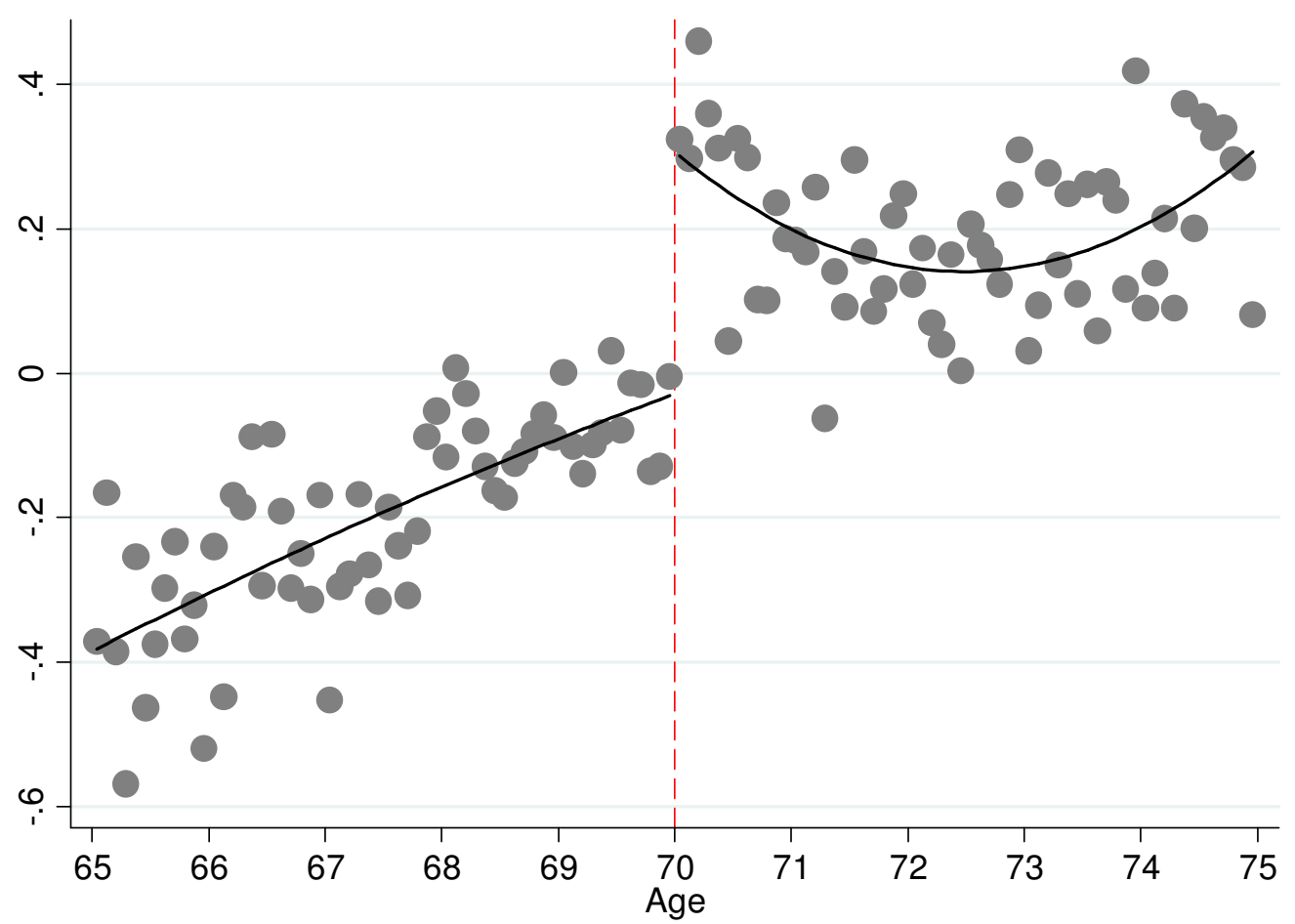

Note: I pool discharge data for 1999, 2002, 2005, and 2008 from the Patient Survey, since surgery-specific information was collected for only these four survey years. I use admissions within three months from discharge, and thus, the sample size is 1,440 . The markers represent the averages of residuals of log outcomes regressed by birth month fixed effects, admission month fixed effects, and the survey year fixed effects, in order to partial out the seasonality in birth and the underlying common shocks in the survey year, respectively. The lines represent fitted regressions from models that assume a quadratic age profile, fully interacted with a dummy for age 70 or older. 
Figure G: Age Profile of Inpatient Admissions for Selected Diagnoses (Log Scale)

G1. Heart Disease

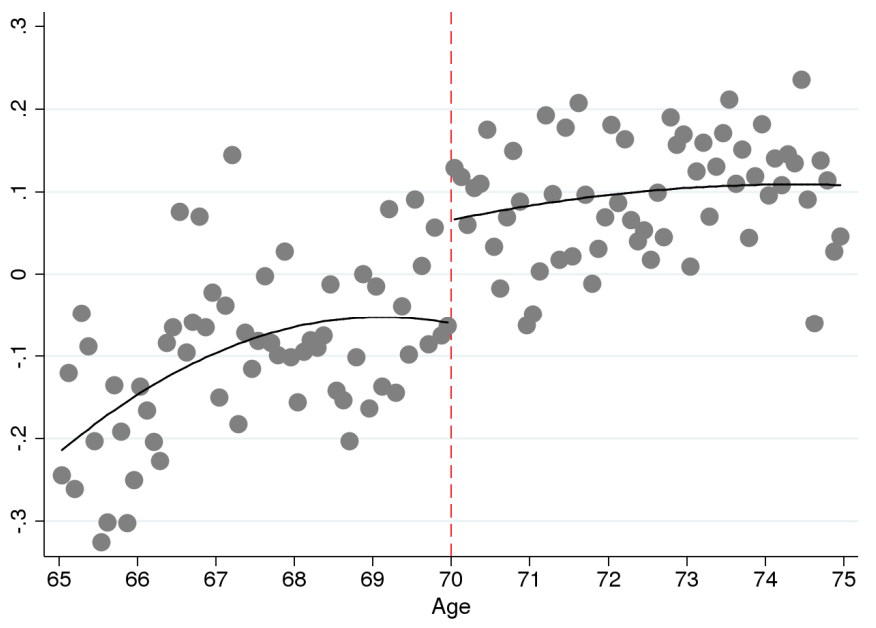

G2. Cerebrovascular Disease

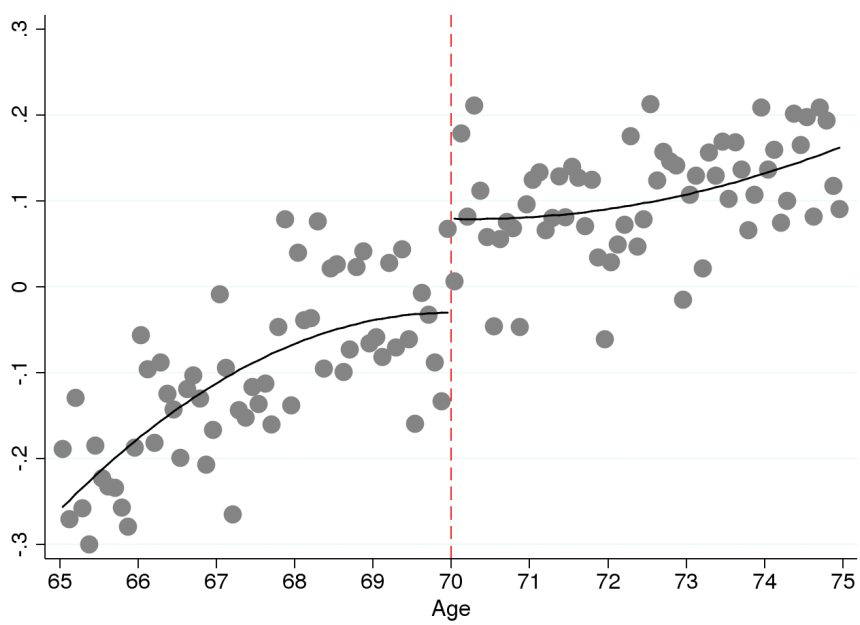

G3. Respiratory Disease

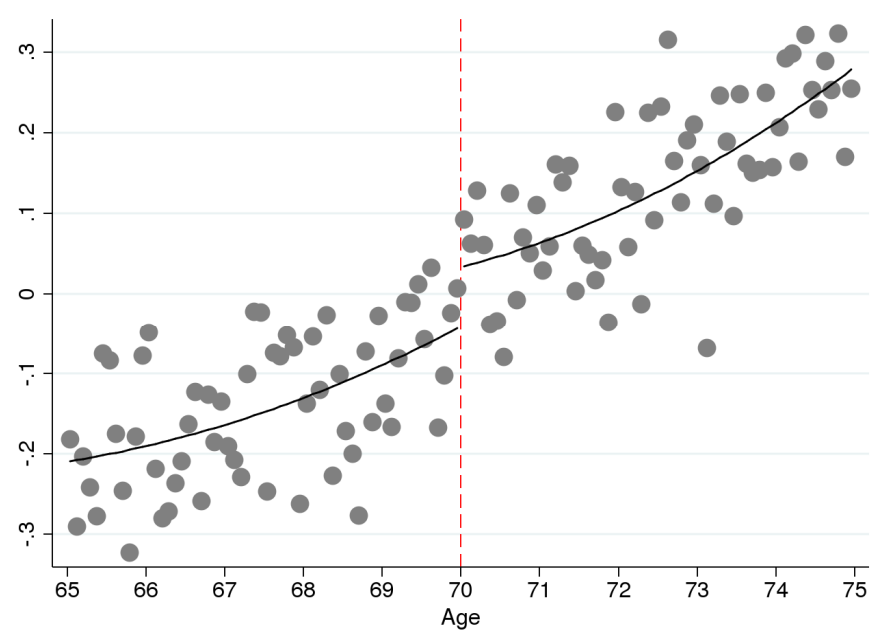

G4. ACSCs

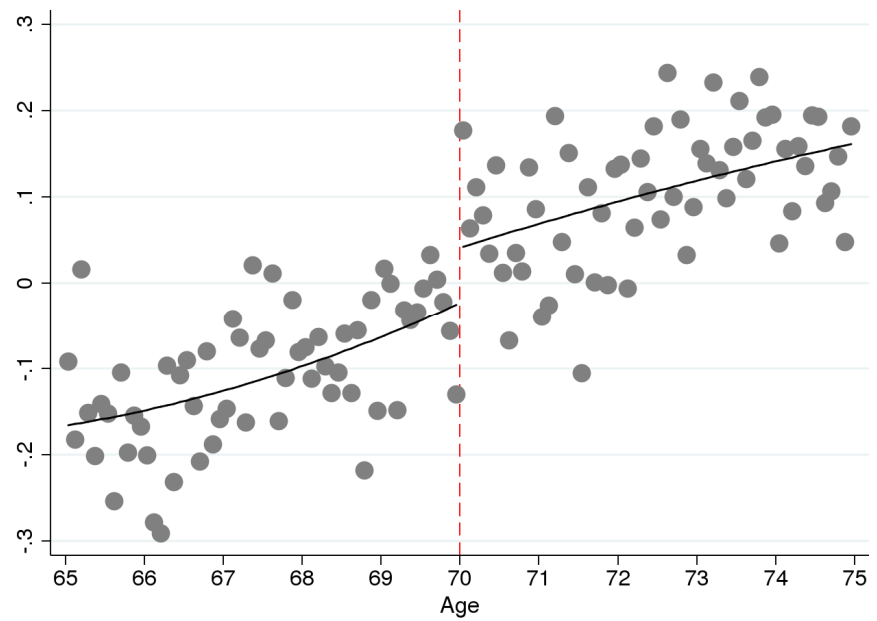

Note: I pool discharge data for 1984-2008 from the Patient Survey. The corresponding RD estimates at age 70 are statistically significant at 5 percent for Figures $\mathrm{H} 1$ and $\mathrm{H} 2$ only. The markers represent the averages of residuals from regressions of log outcomes on birth month fixed effects, admission month fixed effects, and survey year fixed effects (aggregated by age in months). The lines represent fitted regressions from models that assume a quadratic age profile, fully interacted with a dummy for age 70 or older. 


\section{Figure H: Age Profile for Cause-specific Mortality (Log Scale)}

\section{H1. Heart Disease}

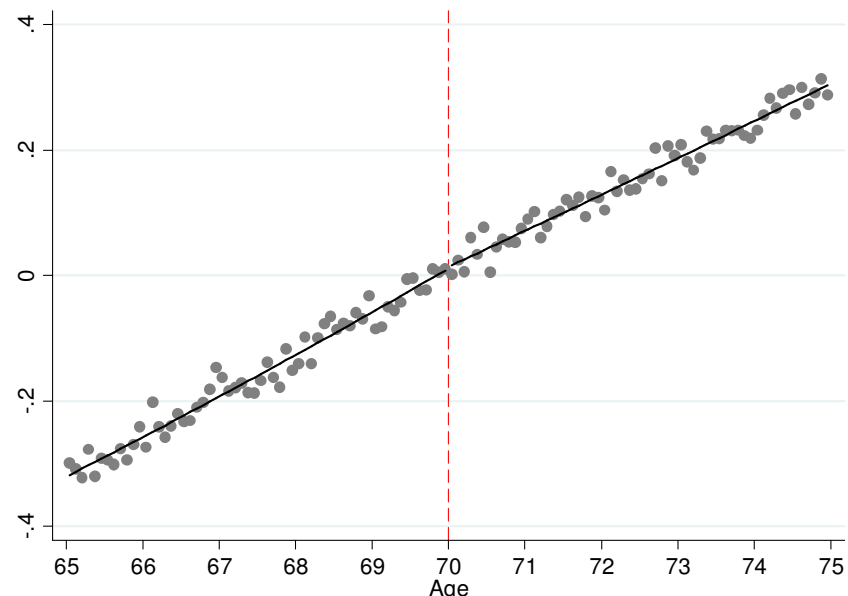

H2. Cerebrovascular Disease

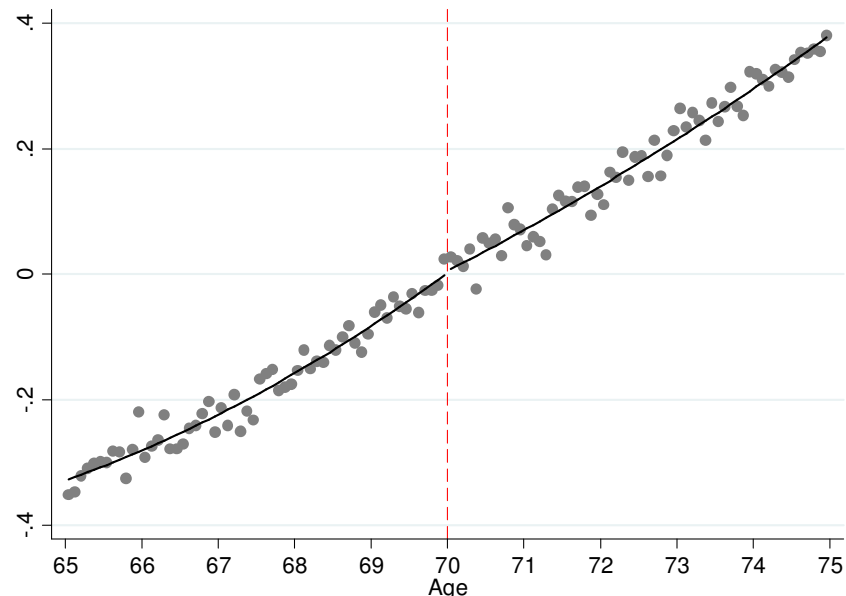

H3. Respiratory Disease

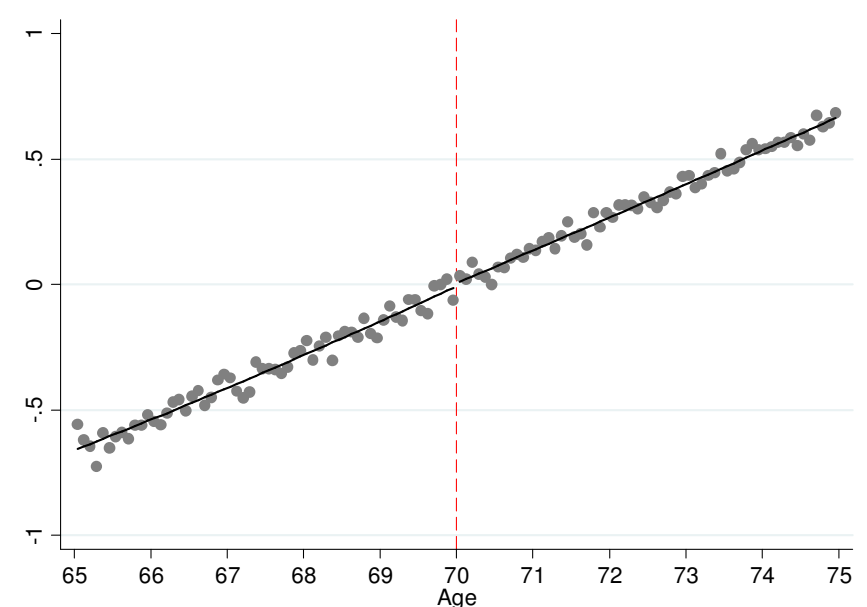

H4. Cancer

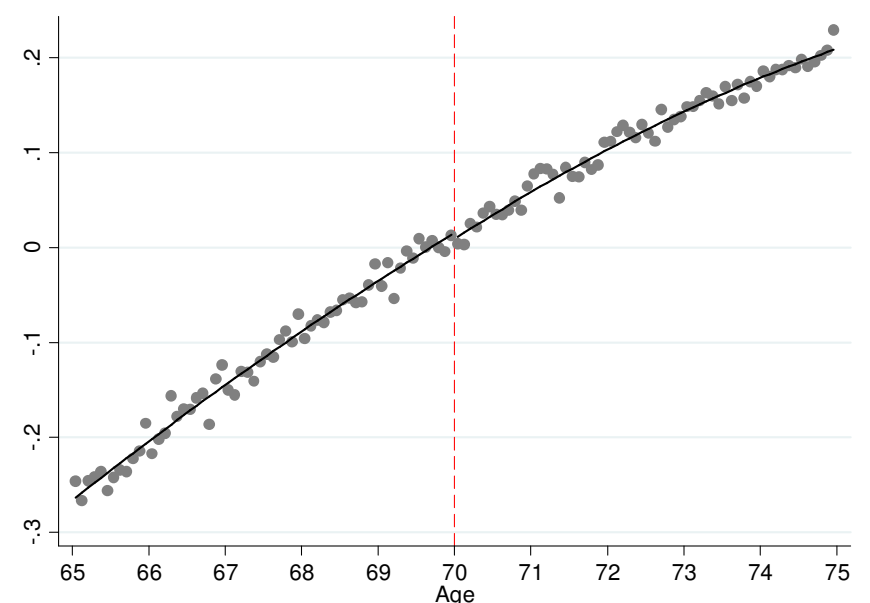

Note: I pool mortality data for 1984-2008 for patients born during 1919-1933. The markers represent the averages of residuals from regressions of log outcomes on birth month fixed effects and death month fixed effects (aggregated by age in month). The lines represent fitted regressions from models that assume a quadratic age profile, fully interacted with a dummy for age 70 or older. 
Figure I: Age Profiles for Fraction in Good or Very Good Health

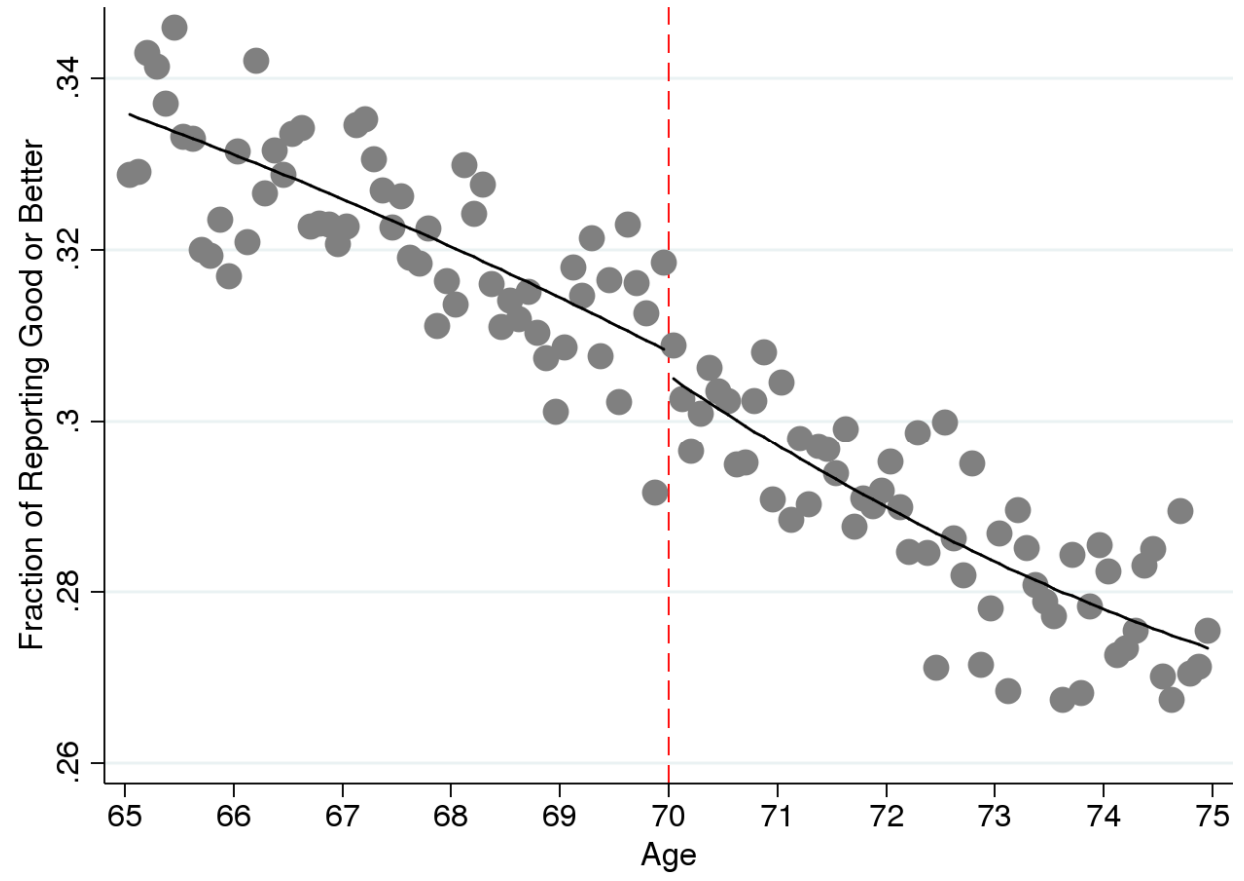

Note: I pool data for 1986-2007 from the CSLC. The markers represent actual averages (age in months), and the lines represent fitted regressions from models that assume a quadratic age profile, fully interacted with a dummy for age 70 or older. 
Figure J: Out-of-pocket Medical Expenditures

J1. Ages 65-69 (Near-elderly) and Ages 70-74 (Elderly)

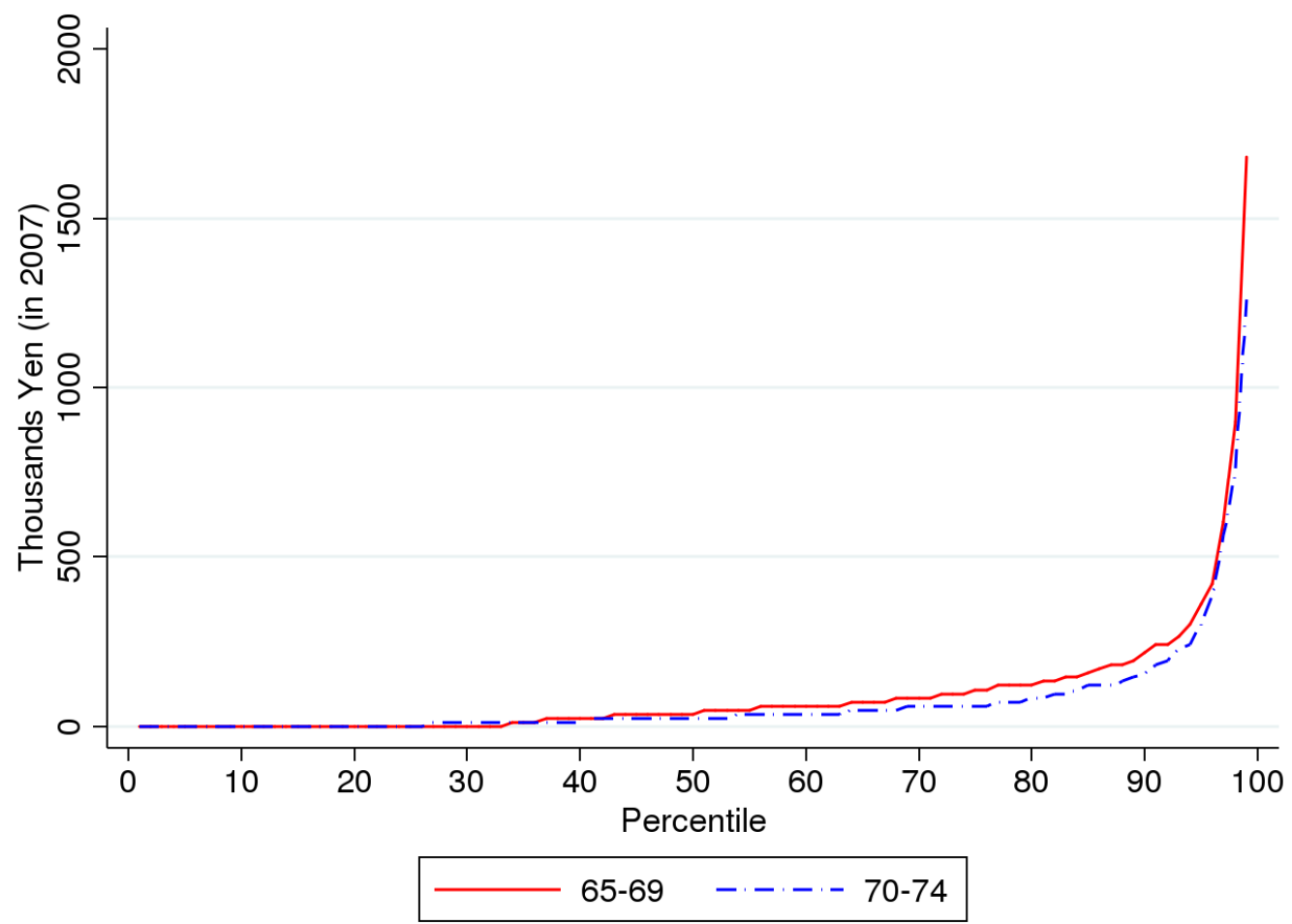

J2. Ages 60-64 and 65-69 (Near-elderly)

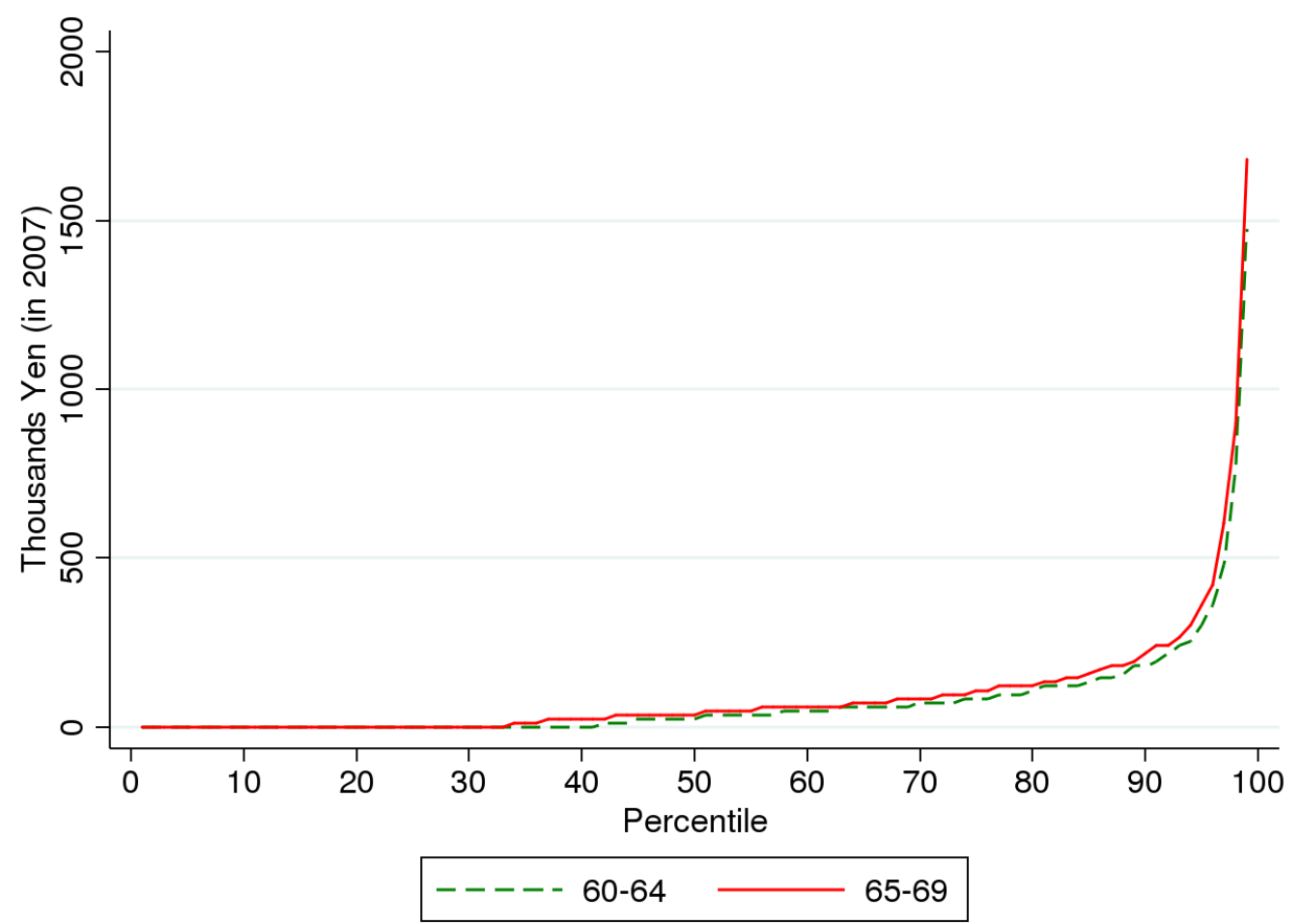

Note: The data are sourced from the 2007 CSLC. I multiply the monthly out-of-pocket expenditures by 12 to convert the values to an annual basis. One thousand Yen roughly equaled 10 US dollars in 2007. 
Figure K: RD Estimates and Fraction of Outpatient or Inpatient Care

K1. RD Estimates on Outpatient Care

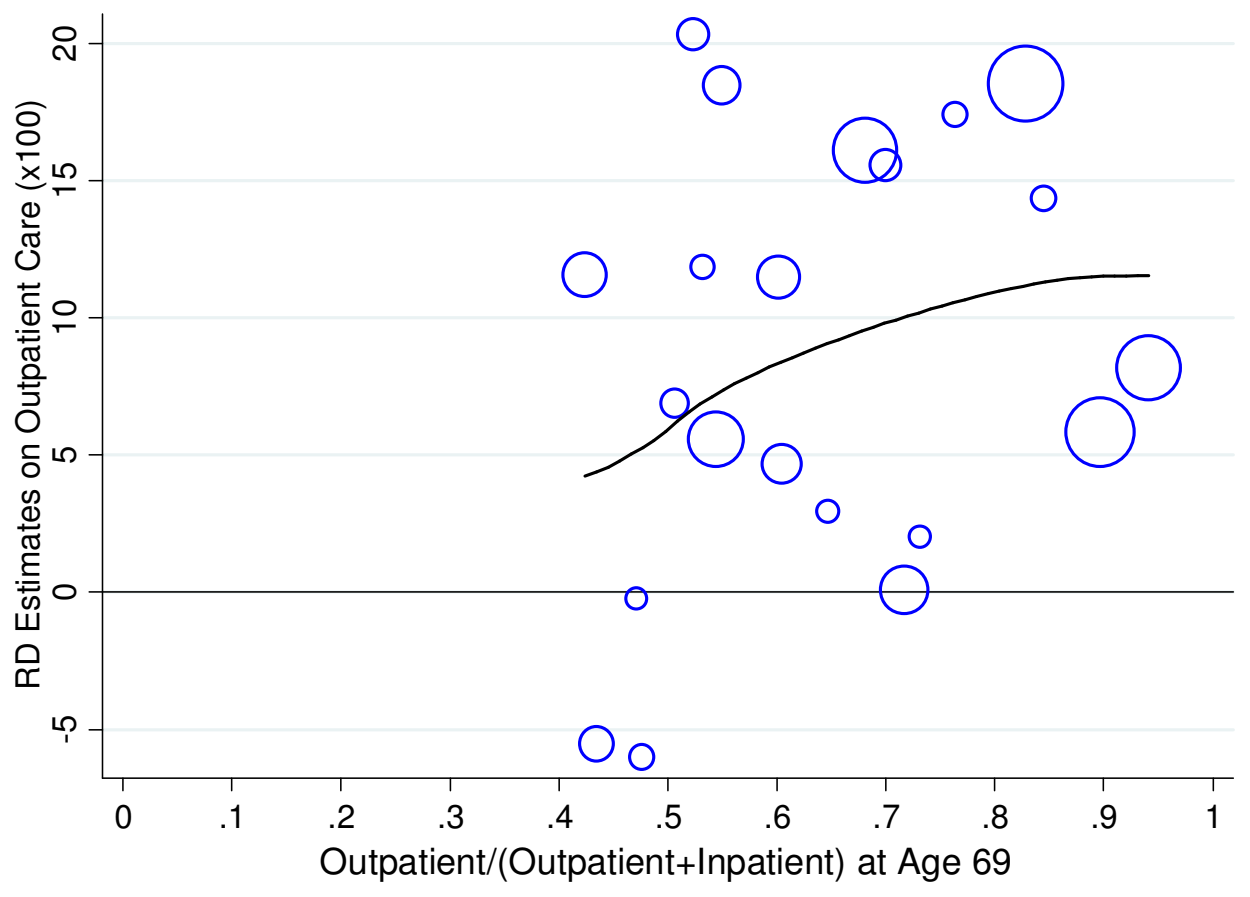

K2. RD Estimates on Inpatient Care

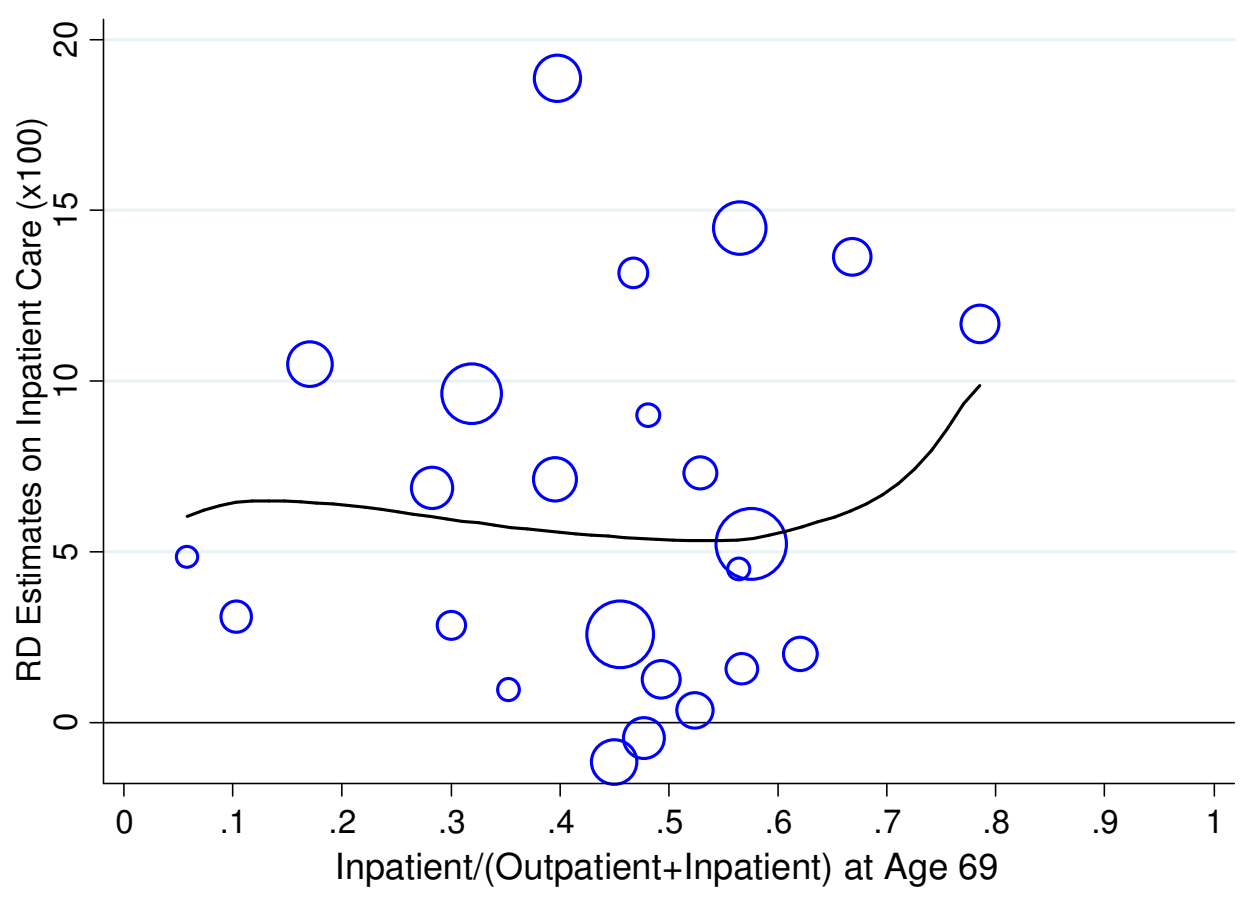

Note: I pool outpatient data and discharge data for 1984-2008 from the Patient Survey. The y-axis represents the $\mathrm{RD}$ estimates at age 70 , and the $\mathrm{x}$-axis is fraction of visits in each diagnosis group using outpatient or inpatient care at age 69, respectively. See Table $\mathrm{G}$ for the list of diagnosis groups. I omit diagnosis groups with less than 1 percent of the total observations of outpatient and inpatient care respectively, because their sample sizes are too small to provide credible estimates. The size of each dot reflects the number of observations for the control group (those aged 69) for outpatient and inpatient care, respectively. The solid line is a kernel-weighted local linear smoothing, using the reciprocal of the variance of each RD estimate as weight for the observation. 
Variables

Mean

(SD)

A. Outpatient Data

Repeat visits

0.94

Hospital

0.44

Clinic

0.56

Male

0.42

With referral

0.05

Days from last outpatient visit (days)

B. Discharge Data

With surgery

0.35

Male

0.54

Hospital

0.99

Clinic

0.01

Open-head surgery

0.007

Open-heart surgery

0.011

Open-stomach surgery

0.038

Musculoskeletal surgery

0.045

Endoscopic surgery: Stomach

0.007

Intraocular lens implantation

0.021

Length of stay (days)

Location before admission: outpatients in the same

hospital

0.67

C. CSLC Data

Self-reported health: Good or better

0.31

Are stressed

0.41

Male

0.45

Currently married

0.74

Employed

0.31

Hours of work per week

6.82

Income (thousand Yen)

1,860

$(1,920)$

Receiving pension

0.95

With long-term health insurance

0.03

D. Mortality Data

Male

0.64

Note: One thousand Yen roughly equaled 10 US dollars. 


\begin{tabular}{|c|c|c|c|c|c|c|}
\hline & & \multirow[b]{2}{*}{ All } & \multicolumn{2}{|c|}{ By Gender } & \multicolumn{2}{|c|}{ Data } \\
\hline & & & Male & Female & $\begin{array}{c}\text { Years } \\
\text { Available }\end{array}$ & $\begin{array}{l}\text { Sample } \\
\text { Size for } \\
\text { "All" }\end{array}$ \\
\hline \multicolumn{7}{|c|}{ A. Employment-related } \\
\hline (1) & Employed & $\begin{array}{c}0.3 \\
(0.4)\end{array}$ & $\begin{array}{c}0.5 \\
(0.5)\end{array}$ & $\begin{array}{c}0.1 \\
(0.5)\end{array}$ & 1986-2007 & 573,104 \\
\hline (2) & Retired & $\begin{array}{l}-0.1 \\
(0.5)\end{array}$ & $\begin{array}{c}0.8 \\
(0.7)\end{array}$ & $\begin{array}{l}-0.7 \\
(0.6)\end{array}$ & 1986-2007 & 573,104 \\
\hline (3) & Hours of work & $\begin{array}{c}0.0 \\
(0.0)\end{array}$ & $\begin{array}{c}0.1 \\
(0.1)\end{array}$ & $\begin{array}{c}0.0 \\
(0.2)\end{array}$ & 2004-2007 & 39,978 \\
\hline (4) & Family income (thousand Yen) & $\begin{array}{c}-54.9 \\
(113.0)\end{array}$ & $\begin{array}{l}-212.0 \\
(174.9)\end{array}$ & $\begin{array}{c}88.1 \\
(144.9)\end{array}$ & 1986-2007 & 77,967 \\
\hline (5) & Income (thousand Yen) & $\begin{array}{l}-32.3 \\
(89.8)\end{array}$ & $\begin{array}{c}-29.9 \\
(179.9)\end{array}$ & $\begin{array}{l}-34.1 \\
(54.3)\end{array}$ & 2004-2007 & 18,757 \\
\hline \multicolumn{7}{|c|}{ B. Family Structure } \\
\hline (6) & Married spouse present & $\begin{array}{c}0.5 \\
(0.5)\end{array}$ & $\begin{array}{c}0.5 \\
(0.5)\end{array}$ & $\begin{array}{c}0.4 \\
(0.7)\end{array}$ & 1986-2007 & 573,104 \\
\hline (7) & Head of household & $\begin{array}{c}0.0 \\
(0.4)\end{array}$ & $\begin{array}{l}-0.1 \\
(0.4)\end{array}$ & $\begin{array}{c}0.1 \\
(0.6)\end{array}$ & 1986-2007 & 573,104 \\
\hline \multicolumn{7}{|c|}{ C. Other } \\
\hline (8) & Receiving pension & $\begin{array}{c}0.3 \\
(0.3)\end{array}$ & $\begin{array}{c}0.2 \\
(0.4)\end{array}$ & $\begin{array}{c}0.4 \\
(0.4)\end{array}$ & 1986-2007 & 573,104 \\
\hline (9) & Long-term care insurance & $\begin{array}{l}-0.1 \\
(0.3)\end{array}$ & $\begin{array}{l}-0.5 \\
(0.4)\end{array}$ & $\begin{array}{c}0.2 \\
(0.3)\end{array}$ & $2001-2007$ & 232,928 \\
\hline
\end{tabular}

Note: Estimated regression discontinuities at age 70 are shown from models that include a quadratic of age, fully interacted with dummy for age 70 or older among people between ages $65-75$. The exception is a pension dummy, since there is a discrete jump at age 65 favoring the probability of receiving pension. Thus, I limit the sample to ages 66-74. Other controls include indicators for gender, region, marital status, birth month, and sample year. I use pooled 1986-2007 samples from the CSLC. Sample sizes differ by variables, since some variables are only collected for a shorter period. Note that income is collected for roughly 15 percent of all samples. Standard errors (in parentheses) are clustered at the age-in-months level, as this is the most refined available version of the age variable. All regressions are weighted to take into account the stratified sampling frame in the data. $* * *, * *$, and $*$ denote significance at the 1 percent, 5 percent, and 10 percent levels respectively. As all coefficients on Post 70 and their standard errors have been multiplied by 100, they can be interpreted as percentage changes. 
Table C: Top 5 Diagnoses and RD Estimates

C1. Outpatient Visits

\begin{tabular}{llcccc}
\hline \hline Rank & Diagnosis & $\begin{array}{c}\text { ICD9 } \\
\text { (3-digit) }\end{array}$ & $\begin{array}{c}\text { Share } \\
\text { (Percent) }\end{array}$ & $\begin{array}{c}\text { RD } \\
\text { Estimates }\end{array}$ & SE \\
\hline 1 & Essential Hypertension & 401 & 16.1 & $8.0^{* * * *}$ & 2.4 \\
2 & Spondylosis and Allied Disorders & 721 & 4.7 & $23.7 * * *$ & 3.6 \\
3 & Diabetes Mellitus & 250 & 4.7 & 1.7 & 4.4 \\
4 & Osteoarthrosis and Allied Disorders & 715 & 4.3 & $25.3^{* * *}$ & 4.2 \\
5 & Cataract & 366 & 3.4 & $12.0^{* *}$ & 4.9 \\
\hline
\end{tabular}

C2. Inpatient Admissions

\begin{tabular}{llcccc}
\hline \hline Rank & Diagnosis & $\begin{array}{c}\text { ICD9 } \\
\text { (3-digit) }\end{array}$ & $\begin{array}{c}\text { Share } \\
\text { (Percent) }\end{array}$ & $\begin{array}{c}\text { RD } \\
\text { Estimates }\end{array}$ & SE \\
\hline 1 & Cataract & 366 & 4.4 & $22.6^{* * * *}$ & 6.5 \\
2 & Angina Pectoris & 413 & 4.1 & 11.4 & 7.3 \\
3 & Occlusion of Cerebral Arteries & 434 & 3.8 & $13.7 * * *$ & 4.6 \\
4 & Diabetes Mellitus & 250 & 3.2 & 7.4 & 5.8 \\
5 & Malignant Neoplasm of the Stomach & 151 & 3.1 & 4.8 & 6.1 \\
\hline
\end{tabular}

Note: For both Figures C1 and C2, I pool outpatient data for 1984-2008 from the Patient Survey. ***, **, and $*$ denote significance at the 1 percent, 5 percent, and 10 percent levels respectively.

Table D: List of Ambulatory Care Sensitive Conditions

\begin{tabular}{ll}
\hline \hline No. & Diagnosis \\
\hline 1 & Diabetes, Short-term Complications \\
3 & Diabetes, Long-term Complications \\
5 & Chronic Obstructive Pulmonary Disease \\
7 & Hypertension \\
8 & Congestive Heart Failure \\
10 & Dehydration \\
11 & Bacterial Pneumonia \\
12 & Urinary Infections \\
13 & Angina without Procedure \\
14 & Uncontrolled Diabetes \\
15 & Adult Asthma \\
16 & Lower Extremity Amputations among Patients with Diabetes \\
\hline $\begin{array}{l}\text { Note: I excluded entry \#2 (Perforated Appendicitis) from the analysis, since this index } \\
\text { indicates the number of admissions for perforated appendices as a share of admissions for }\end{array}$ \\
appendicitis only. In addition, entry \#14 requires the fifth digit of ICD9, which I do not have, \\
since this diagnosis includes 25002 and 25003 only (25000, 25001, and 25009 should not be \\
included). To account for this, I only include Diabetes (2500), which also report secondary \\
diagnosis.
\end{tabular}


Table E: Robustness of RD Estimates on Outpatient Visits for Selected Outcomes

Running Variable: Age in

\begin{tabular}{|c|c|c|c|c|c|}
\hline \multicolumn{3}{|c|}{ Month } & \multicolumn{3}{|c|}{ Day } \\
\hline Basic & $\begin{array}{c}\text { Age } \\
67-73\end{array}$ & Cubic & Basic & $\begin{array}{c}\text { Age } \\
67-73\end{array}$ & Cubic \\
\hline
\end{tabular}

$(1)$

$(1)$

(2)

(3)

.

(4)

$(5)$

(6)

A. All

(2.6)

$11.4 * * *$

$12.3^{*}$

B. By Period Years 1984-1999

$\begin{array}{cccccc}12.0^{* * *} & 12.3 * * * & 12.5 * * * & 14.0 * * * & 14.1^{* * *} & 14.2^{* * *} \\ (1.8) & (2.2) & (2.5) & (1.7) & (2.2) & (2.3) \\ & & & & & \\ 10.3 * * * & 11.2 * * * & 12.1 * * * & 11.4 * * * & 12.1 * * * & 12.5 * * * \\ (1.9) & (2.3) & (2.6) & (1.6) & (2.1) & (2.2)\end{array}$

D. Days from Last Outpatient Visits among Repeat Visits

$\begin{array}{lcccccc}1 \text { day } & 16.4^{* * *} & 20.9^{* * *} & 21.6^{* * *} & 15.7^{* * *} & 17.1^{* * *} & 16.5^{* * *} \\ 4-7 \text { days } & (4.4) & (6.1) & (6.5) & (2.1) & (2.7) & (2.9) \\ & 8.5^{* * *} & 6.6 & 8.7^{*} & 9.6^{* * *} & 11.7^{* * *} & 10.5^{* * *} \\ & (3.0) & (4.1) & (4.6) & (2.3) & (3.1) & (3.2)\end{array}$

E. By Institution

Clinic

$$
13.8 * * *
$$

$15.1^{* * *} \quad 16.0 * * *$

$13.4 * * * \quad 14.2 * * *$

$14.7 * * *$

F. By Referral

(1.1)

(1.5)

Without referral

$$
10.5 * * *
$$

$11.6^{* * * *}$

$12.5^{* * *}$

$11.5 * * *$

$12.3 * * * \quad 12.8 * * *$

G. By Gender

\begin{tabular}{cccccc}
$11.3 * * *$ & $11.7 * * *$ & $12.5 * * *$ & $12.7 * * *$ & $14.2 * * *$ & $13.6 * * *$ \\
$(2.2)$ & $(2.7)$ & $(3.1)$ & $(2.0)$ & $(2.7)$ & $(2.8)$ \\
$9.7 * * *$ & $11.1 * * *$ & $11.9 * * *$ & $10.1 * * *$ & $11.3 * * *$ & $12.3 * * *$ \\
$(1.9)$ & $(2.3)$ & $(2.6)$ & $(1.7)$ & $(2.2)$ & $(2.4)$ \\
\hline
\end{tabular}

Note: Each cell is the estimate from separate estimated regression discontinuities at age 70. I use pooled 1984-2008 samples of outpatient data. Column (1) is the model that includes quadratic of age, fully interacted with dummy for age 70 or older among people between ages 65-75, where the data are collapsed into age in months. Controls are dummies for each survey year and each month of birth. The "Basic" model in Column (4) includes a quadratic age profile, fully interacted with dummy for age 70 or older among people between ages 65-75, where the data are collapsed into age in days. Controls are dummies for each survey year and each day of the year. Robust standard errors are in parentheses. $* * *, * *$, and * denote significance at the 1 percent, 5 percent, and 10 percent levels respectively. As all coefficients on Post 70 and their standard errors have been multiplied by 100 , they can be interpreted as percentage changes. 
Basic Age 67-73 Cubic

\begin{tabular}{|c|c|c|c|c|}
\hline & & & & \\
\hline & & $(1)$ & (2) & (3) \\
\hline A. & All & $\begin{array}{c}8.2 * * * \\
(2.6)\end{array}$ & $\begin{array}{c}10.0 * * * \\
(3.4)\end{array}$ & $\begin{array}{c}11.2 * * * \\
(3.6)\end{array}$ \\
\hline B. & By Period & & & \\
\hline & Years 1984-1999 & $\begin{array}{c}9.6^{* * * *} \\
(2.2)\end{array}$ & $\begin{array}{c}10.9 * * * \\
(2.8)\end{array}$ & $\begin{array}{c}12.2 * * * \\
(3.0)\end{array}$ \\
\hline & Years 2002-2008 & $\begin{array}{l}5.3^{* *} \\
(2.6)\end{array}$ & $\begin{array}{l}8.0^{* *} \\
(3.3)\end{array}$ & $\begin{array}{c}9.4 * * * \\
(3.6)\end{array}$ \\
\hline C. & By Admission Day & & & \\
\hline & First half of the month & $\begin{array}{c}9.8 * * * \\
(2.8)\end{array}$ & $\begin{array}{c}12.1 * * * \\
(3.6)\end{array}$ & $\begin{array}{c}13.8 * * * \\
(3.7)\end{array}$ \\
\hline & Second half of the month & $\begin{array}{c}8.7 * * * \\
(3.2)\end{array}$ & $\begin{array}{c}10.4 * * \\
(4.2)\end{array}$ & $\begin{array}{c}11.8^{* * * *} \\
(4.4)\end{array}$ \\
\hline D. & Surgery & & & \\
\hline & Without surgery & $\begin{array}{l}6.4^{* * *} \\
(2.6)\end{array}$ & $\begin{array}{c}6.9^{* * *} \\
(3.4)\end{array}$ & $\begin{array}{l}8.0^{* *} \\
(3.6)\end{array}$ \\
\hline & With surgery & $\begin{array}{c}12.0 * * * \\
(3.5)\end{array}$ & $\begin{array}{c}17.3 * * * \\
(4.5)\end{array}$ & $\begin{array}{c}20.0 * * * \\
(4.7)\end{array}$ \\
\hline E. & Type of Surgery & & & \\
\hline & Open-stomach surgery & $\begin{array}{c}12.6^{* *} \\
(5.3)\end{array}$ & $\begin{array}{c}15.1^{* *} \\
(6.6)\end{array}$ & $\begin{array}{c}15.5^{* *} \\
(6.9)\end{array}$ \\
\hline & Intraocular lens implantation & $\begin{array}{c}22.9 * * * \\
(5.2)\end{array}$ & $\begin{array}{c}29.7 * * * \\
(6.7)\end{array}$ & $\begin{array}{c}38.5 * * * \\
(8.3)\end{array}$ \\
\hline F. & Gender & & & \\
\hline & Male & $\begin{array}{c}8.1 * * * \\
(2.8)\end{array}$ & $\begin{array}{c}10.2 * * * \\
(3.6)\end{array}$ & $\begin{array}{c}11.1^{* * *} \\
(3.8)\end{array}$ \\
\hline & Female & $\begin{array}{c}9.0^{* * *} \\
(2.8)\end{array}$ & $\begin{array}{c}10.4 * * * \\
(3.6)\end{array}$ & $\begin{array}{c}12.2 * * * \\
(3.9)\end{array}$ \\
\hline G. & By Diagnosis & & & \\
\hline & Cataract & $\begin{array}{c}22.6^{* * * *} \\
(6.5)\end{array}$ & $\begin{array}{c}31.6^{* * * *} \\
(8.5)\end{array}$ & $\begin{array}{c}46.4 * * * \\
(9.7)\end{array}$ \\
\hline & Occlusion of cerebral arteries & $\begin{array}{c}13.7 * * * \\
(4.6)\end{array}$ & $\begin{array}{c}16.3 * * * \\
(5.9)\end{array}$ & $\begin{array}{c}18.2 * * * \\
(6.3)\end{array}$ \\
\hline & Ischaemic heart disease & $\begin{array}{c}14.5^{* *} \\
(7.1)\end{array}$ & $\begin{array}{l}17.3^{*} \\
(9.3)\end{array}$ & $\begin{array}{c}16.5^{*} \\
(9.7)\end{array}$ \\
\hline & Cerebral infarction & $\begin{array}{c}12.8^{* * *} \\
(4.6)\end{array}$ & $\begin{array}{c}14.4 * * \\
(6.0)\end{array}$ & $\begin{array}{c}14.5 * * \\
(6.3)\end{array}$ \\
\hline $\mathrm{H}$. & $\begin{array}{l}\text { Location Before Admission } \\
\text { Outpatients in the same hospital }\end{array}$ & $\begin{array}{c}9.7 * * * \\
(2.9)\end{array}$ & $\begin{array}{c}11.3^{* * * *} \\
(3.7)\end{array}$ & $\begin{array}{c}13.0^{* * * *} \\
(3.9)\end{array}$ \\
\hline
\end{tabular}

Note: The "Basic" model includes a quadratic age profile, fully interacted with dummy for age 70 or older among people between ages 65-75. Controls are dummies for each survey year, each month of birth, and each month of admission. I use pooled 1984-2008 samples of discharge data. Robust standard errors are in parentheses. ***,**, and * denote significance at the 1 percent, 5 percent, and 10 percent levels respectively. As all coefficients on Post 70 and their standard errors have been multiplied by 100 , they can be interpreted as percentage changes. 
Table G: List of Diagnosis Groups

\begin{tabular}{|c|c|c|}
\hline No. & ICD 9 & Diagnosis Group \\
\hline 1 & $001-009$ & Intestinal Infectious Diseases \\
\hline 2 & 010-018 & Tuberculosis \\
\hline 3 & 020-041 & Other Bacterial Diseases \\
\hline 4 & 045-079 & Viral Diseases \\
\hline 5 & 080-088 & Rickettsiosis and Other Arthropod-borne Diseases \\
\hline 6 & 090-099 & Venereal Diseases \\
\hline 7 & $100-139$ & $\begin{array}{l}\text { Other Infectious and Parasitic Diseases and Late Effects of Infectious and } \\
\text { Parasitic Diseases }\end{array}$ \\
\hline 8 & $140-149$ & Malignant Neoplasm of Lip, Oral Cavity, and Pharynx \\
\hline 9 & $150-159$ & Malignant Neoplasm of Digestive Organs and Peritoneum \\
\hline 10 & $160-165$ & Malignant Neoplasm of Respiratory and Intrathoracic Organs \\
\hline 11 & $170-175$ & Malignant Neoplasm of Bone, Connective Tissue, Skin, and Breast \\
\hline 12 & 179-189 & Malignant Neoplasm of Genitourinary Organs \\
\hline 13 & 190-199 & Malignant Neoplasm of Other and Unspecified Sites \\
\hline 14 & $200-208$ & Malignant Neoplasm of Lymphatic and Hematopoietic Tissue \\
\hline 15 & $210-229$ & Benign Neoplasm \\
\hline 16 & $230-234$ & Carcinoma in Situ \\
\hline 17 & 235-239 & Other and Unspecified Neoplasm \\
\hline 18 & $\begin{array}{l}240-259 \\
270-279\end{array}$ & Endocrine and Metabolic Diseases, Immunity Disorders \\
\hline 19 & $260-269$ & Nutritional Deficiencies \\
\hline 20 & 280-289 & Diseases of Blood and Blood-forming Organs \\
\hline 21 & 290-319 & Mental Disorders \\
\hline 22 & $320-359$ & Diseases of the Nervous System \\
\hline 23 & $360-379$ & Disorders of the Eye and Adnexa \\
\hline 24 & 380-389 & Diseases of the Ear and Mastoid Process \\
\hline 25 & $390-398$ & Rheumatic Fever and Heart Disease \\
\hline 26 & $401-405$ & Hypertensive Disease \\
\hline 27 & $410-414$ & Ischemic Heart Disease \\
\hline 28 & $415-429$ & Diseases of Pulmonary Circulation and Other Forms of Heart Disease \\
\hline 29 & $430-438$ & Cerebrovascular Disease \\
\hline 30 & $440-459$ & Other Diseases of the Circulatory System \\
\hline 31 & $\begin{array}{l}460-465, \\
470-478\end{array}$ & Diseases of the Upper Respiratory Tract \\
\hline 32 & $466,480-519$ & Other Diseases of the Respiratory System \\
\hline 33 & $520-529$ & Diseases of Oral Cavity, Salivary Glands, and Jaws \\
\hline 34 & $530-579$ & Diseases of Other Parts of the Digestive System \\
\hline 35 & $580-599$ & Diseases of Urinary System \\
\hline 36 & $600-608$ & Diseases of Male Genital Organs \\
\hline 37 & $610-629$ & Diseases of Female Genital Organs \\
\hline 38 & $630-639$ & Abortion \\
\hline 39 & $640-646$ & Direct Obstetric Causes \\
\hline 40 & $647-648$ & Indirect Obstetric Causes \\
\hline 41 & 650 & Normal Delivery \\
\hline 42 & $680-709$ & Diseases of Skin and Subcutaneous Tissue \\
\hline 43 & $710-739$ & Diseases of the Musculoskeletal System and Connective Tissue \\
\hline 44 & $740-759$ & Congenital Anomalies \\
\hline 45 & $760-779$ & Certain Conditions Originating in the Perinatal Period \\
\hline 46 & 780-799 & Signs, Symptoms, and Ill-defined Conditions \\
\hline 47 & $800-829$ & Fractures \\
\hline 48 & $830-848$ & Dislocations, Sprains, and Strains \\
\hline 49 & $\begin{array}{l}850-869 \\
950-957\end{array}$ & Intracranial and Internal Injuries, Including Nerves \\
\hline 50 & 870-904 & Open Wounds and Injury to Blood Vessels \\
\hline 51 & $930-939$ & Effects of Foreign Body Entering through Orifice \\
\hline
\end{tabular}




\begin{tabular}{lll}
\hline 52 & $940-949$ & Burns \\
53 & $960-989$ & Poisonings and Toxic Effects \\
54 & $996-999$ & Complications of Medical and Surgical Care \\
55 & $910-929$, & Other Injuries, Early Complications of Trauma \\
& $958-959$, & \\
56 & $990-995$ & \\
& $905-909$ & $\begin{array}{l}\text { Late Effects of Injuries, of Poisonings, of Toxic Effects, and of Other External } \\
\text { Causes }\end{array}$ \\
\hline
\end{tabular}

Note: This list of diagnosis groups is sourced from the Basic Tabulation List of ICD 9. Note there are no observations for birth-related group 38-41 and 45. See http://www.wolfbane.com/icd/icd9a.htm.

Table H: RD Estimates on Morbidity at Age 70

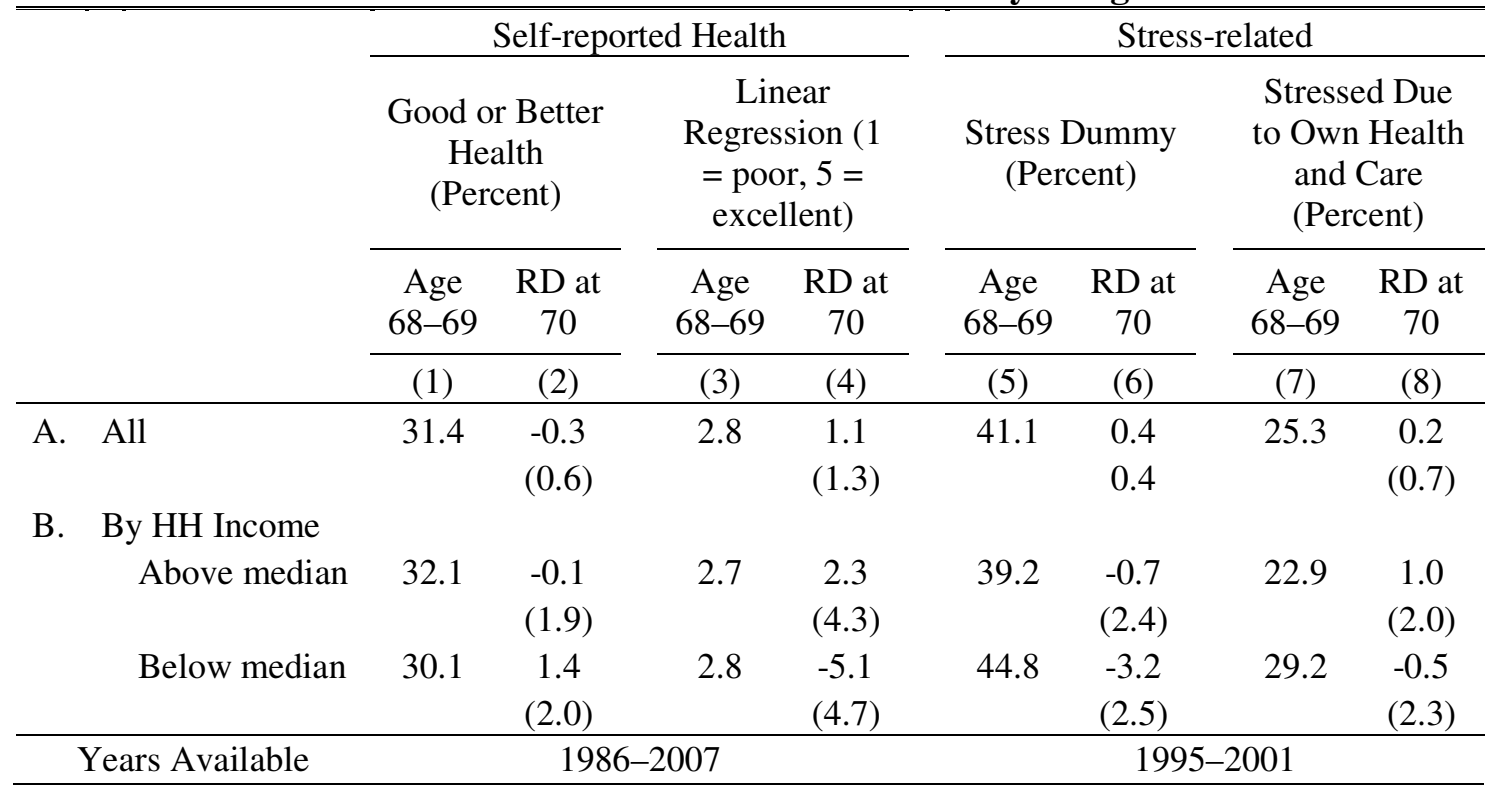

Note: Entries in the odd-numbered columns are the mean of the outcome variables shown in the column headings for 68-69 years-olds. Entries in the even-numbered columns are estimated regression discontinuities at age 70, from models that include quadratic control for age, fully interacted with a dummy for age 70 or older among people between ages 65-70. Other controls include indicators for gender, region, marital status, birth month, and survey year. Except Column (4), estimates are based on a linear probability model fit to pooled samples of CSLC conducted every three years since 1986. Standard errors (in parentheses) are clustered at the age-in-months level, as this is the most refined available version of the age variable. All regressions are weighted to take into account the stratified sampling frame in the data. $* * * * *$, and $*$ denote significance at the 1 percent, 5 percent, and 10 percent levels respectively. Available years for each outcome are described in the last row. Income is collected for roughly 15 percent of all samples, and thus, the sample size of Panel B is smaller than that of the full sample. All coefficients in the even-numbered columns on Post 70 and its standard error have been multiplied by 100, in order to interpret them as percentage changes. HH stands for household. 
Table I: RD Estimates on Out-of-pocket Medical Expenditures at Age 70

\begin{tabular}{ccc} 
& $\begin{array}{c}\text { Out-of-pocket } \\
\text { Expenditure Just } \\
\text { Below Age 70 }\end{array}$ & $\begin{array}{c}\text { RD Estimates at } \\
\text { Age 70 }\end{array}$ \\
\cline { 2 - 3 } & $(1)$ & $(2)$ \\
\hline Mean & 152 & -52 \\
\hline 40th Percentile & 30 & $-13 * * *$ \\
Median & 52 & $-24 * * *$ \\
60th Percentile & 65 & $-24 * * *$ \\
70th Percentile & 96 & $-38^{* * *}$ \\
80th Percentile & 139 & $-50 * * *$ \\
90th Percentile & 247 & $-74 * * *$ \\
95th Percentile & 419 & $-107 * * *$ \\
99th Percentile & 1,793 & $-499 *$ \\
\hline
\end{tabular}

Note: All monetary values are in thousand Yen in 2007 (roughly equal to 10 US dollars). ***, **, and $*$ denote significance at the 1 percent, 5 percent, and 10 percent levels respectively.

Table J: Sensitivity of Welfare Gain from Risk Protection

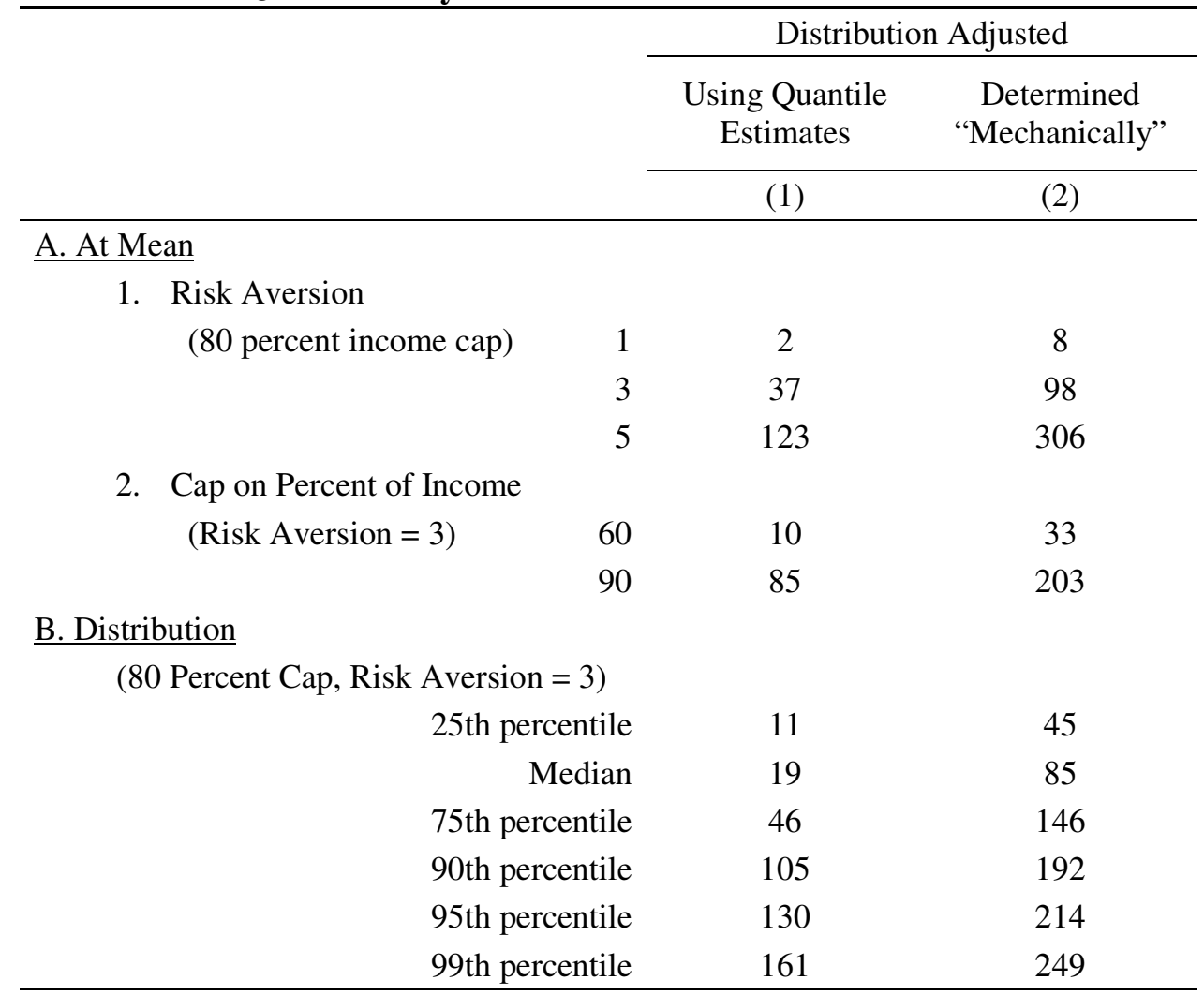

Note: All estimates are in thousand Yen in 2007. One thousand Yen roughly equaled 10 US dollars in 2007. See Section A2 in the Online Appendix for details. 
Table K: Estimated Out-of-pocket Medical Expenditures per Month across Survey Years K1. Outpatient Visits

\begin{tabular}{|c|c|c|c|c|c|}
\hline \multirow[b]{2}{*}{ Year } & \multicolumn{3}{|c|}{ Cost Sharing } & \multicolumn{2}{|c|}{$\begin{array}{l}\text { Percent Reached } \\
\text { Stop-loss }\end{array}$} \\
\hline & $\begin{array}{c}\text { Below } 70 \\
(1)\end{array}$ & $\begin{array}{c}\text { Above } 70 \\
\text { (2) }\end{array}$ & $\begin{array}{c}\text { Percent } \\
\text { Reduction } \\
((1)-(2)) /(1)\end{array}$ & $\begin{array}{c}\text { Below } 70 \\
(4)\end{array}$ & $\begin{array}{c}\text { Above } 70 \\
(5)\end{array}$ \\
\hline All & 3.99 & 1.08 & 73 & 0.1 & 0.6 \\
\hline 1987 & 3.96 & 0.80 & 80 & 0.1 & - \\
\hline 1990 & 4.26 & 0.80 & 81 & 0.1 & - \\
\hline 1993 & 4.48 & 1.00 & 78 & 0.1 & - \\
\hline 1996 & 4.23 & 1.02 & 76 & 0.1 & - \\
\hline 1999 & 3.91 & 1.00 & 74 & 0.2 & - \\
\hline 2002 & 3.61 & 1.30 & 64 & 0.1 & 0.5 \\
\hline 2005 & 3.97 & 1.28 & 68 & 0.2 & 0.7 \\
\hline 2008 & 3.69 & 1.20 & 68 & 0.1 & 0.5 \\
\hline \multicolumn{6}{|c|}{ K2. Inpatient Admissions } \\
\hline & \multicolumn{3}{|c|}{ Cost Sharing } & \multicolumn{2}{|c|}{$\begin{array}{l}\text { Percent Reached } \\
\text { Stop-loss }\end{array}$} \\
\hline Year & $\begin{array}{c}\text { Below } 70 \\
\text { (1) }\end{array}$ & $\begin{array}{c}\text { Above } 70 \\
\text { (2) }\end{array}$ & $\begin{array}{c}\text { Percent } \\
\text { Reduction } \\
((1)-(2)) /(1)\end{array}$ & $\begin{array}{c}\text { Below } 70 \\
(4)\end{array}$ & $\begin{array}{c}\text { Above } 70 \\
(5)\end{array}$ \\
\hline All & 41.65 & 13.10 & 69 & 14.6 & 0.0 \\
\hline 1987 & 44.52 & 7.86 & 82 & 26.6 & 0.0 \\
\hline 1990 & 42.21 & 7.42 & 82 & 21.6 & 0.0 \\
\hline 1993 & 40.78 & 11.91 & 71 & 11.5 & 0.0 \\
\hline 1996 & 39.70 & 10.65 & 73 & 11.5 & 0.0 \\
\hline 1999 & 38.65 & 15.09 & 61 & 9.2 & 0.0 \\
\hline 2002 & 35.86 & 15.54 & 57 & 8.7 & 0.0 \\
\hline 2005 & 46.39 & 15.73 & 66 & 18.3 & 0.0 \\
\hline 2008 & 45.64 & 15.63 & 66 & 13.5 & 0.0 \\
\hline
\end{tabular}

Note: All monetary values are in thousand Yen in 2007 (roughly equal to 10 US dollars). See Section A1 in the Online Appendix for details. 